$11 / 8-9-938 \delta 0$

SAND93 -7051

Unlimited Release

UC -274

\title{
Defect Behavior of Polycrystalline Solar Cell Silicon
}

D. K. Schroder, S. H. Park, I. G. Hwang, J. B. Mohr, M. P. Hanly Center for Solid State Electronics Research Arizona State University

Tempe, AZ 85287-5706

Prepared by Sandia National Laboratories Albuquerque, New Mexico 87185

and Livermore, California 94550 for the United States Department of Energy under Contract DE-AC04-76DP00789

Printed May 1993 


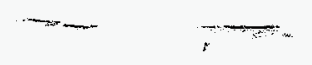

Issued by Sandia National Laboratories, operated for the United States Department of Energy by Sandia Corporation.

NOTICE: This report was prepared as an account of work sponsored by an agency of the United States Government. Neither the United States Government nor any agency thereof, nor any of their employees, nor any of their contractors, subcontractors, or their employees, makes any warranty, express or implied, or assumes any legal liability or responsibility for the accuracy, completeness, or usefulness of any information, apparatus, product, or process disclosed, or represents that its use would not infringe privately owned rights. Reference herein to any specific commercial product, process, or service by trade name, trademark, manufacturer, or otherwise, does not necessarily constitute or imply its endorsement, recommendation, or favoring by the United States Government, any agency thereof or any of their contractors or subcontractors. The views and opinions expressed herein do not necessarily state or reflect those of the United States Government, any agency thereof or any of their contractors.

Printed in the United States of America. This report has been reproduced directly from the best available copy.

Available to DOE and DOE contractors from Office of Scientific and Technical Information

PO Box 62

Oak Ridge, TN 37831

Prices available from (615) 576-8401, FTS 626-8401

Available to the public from

National Technical Information Service

US Department of Commerce

5285 Port Royal Rd

Springfield, VA 22161

NTIS price codes

Printed copy: A05

Microfiche copy: A01 
Distribution

Category UC-274

SAND93-7051

Unlimited Release

Printed May 1993

\title{
DEFECT BEHAVIOR OF POLYCRYSTALLINE SOLAR CELL SILICON
}

\author{
D.K. Schroder, S.H. Park, I.G. Hwang, J.B. Mohr and M.P. Hanly \\ Center for Solid State Electronics Research \\ Arizona State University \\ Tempe AZ 85287-5706
}

Sandia Contract: 55-0702a

\begin{abstract}
The major objective of this study, conducted from October 1988 to September 1991, was to gain an understanding of the behavior of impurities in polycrystalline silicon and the influence of these impurities on solar cell efficiency. We studied edge-defined film-fed growth (EFG) and cast poly-Si materials and solar cells. With EFG Si we concentrated on chromium-doped materials and cells to determine the role of $\mathrm{Cr}$ on solar cell performance. Cast poly-Si samples were not deliberately contaminated. Samples were characterized by cell efficiency, current-voltage, deep-level transient spectroscopy (DLTS), surface photovoltage (SPV), open-circuit voltage decay, secondary ion mass spectrometry, and Fourier transform infrared spectroscopy measurements. We find that $\mathrm{Cr}$ forms $\mathrm{Cr}$ - $\mathrm{B}$ pairs with boron at room temperature and these pairs dissociate into $\mathrm{Cr}_{i}{ }^{+}$and $\mathrm{B}^{-}$during anneals at $210^{\circ} \mathrm{C}$ for $10 \mathrm{~min}$. Following the anneal, $\mathrm{Cr}-\mathrm{B}$ pairs reform at room temperature with a time constant of $230 \mathrm{~h}$. Chromium forms $\mathrm{CrSi}_{2}$ precipitates in heavily contaminated regions and we find evidence of $\mathrm{CrSi}_{2}$ gettering, but a lack of chromium segregation or precipitation to grain boundaries and dislocations. Cr-B pairs have well defined DLTS peaks. However, DLTS spectra of other defects are not well defined, giving broad peaks indicative of defects with a range of energy levels in the band gap. In some high-stress, low-efficiency cast poly-Si we detect SiC precipitates, but not in low-stress, highefficiency samples. SPV measurements result in nonlinear SPV curves in some materials that are likely due to varying optical absorption coefficients due to locally varying stress in the material.
\end{abstract}

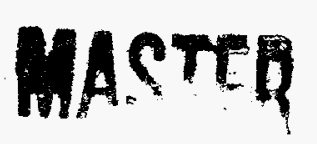




\section{ACKNOWLEDGMENTS}

This work was supported by Sandia National Laboratories with funding from the Photovoltaic Energy Division of the U.S. Department of Energy under Contract No. 550702a.

We like to thank J.M. Gee and J.D. McBrayer, our contract monitors at Sandia National Laboratories, for their support. We also thank J.P. Kalejs and F.V. Wald from the Mobil Solar Energy Corporation, and J.H. Wohlgemuth from the Solarex Corporation for providing the polycrystalline silicon materials and solar cells for this study. 


\section{DISCLAIMER}

Portions of this document may be illegible electronic image products. Images are produced from the best available original document. 


\section{TABLE OF CONTENTS}

Chromium-Contaminated EFG Silicon ................................ 1

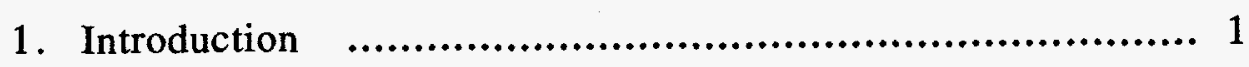

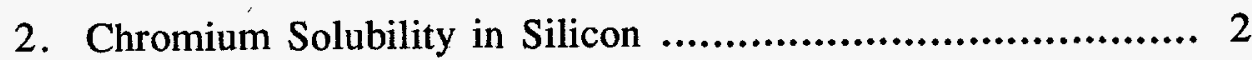

3. Cr-B Pairing in EFG Silicon .................................... 4

4. Chromium Silicide Precipitates .................................... 7

4.1 Material ......................................................... 7

4.2 Microstructure Examination .................................... 8

4.2 .1 Visual ................................................ 8

4.2.2 SEM/EBIC/EDS Observation .......................... 8

4.2.3 Secondary Ion Mass Spectrometry ...................... 9

4.2.4 Deep Level Transient Spectroscopy ...................... 13

5. Minority Carrier Diffusion Length ................................ 20

6. Junction and Substrate Properties of Solar Cells ................... 29

$6.1 \mathrm{I}-\mathrm{V}$ Characteristics .......................................... 29

6.2 Surface Photovoltage and Diffusion Length Dependence on

Diode Ideality Factor ....................................... 33

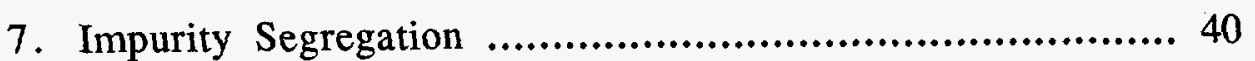

7.1 "Non-rash" EFG Silicon ..................................... 40

7.1.1 EBIC Mapping ....................................... 40

7.1.2 SIMS Depth Profiles Through Electrically Active

Grain Boundaries ....................................... 44

7.1.3 Lack of Precipitation at Grain Boundaries and

Dislocations .......................................... 45

7.2 "Rash" EFG Silicon ....................................... 52

7.2.1 SIMS Grain Boundary Imaging ....................... 52

7.2.2 EBIC Evidence of Gettering .......................... 53

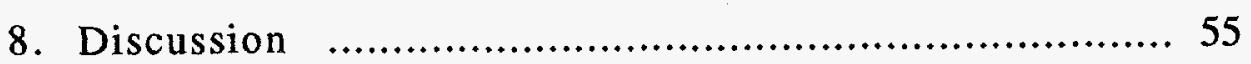

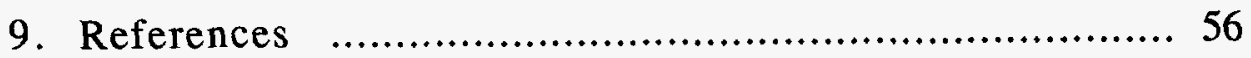


Microstructure and Electrical Characterization of Silicon Carbide Precipitates in Cast Polycrystalline Silicon

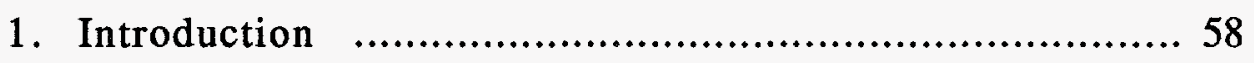

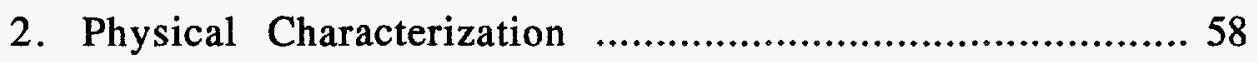

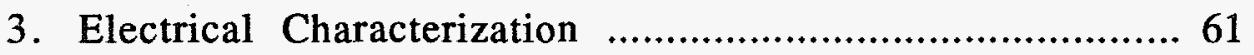

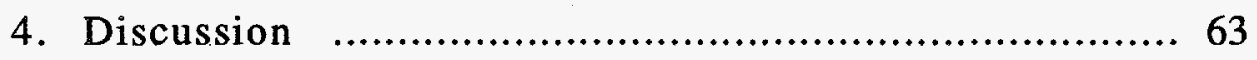

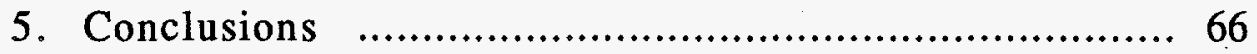

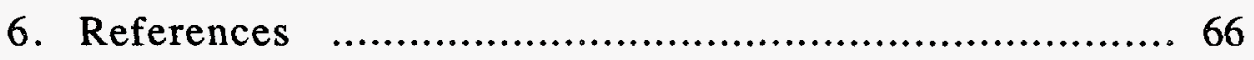

Appendix A

Preparation of Schottky Diodes on As-Grown EFG Silicon

A1. EBIC Sample Preparation

A2. Surface Photovoltage Sample Preparation

A3. DLTS Sample Preparation 


\section{CHROMIUM-CONTAMINATED EFG SILICON}

\section{Introduction}

The use of less pure silicon starting material to reduce the cost of solar cells intended for large scale terrestrial electric power generation requires an understanding of the incorporation and degradation mechanisms of the impurities found in significant concentration in low-cost starting material. Davis et al. studied the effect of most transition elements on the efficiency of cells produced from intentionally contaminated Czochralski (CZ) ingots. (1) They found that above a threshold concentration, specific to each element, all the impurities decreased the diffusion length in the base. $\mathrm{Zr}$, Mo, and Ti had the lowest threshold concentrations of around $10^{12}$ atoms $/ \mathrm{cm}^{3}$. The threshold for chromium was $1.3 \times 10^{14} \mathrm{atoms} / \mathrm{cm}^{3}$ and all of the impurities tested had threshold concentrations less than $10^{15}$ atoms $/ \mathrm{cm}^{3} . \mathrm{Cu}, \mathrm{Ni}$, and $\mathrm{Fe}$ were found to cause junction shunting in addition to a decrease in diffusion length. Studies have since shown it is inappropriate to extend these results to cells produced from polycrystalline silicon material directly. Cretella et al. and most recently, Bathey et al. have shown that 11-13\% efficient cells can be produced from material with impurity concentrations of $\approx 10^{17} \mathrm{Fe}$ atoms $/ \mathrm{cm}^{3}$ in the melt. ${ }^{2-4}$ The relative immunity of polycrystalline silicon cells to some impurities is significant since if the degradation mechanisms were understood, control of processing parameters might allow utilization of lower cost "solar" grade or possibly even "up-graded" metallurgical silicon.

Optimum cell efficiency in EFG (edge-defined film-fed growth) Si solar cells occurs for silicon substrates with higher resistivity than for single-crystal Si. For example, the highest cell efficiency occurs for resistivities in the 0.2 to $0.3 \mathrm{ohm}-\mathrm{cm}$ range for FZ Si, but around 1 to $5 \mathrm{ohm}-\mathrm{cm}$ for EFG Si. Such behavior can be explained if the minority carrier lifetime is doping concentration dependent ${ }^{5}$ and if the responsible impurities have higher concentrations in poly-Si than in single-crystal Si. We have investigated such behavior and have chosen chromium as the impurity to determine if such a dependence exists. $\mathrm{Cr}$, being a constituent of stainless steel, is one of the metal impurities typically found in EFG polycrystalline silicon. It has been found that $\mathrm{Cr}$ in low or moderate concentrations has little effect on the electronic properties of the cells, but acts strongly on the crystallization process. ${ }^{4}$ It does have a major effect on cell performance if present in high concentrations. ${ }^{6}$

The feedstock material used in this investigation was high purity semiconductor grade silicon in order to minimize any ambiguity about which impurity was responsible for a ribbon characteristic. We will present the results of a microstructure and deep level transient spectrometry (DLTS) investigation of EFG silicon ribbon grown from material intentionally contaminated with chromium. Although the behavior of $\mathrm{Cr}$ in $\mathrm{Si}$ has been studied by 
others ${ }^{7-10}$ the solid solubility and the diffusivity of $\mathrm{Cr}$ in $\mathrm{Si}$ at room temperature are not yet clearly understood. Cr generally does not exist as isolated $\mathrm{Cr}$ ions in the Si lattice, but forms pairs with acceptor impurities like boron. In this study, EFG Si is intentionally doped with high concentrations of $\mathrm{Cr}$. The EFG material, doped with $\mathrm{Cr}$ to $1-5 \times 10^{17} \mathrm{~cm}^{-3}$, is characterized by second phase formation called "rash" and has been studied in detail in terms of generation mechanisms of the second phase by Kalejs et al. ${ }^{11}$ The "rash" is caused by the effective unity segregation coefficient due to the die and the high growth rate of EFG $\mathrm{Si}$ and consists of $\mathrm{CrSi}_{2}$ and eutectics. ${ }^{11-12}$

We calculate the solid solubility of $\mathrm{Cr}$ in $\mathrm{Si}$ using the linear relation between the solid solubility of $\mathrm{Cr}$ and boron in $\mathrm{Si}$ at boron concentrations high compared to the $\mathrm{Cr}$ concentration. The diffusivity of $\mathrm{Cr}$ in $\mathrm{Si}$ is determined from the relaxation time constant of Cr-B pair formation. Deep-level transient spectroscopy (DLTS) measurements were used to characterize the Cr-B pair properties in both "rash-free" and "rash" areas. We find higher Cr-B pairs concentration in the "rash" area than in the "rash-free" areas.

The most important solar cell parameters are the open circuit voltage $\left(V_{O c}\right)$, the short circuit current $\left(I_{\mathrm{sc}}\right)$, and the fill factor. The surface photovoltage (SPV) technique gives information about both $\mathrm{V}_{\mathrm{OC}}$ and $\mathrm{I}_{\mathrm{Sc}}$. The voltage measured during SPV characterization is related to $V_{o c}$ and the measured diffusion length is closely related to the short circuit current. We find SPV to be a very effective characterization method and have combined it with open-circuit voltage decay (OCVD) recombination lifetime and cell current-voltage measurements. From I-V measurements we determine, among other parameters, the diode ideality factor $\mathrm{n}$. However, SPV measurements on certain types of poly-Si must be interpreted with caution. We find the diode ideality factor and the recombination lifetime to be important factors that confirm the SPV measurements. To investigate $\mathrm{Cr}$ precipitation, we use electron beam induced current (EBIC), energy-dispersive X-ray spectroscopy (EDS), secondary ion mass spectrometry (SIMS), and transmission electron microscopy (TEM) as well as chemical etching.

\section{Chromium Solid Solubility in Silicon}

It has been shown by Reiss et al. that the metal solid solubility in semiconductors is closely related to the doping concentration of the semiconductor. ${ }^{13} \mathrm{We}$ follow their analysis here. In this study, the $\mathrm{Cr}$ concentration in silicon is assumed to be identical to the $\mathrm{Cr}-\mathrm{B}$ concentration measured by DLTS after the samples are stored at room temperature for several weeks or longer. We believe that all $\mathrm{Cr}$ atoms form $\mathrm{Cr}$-B pairs after a sufficiently long time and our measurements indicate that several weeks is a sufficiently long time for 
this to happen. This assumption that all $\mathrm{Cr}$ interstitial impurities $\left(\mathrm{Cr}_{\mathrm{i}}\right)$ form $\mathrm{Cr}-\mathrm{B}$ pairs with boron at room temperature is verified by Reiss et al. ${ }^{13}$ With the mass action law applied to the $\mathrm{Cr}-\mathrm{Si}$ system, the chromium solid solubility $\mathrm{Cr}^{+}$is given by

$$
\mathrm{Cr}^{+}=\mathrm{K}\left(1+\sqrt{1+\left(\mathrm{Cr}_{0}^{+} / \mathrm{K}\right)^{2}}\right)
$$

where

$$
\mathrm{K}=\frac{\mathrm{N}_{\mathrm{A}}^{-}}{1+\sqrt{1+\left(2 \mathrm{n}_{\mathrm{i}} / \mathrm{Cr}_{0}^{+}\right)^{2}}}
$$

Here $\mathrm{Cr}^{+}$is the ionized $\mathrm{Cr}$ concentration, $\mathrm{N}_{\mathrm{A}^{-}}$the ionized acceptor concentration, $\mathrm{n}_{\mathrm{i}}$ the intrinsic carrier concentration, and $\mathrm{Cr}_{0}{ }^{+}$the $\mathrm{Cr}$ solid solubility in intrinsic silicon. When $\mathrm{N}_{\mathrm{A}}{ }^{-}$is sufficiently large, Eq.(1) becomes

$$
\mathrm{Cr}^{+} \approx \frac{2 \mathrm{~N}_{\mathrm{A}}^{-}}{1+\sqrt{1+\left(2 \mathrm{n}_{\mathrm{i}} / \mathrm{Cr}_{\mathrm{o}}^{+}\right)^{2}}}
$$

Using Eq. (2), $\mathrm{Cr}_{0}{ }^{+}$is determined from a plot of $\mathrm{Cr}^{+}$versus $\mathrm{N}_{\mathrm{A}^{-}}$where $\mathrm{Cr}^{+}$is the measured $\mathrm{Cr}$ - $\mathrm{B}$ pair concentration two months after a $\mathrm{Cr}-\mathrm{B}$ pair dissociation anneal. We have found that time to be a sufficiently long time for $\mathrm{Cr}-\mathrm{B}$ pair formation. The value of $\mathrm{Cr}_{\mathrm{o}}{ }^{+}$at room temperature is $9.8 \times 10^{6} \mathrm{~cm}^{-3}$. This value is very large compared to the extrapolated value of $6 \times 10^{-24} \mathrm{~cm}^{-3}$ from Weber's $\mathrm{Cr}$ solid solubility expression near the eutectic temperature of $1335^{\circ} \mathrm{C} .14 \mathrm{Fig} .1$ shows the calculated solid solubility of $\mathrm{Cr}$ in $\mathrm{Si}$ at room temperature as a function of boron concentration using Eq.(1) together with measured data from the Cr-doped EFG as-grown material.

The calculated and measured data show good agreement. However, the $\mathrm{Cr}$ concentration in EFG as-grown material measured by neutron activation analysis, atomic absorption spectroscopy, and glow discharge mass spectroscopy ranges from $10^{15} \mathrm{~cm}^{-3}$ to $10^{18} \mathrm{~cm}^{-3}$ in "rash-free" areas and "rash" areas, respectively. 11 There is a significant difference in the Cr concentration measured by DLTS and by the other techniques. DLTS measures only electrically active impurities. This implies that a large portion of the $\mathrm{Cr}$ impurities is electrically inactive. Much of it is precipitated; some as $\mathrm{CrSi}_{2}$ silicide precipitates.

There are two important mechanisms to explain this difference. First, $\mathrm{Cr}$ is known to precipitate at temperatures as low as $170^{\circ} \mathrm{C}$ and the precipitation time becomes shorter as the 
dislocation density or the temperature increase. ${ }^{7}$ For example, at $300^{\circ} \mathrm{C}$, the precipitation time is $6 \mathrm{~min}$ for silicon having a dislocation density of less than $10^{3} \mathrm{~cm}^{-2}$. Therefore, EFG material with much higher dislocation densities $\left(>10^{7} \mathrm{~cm}^{-2}\right)$ must have a precipitation time shorter than $6 \mathrm{~min}$. Once $\mathrm{Cr}$ precipitates, the $\mathrm{Cr}$ concentration determined by DLTS is less than that before precipitation. The second reason for the difference are electrically inactive silicides and complexes of $\mathrm{Cr}$ formed during cooling. Below the eutectic temperature the solid solution of $\mathrm{Cr}$ in $\mathrm{Si}$ can reach equilibrium with $\mathrm{CrSi}_{2} \cdot{ }^{13}$

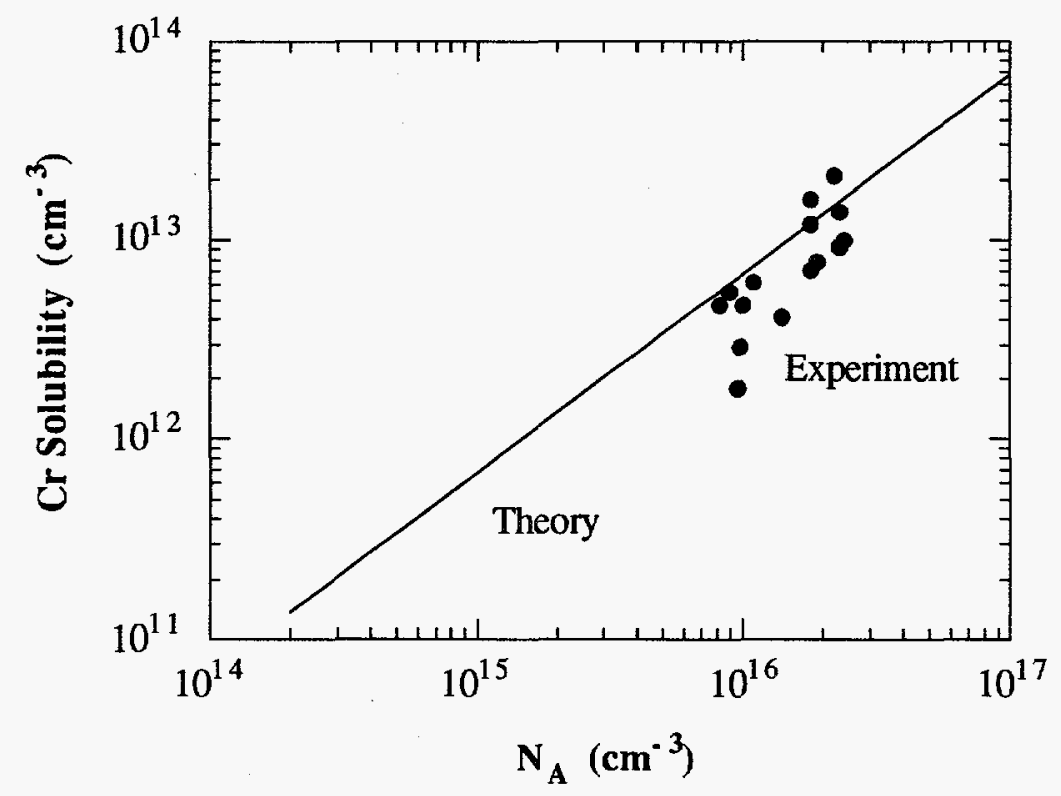

Fig. $1 \mathrm{Cr}$ solid solubility in $\mathrm{Si}$ at $27^{\circ} \mathrm{C}$ as a function of $\mathrm{N}_{\mathrm{A}}$. Solid line: theoretical prediction; points: experimental data.

\section{Cr-B Pairing in EFG Silicon}

$\mathrm{Cr}$ diffuses interstitially in Si and resides predominantly on interstitial sites. At the melting temperature of $\mathrm{Si}$, the $\mathrm{Cr}$ diffusion coefficient is approximately $10^{-5} \mathrm{~cm}^{2} / \mathrm{s}$, which is much higher than that of $\mathrm{B}\left(10^{-11} \mathrm{~cm}^{2} / \mathrm{s}\right) . \mathrm{Cr}$ is a donor type impurity charged positively when uncompensated in p-type $\mathrm{Si}$. The highly mobile, positively charged $\mathrm{Cr}$ ions diffuse easily toward the negatively charged $\mathrm{B}$ - acceptors. The charged ions form $\mathrm{Cr}-\mathrm{B}$ pairs having a donor energy level at $E_{v}+0.27 \mathrm{eV}$, while interstitial $\mathrm{Cr}$ has an energy level at about $E_{\mathrm{c}}-0.20$ eV. ${ }^{9}$ It has been also shown that $\mathrm{Cr}-\mathrm{B}$ pairs indeed are formed only if a Coulombic attraction is present. ${ }^{10}$ The $\mathrm{Cr}-\mathrm{B}$ pairs dissociate into $\mathrm{Cr}^{+}$and $\mathrm{B}^{-}$by annealing at moderate 
temperatures. We found the pairs to dissociate during anneals of $210^{\circ} \mathrm{C}$ for $10 \mathrm{~min}$. The dissociated ions form $\mathrm{Cr}-\mathrm{B}$ pairs again at room temperature. This behavior of pair formation and dissociation is similar to that observed for $\mathrm{Fe}$ in $\mathrm{Si}$. Formation of $\mathrm{Cr}-\mathrm{B}$ pairs, monitored by DLTS, is shown in Fig. 2 for two different boron concentrations.

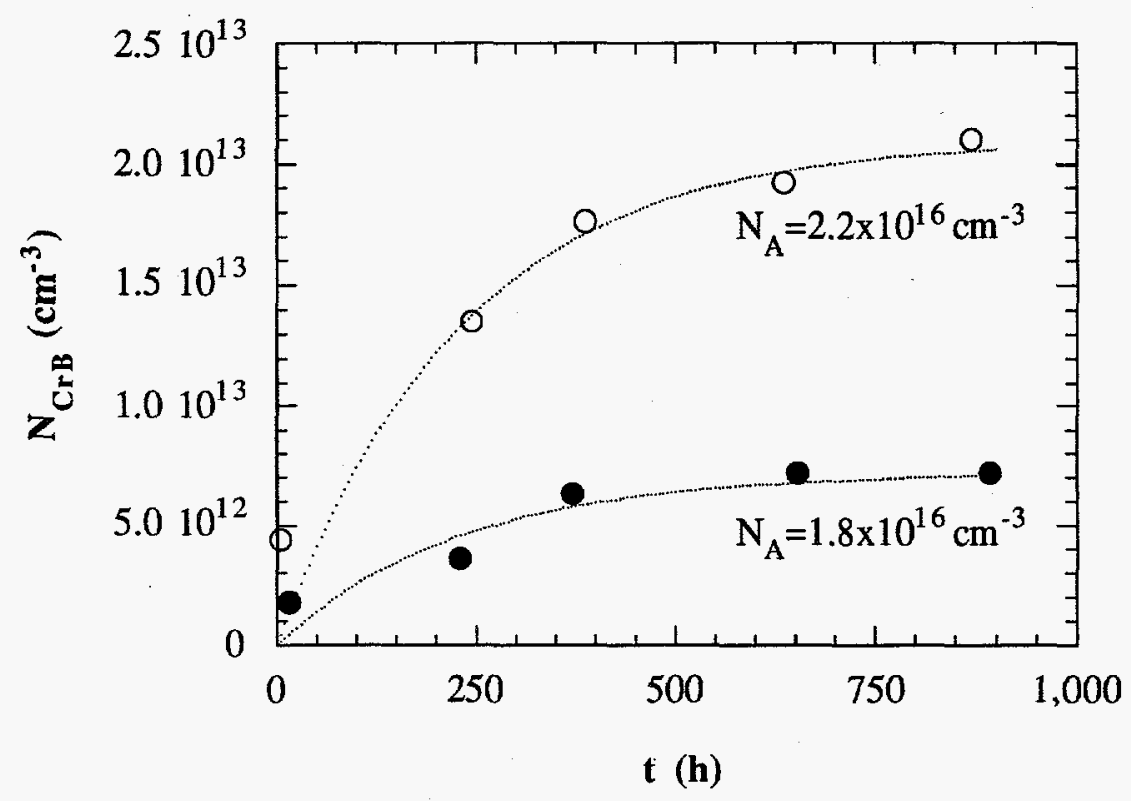

Fig. 2 Formation of $\mathrm{Cr}$-B pairs in $\mathrm{Cr}$ doped as-grown EFG-Si. The formation time constant is $230 \mathrm{~h}$ after a dissociation anneal at $210^{\circ} \mathrm{C}$ for $10 \mathrm{~min}$.

The rate of increase of $\mathrm{Cr}-\mathrm{B}$ pairs with time is equal to the rate of decrease of $\mathrm{Cr}_{\mathbf{i}}$ with time constant $\tau$

$$
\frac{\mathrm{dN}_{\mathrm{CrB}}}{\mathrm{dt}}=-\frac{\mathrm{N}_{\mathrm{Cri}}}{\tau}
$$

where $\mathrm{N}_{\mathrm{CrB}}$ is the concentration of $\mathrm{Cr}-\mathrm{B}$ pairs and $\mathrm{N}_{\mathrm{Cri}}$ the concentration of $\mathrm{Cr}$ interstitials. Using $\mathrm{N}_{\mathrm{T}}=\mathrm{N}_{\mathrm{Cr}} \mathrm{B}+\mathrm{N}_{\mathrm{Cri}}$ and the initial condition of $\mathrm{N}_{\mathrm{CrB}}(0)=0$, the solution of Eq.(3) is

$$
\mathrm{N}_{\mathrm{CrB}}=\mathrm{N}_{\mathrm{T}}(1-\exp (-\mathrm{t} / \tau))
$$

with the time constant of pair formation $\tau$ given by 


$$
\tau \approx \frac{\mathrm{K}_{\mathrm{S}} \varepsilon_{0} \mathrm{kT}}{\mathrm{q}^{2} \mathrm{~N}_{\mathrm{A}} \mathrm{D}}
$$

where $\mathrm{N}_{\mathrm{A}}$ is the acceptor concentration and $\mathrm{D}$ the diffusion constant of the mobile species.

Since iron behaves in some ways similar to chromium in silicon, we have compared the two in some cases. The behavior of iron in silicon follows Eq.(5) quite well. The diffusion coefficient for $\mathrm{Fe}$ in $\mathrm{Si}$ is given by $\mathrm{D}=1.3 \times 10^{-3} \exp (-0.68 / \mathrm{kT})$ measured over the temperature range of 30 to $1250^{\circ} \mathrm{C} .14$ At room temperature this gives the Fe-B pair formation time constant $\tau=9.5 \times 10^{15} / \mathrm{N}_{B}$, with $\tau$ in hours. This relationship is shown in Fig. 3 in conjunction with experimental data. Agreement between theory and experiment is very good. For $\mathrm{Cr}$ in $\mathrm{Si}$ we have the diffusion coefficient given by $\mathrm{D}=0.01 \exp \left(-1 / \mathrm{k}^{\mathrm{T}} \mathrm{T}\right)$ measured over the 900 to $1250^{\circ} \mathrm{C}$ temperature range. 15 When extrapolated to room temperature, this gives $\tau=2.9 \times 10^{20} / \mathrm{N}_{\mathrm{A}}(\mathrm{h})$, also shown in Fig. 3 by the "Prior theory" line.

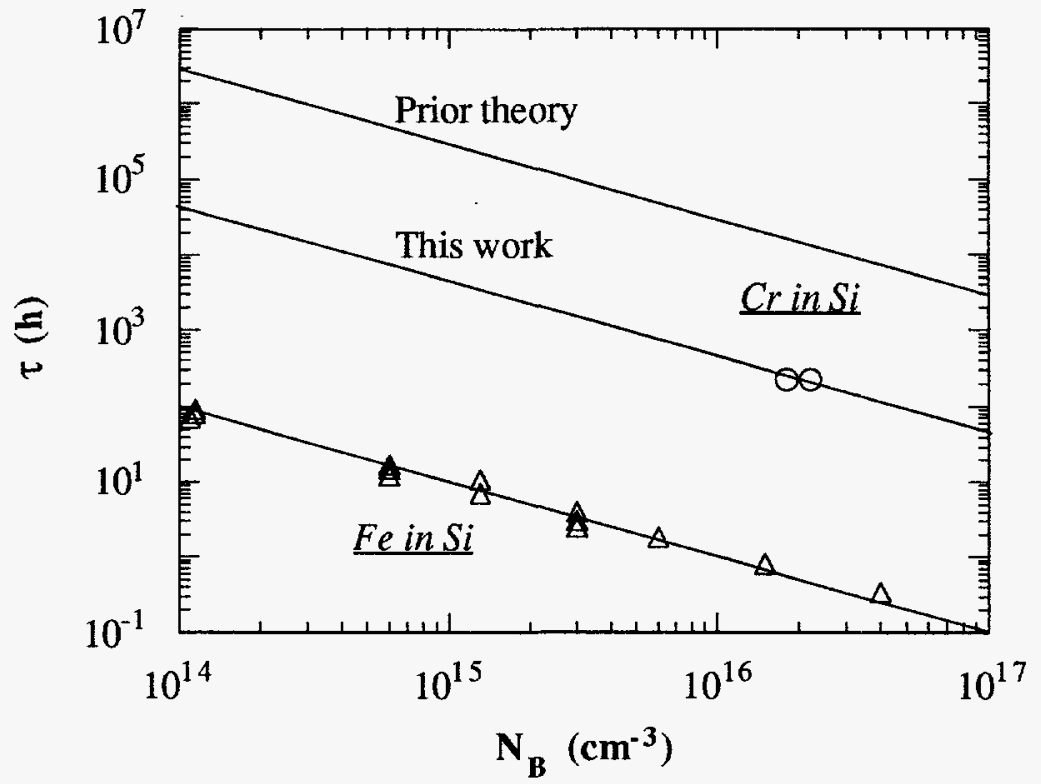

Fig. $3 \mathrm{Fe}-\mathrm{B}$ and $\mathrm{Cr}-\mathrm{B}$ pairing time constants at $\mathrm{T}=300 \mathrm{~K}$ as a function of boron concentration. Fe data after ref. 16.

The measured time constant of $\mathrm{Cr}$ in $\mathrm{Si}$, which is $230 \mathrm{~h}$, is shown by the open circle in Fig.3. It falls significantly below the predicted line. This behavior may be due to the uncertainty in the value of the diffusion coefficient when extrapolated from the high temperatures to room temperature or it may be associated with the fact that our measurements are made in EFG poly-Si, whereas all other measurements have been made 
in single crystal $\mathrm{Si}$. However, the polycrystalline nature should have any a minor effect since the grains are large compared to the $\mathrm{Cr}$ - B pair formation interaction volume. Since we have measured the time constant of $\mathrm{Cr}-\mathrm{B}$ pair formation, we use these data to determine the Cr diffusion coefficient. This leads to the "This work" line in Fig. 3 through the open circle experimental data points.

The measured and calculated $\mathrm{N}_{\mathrm{CrB}}$, shown in Fig.2, agree well. There are two graphs from two samples with different boron concentrations. The time constant is invariant for this range of boron concentrations. The different maximum $\mathrm{Cr}$ - $\mathrm{B}$ concentrations of each sample can be explained by the fact that higher boron concentrations lead to higher $\mathrm{Cr}-\mathrm{B}$ concentrations according to Eq.(1). The pairing velocity of $\mathrm{Cr}$-B depends on the boron concentration in silicon very much like the formation of Fe-B pairs. ${ }^{14}$ The time constant of Cr-B pair relaxation for a boron concentration of $10^{15} \mathrm{~cm}^{-3}$ is about 10 times higher than that found by Weber. From the measured time constant, we can determine the diffusion coefficient of $\mathrm{Cr}_{i}$ in $\mathrm{Si}$ at room temperature using the equation ${ }^{13}$

$$
\mathrm{D} \approx \frac{\mathrm{K}_{\mathrm{S}} \varepsilon_{0} k T}{\mathrm{q}^{2} \mathrm{~N}_{\mathrm{A}} \tau}
$$

where $\mathrm{D}$ is the diffusion coefficient of $\mathrm{Cr}_{\mathbf{i}}, \mathrm{N}_{\mathrm{T}}$ the concentration of $\mathrm{Cr}_{\mathbf{i}}$, and $\tau$ the time constant. The calculated room temperature diffusion coefficient for a $\mathrm{Cr}_{\mathbf{i}}$ concentration of $2 \times 10^{13} \mathrm{~cm}^{-3}$ is $10^{-17} \mathrm{~cm}^{2} / \mathrm{s}$. The diffusion coefficient determined at temperatures of 900 $1100^{\circ} \mathrm{C}$ is $\mathrm{D}=0.01 \exp (-1 / \mathrm{kT}) .{ }^{10}$ Evaluated at room temperature, this latter expression gives $\mathrm{D}=1.5 \times 10^{-19} \mathrm{~cm}^{2} / \mathrm{s}$, which is significantly lower than our value of $10^{-17} \mathrm{~cm}^{2} / \mathrm{s}$. The large discrepancy may be due to uncertainties in the high-temperature diffusion data and the large extrapolation from the high measurement temperatures to room temperature.

\section{Chromium Silicide Precipitates}

\subsection{Material}

The Si melt was intentionally contaminated to $1-5 \times 10^{17}$ atoms $/ \mathrm{cm}^{3}$ of chromium by adding 99.999\% pure chromium wire. EFG nonagons were pulled at $2 \mathrm{~cm} / \mathrm{min}$ into a $\mathrm{CO}_{2}$ ambient. Growth in $\mathrm{CO}_{2}$ ambient controls the amount of oxygen in the ribbon to about $5 \times 10^{16}$ atoms $/ \mathrm{cm}^{3} .17$ The characteristics of EFG ribbon have been thoroughly described in the literature. ${ }^{17-19}$ However it is significant to point out the ribbon is saturated with carbon ( $2 \times 10^{18}$ atoms $/ \mathrm{cm}^{3}$ substitutional carbon) due to dissolution of the graphite die used to maintain the $300 \mu \mathrm{m}$ ribbon thickness. This is in sharp contrast with $\mathrm{Cz}$ silicon which contains approximately $1 \times 10^{18}$ atoms $/ \mathrm{cm}^{3}$ oxygen but only $\approx 1 \times 10^{17}$ atoms $/ \mathrm{cm}^{3}$ carbon. ${ }^{17}$ 
The "as-grown" material was prepared three ways in this study. First, samples of asgrown material were reserved. Second, some as-grown material was annealed in argon for 4 hours at $950^{\circ} \mathrm{C}$ in an attempt to extend precipitate growth to consume as much chromium as possible from the ribbon. The rest was fabricated into cells using the standard phosphorus diffusion process to form the junction. The backside contact was aluminum, annealed to form an ohmic contact subsequently plated with a multilayer structure for solderability. The specific cell used in this study had $11.5 \%$ efficiency with an AR coating.

\subsection{Microstructure Examination}

\subsubsection{Visual}

Degenerate patches of ribbon were clearly visible on both the as-grown and cell material. ${ }^{11}$ The patches, called "rash", are usually 1 to $3 \mathrm{~cm}$ wide extending many centimeters in length. The degenerate areas consist of irregular undulations in the surface with about 50 $\mu \mathrm{m}$ amplitude. The typical orderly EFG crystal structure consisting of mainly twin boundaries and occasional low angle grain boundaries through the ribbon thickness 17,19 has been altered in the "rash" area. Distinct subsurface grain boundaries, many parallel to the ribbon face are common as shown in Fig. 4. The material to be investigated was cut from areas with "rash".

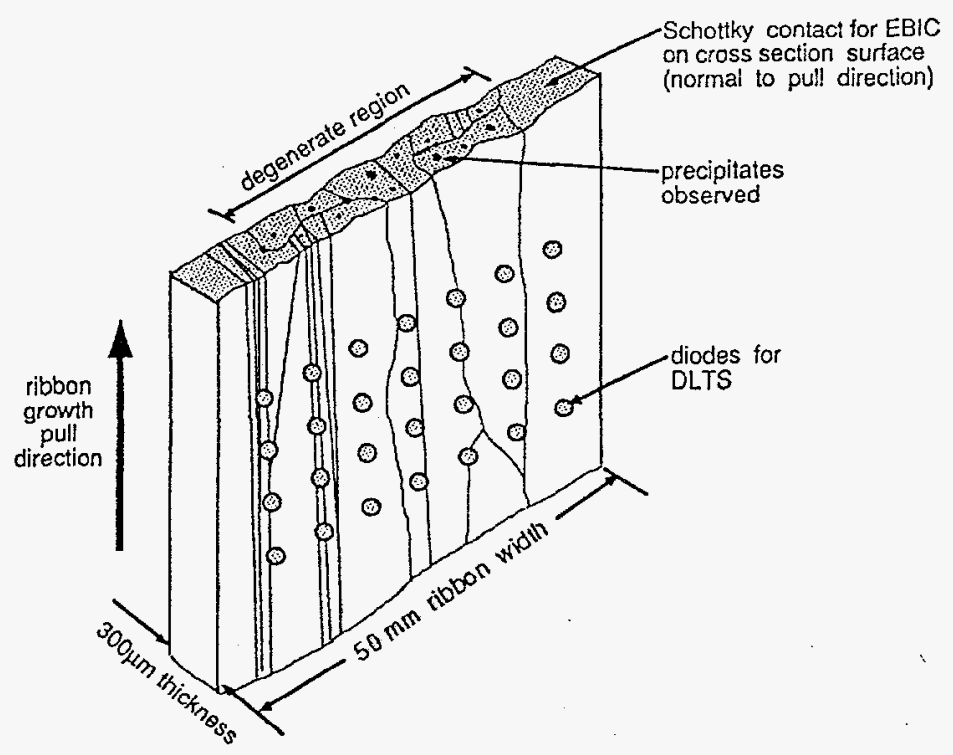

Fig. 4 Schematic showing precipitate location and location of Schottky devices.

\subsubsection{SEM/EBIC/EDS Observation}

Ribbon cross sections were polished in a plane normal to the crystal pull direction as shown in Fig. 4. Mechanical damage was removed from the polished edge by swabbing 
with an etch solution composed of 9:1 $\mathrm{HNO}_{3}: \mathrm{HF}$ for $30 \mathrm{sec}$. The samples were RCA cleaned ${ }^{20}$ and a $200 \AA$ thick aluminum Schottky contact was evaporated onto the edge. A thin gold ohmic contact was evaporated on the sample back surface. Schottky contacts were also formed on the faces of the samples. In this way, we were able to make EBIC measurements both on the sample faces and also on the cross-sectional area to study the sample behavior along and across the growth planes.

Electron beam induced current (EBIC) examination at $35 \mathrm{keV}$ beam energy and $100 \mathrm{pA}$ beam current clearly showed large black spots of typically 50-75 $\mu \mathrm{m}$ diameter on the asgrown and as-grown annealed material indicating a reduction in EBIC current in each spot (Fig. 5). Similar spots were found on the cell. However, they were more sharply defined and only about $10-20 \mu \mathrm{m}$ in diameter (Fig. 5). Closer SEM examination revealed a precipitate centered in most spots. Most spots on the cell material were surrounded by clearly defined bright halos approximately $50 \mu \mathrm{m}$ in diameter. In contrast, neither the asgrown nor annealed as-grown material exhibited these bright halos.

The precipitates take on many interesting shapes as shown in Fig. 6. The most common is spherical and 5-15 $\mu \mathrm{m}$ in diameter. Other shapes include "daggers" and "platelets" some with aspect ratios as high as 100 . The large precipitates seem to be strictly confined to the "rash" areas as no precipitates could be located more than $1 \mathrm{~mm}$ on either side of a "rash" area. A plot (Fig.7) of the precipitate position as a percentage of the distance from the ribbon front surface indicates there is no segregation with respect to ribbon thickness. There is also no overwhelming tendency for the precipitates to form in the grain boundaries since many precipitates have been observed in the grain bulk.

Quantitative energy dispersive X-ray spectroscopy (EDS) analysis was done on some of the larger precipitates with smoother, flatter surfaces indicating a composition very close to chromium disilicide $\left(\mathrm{CrSi}_{2}\right)$. No other impurities were detected in the analysis.

\subsubsection{Secondary Ion Mass Spectrometry}

A Cameca-3f ion microscope was used to make SIMS images of a polished cross section of an unetched cell sample without Schottky contacts, to see if chromium segregation to the grain boundaries could be detected. We bombarded the sample with $\mathrm{O}_{2}{ }^{+}$primary ions to enhance the $\mathrm{Cr}^{+}$signal. The beam ( $200 \mathrm{nA}$ current) was rastered over a $250 \mu \mathrm{m} \times 250 \mu \mathrm{m}$ area. Our detection limit for chromium is approximately $10^{15}$ atoms $/ \mathrm{cm}^{3}$ with a spatial resolution of about $1 \mu \mathrm{m} .{ }^{21}$ As shown in Fig. 8 we could easily detect the precipitates. They align with a grain boundary, but there was no indication of chromium segregation to the boundary. This is discussed further in Chapter 7 . 


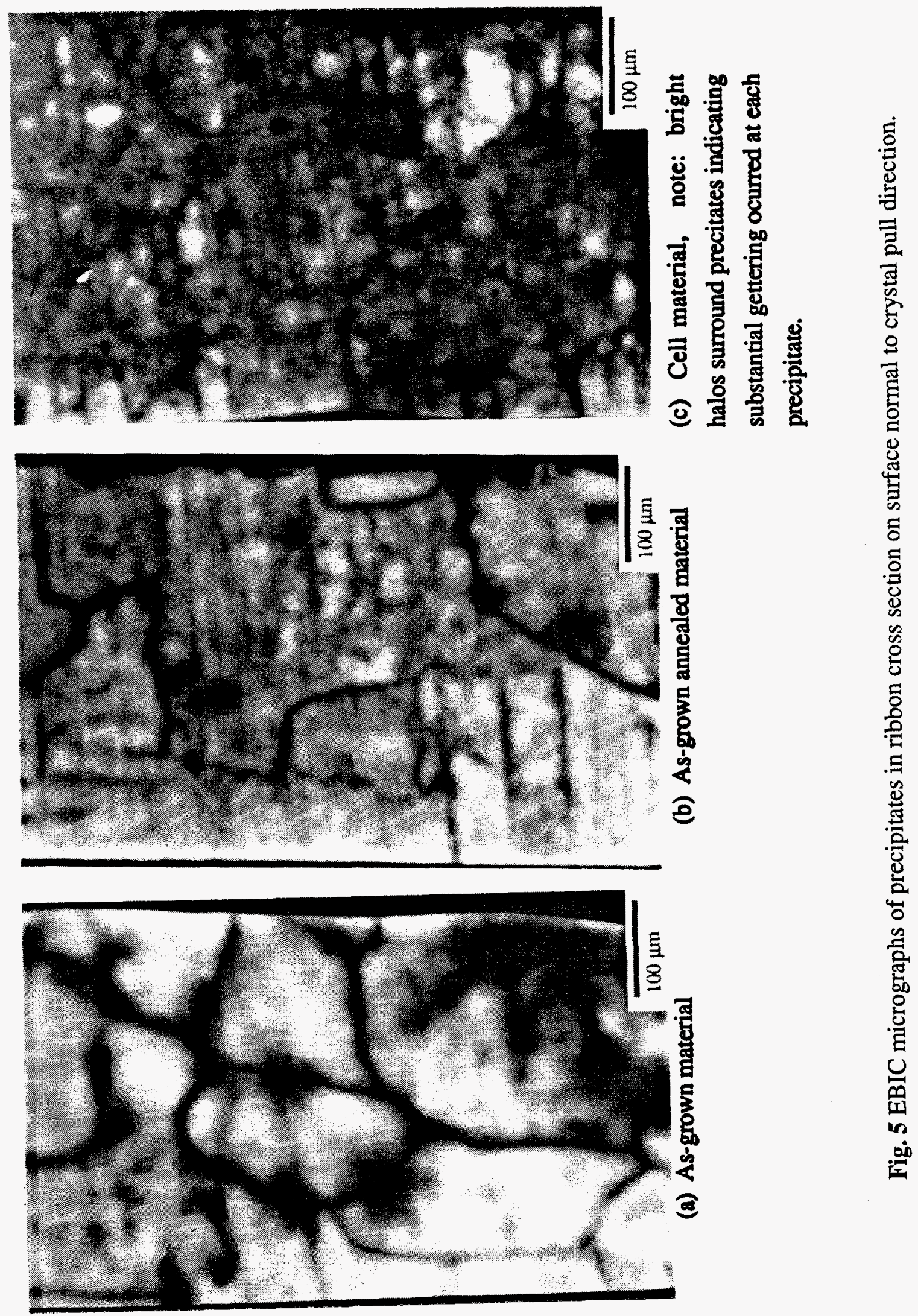



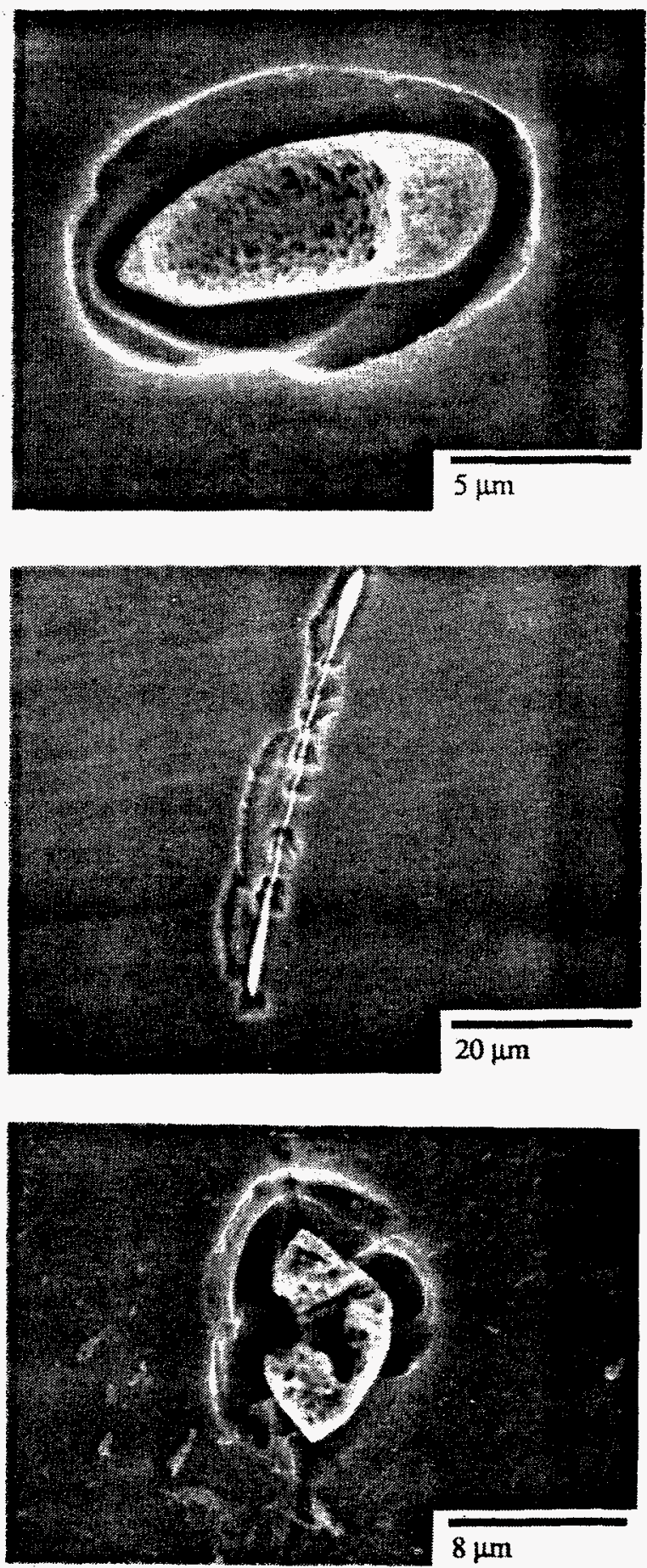

Fig. $6 \mathrm{SEM}$ micrographs of $\mathrm{CrSi}_{2}$ precipitates. 


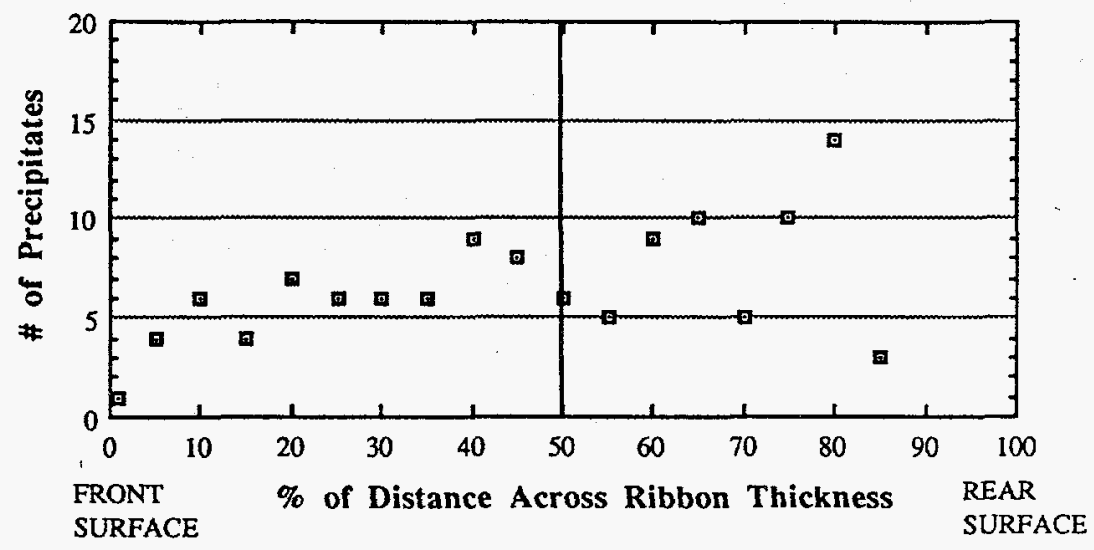

Fig. 7 Precipitate position through the ribbon thickness.

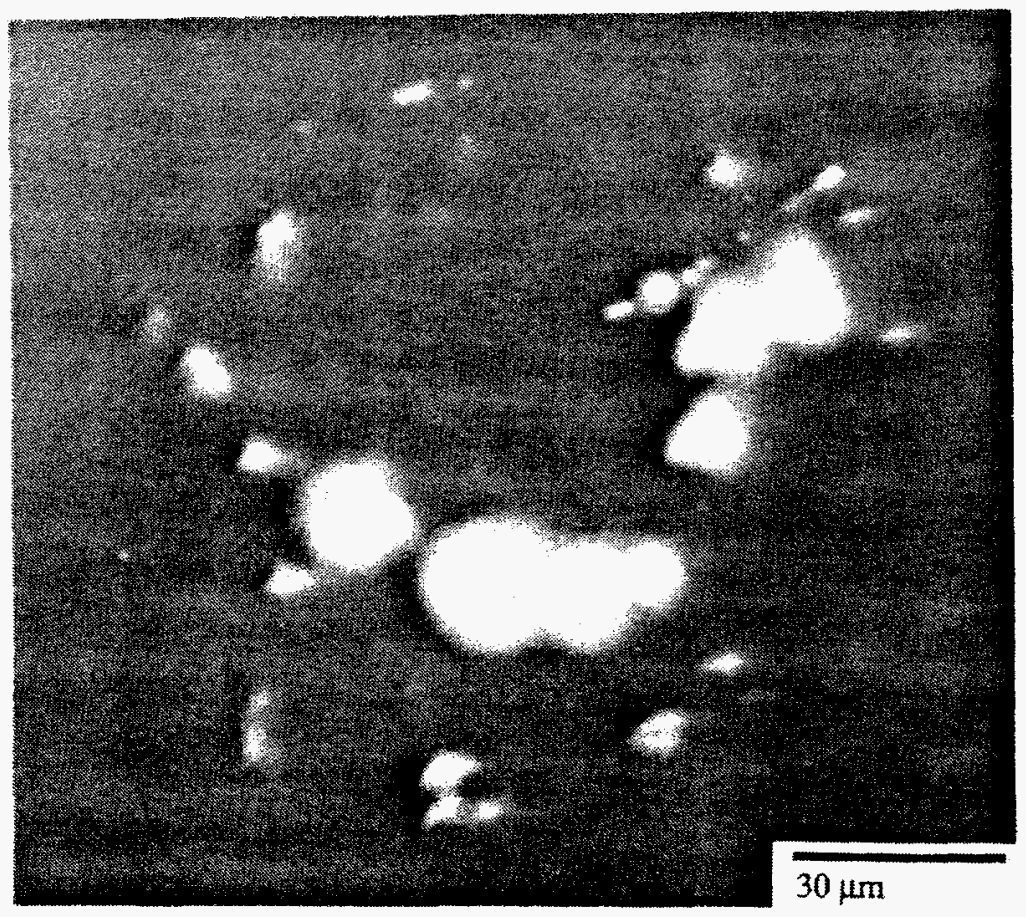

Fig. 8 SIMS image of precipitates aligned to a grain boundary showing no evidence of $\mathrm{Cr}$ segregation to the boundary. 


\subsubsection{Deep Level Transient Spectroscopy}

DLTS measurements, using a lock-in amplifier based system, were made on $0.5 \mathrm{~mm}$ diameter Schottky diodes on as-grown material and on etched 1-2 mm diameter mesa diodes on the cell, utilizing the existing $\mathrm{n}^{+} \mathrm{p}$ junction. Due to poor probe contact to $\mathrm{Ti}$ we used Ti/Al Schottky contacts. E-beam evaporation of $800 \AA$ of Ti on the silicon surface prepared by etching in 10:1 $\mathrm{HNO}_{3}$ :HF was followed by deposition of $2000 \AA$ of Al. DLTS measurements were made using five different period injection pulses. The DLTS plots depicted in the following figures were ones measured for a $20 \mathrm{~ms}$ injection pulse period.

We measured the impurities in Cr-doped EFG materials and solar cells. In Cr-doped EFG materials, Schottky diodes in the most heavily "rash" areas had reverse leakage current as large as $10 \mu \mathrm{A}$ at $2.5 \mathrm{~V}$ making them unsuitable for DLTS measurements. All measurements using Schottky diodes were made near the edges of the rashes areas on diodes with less than $1 \mu \mathrm{A}$ leakage current at $2.5 \mathrm{~V}$ reverse bias. The poor Schottky contacts are believed to be caused by large chromium silicide precipitates. Several different DLTS peaks were found in Cr-doped EFG materials as shown in Fig.9 through Fig.11. Among them the energy level at $E_{\mathrm{V}}+0.27 \mathrm{eV}$ is almost always found although the concentrations vary depending on the diode locations in a sample and due to nonuniform distribution of the corresponding impurity in a sample and the different boron doping concentrations, respectively. It is known that the energy level at $\mathrm{E}_{\mathrm{v}}+0.27 \mathrm{eV}$ is due to $\mathrm{CrB}$ pairs in p-type silicon. ${ }^{9}$ An energy level at $\mathrm{E}_{\mathrm{C}}-0.23 \mathrm{eV}$ in n-type silicon is attributed to interstitial chromium. ${ }^{9}$ Fig.9 shows DLTS spectra representing four different energy levels: peak $A$ : $C r B$ pairs at $E_{\mathrm{V}}+0.27 \mathrm{eV}$ with a hole capture cross section of $2 \times 10^{-15} \mathrm{~cm}^{2}$; peak B: single energy state at $E_{\mathrm{v}}+0.39 \mathrm{eV}$ with a hole capture cross section of $6 \times 10^{-15} \mathrm{~cm}^{2}$; peak C: multi-energy states centered at $E_{\mathrm{V}}+0.30 \mathrm{eV}$ with an effective hole capture cross section of $8 \times 10^{-17} \mathrm{~cm}^{2}$; peak D: multi-energy states centered at $E_{v}+0.34 \mathrm{eV}$ with an effective capture cross section of $3 \times 10^{-16} \mathrm{~cm}^{2}$. In the "rash-free" areas, only $\mathrm{CrB}$ pairs, peak $\mathrm{A}$, is observed. On the other hand, in "rash" areas, peak C and D are frequently found. The degeneracy of the crystal structure is extensive in the "rash" area causing the energy states observed.

The DLTS peak width is often used to estimate qualitatively the number of energy states of a particular peak. A single deep energy state generates a DLTS peak whose FWHM is equal to $0.1 \mathrm{~T}_{\max }$, where $\mathrm{T}_{\max }$ is the temperature of the DLTS peak. If the peak is wider than $0.1 \mathrm{~T}_{\max }$, the peak is considered to be generated by more than one deep energy state. In terms of DLTS peak width, there is a consistency in our measurements of $\mathrm{Cr}$-doped EFG, as-grown materials. Most of the DLTS peak widths, except for CrB pairs, have a DLTS FWHM peak equal to $0.2 \mathrm{~T}_{\max }$. We are not sure at this point whether this finding 


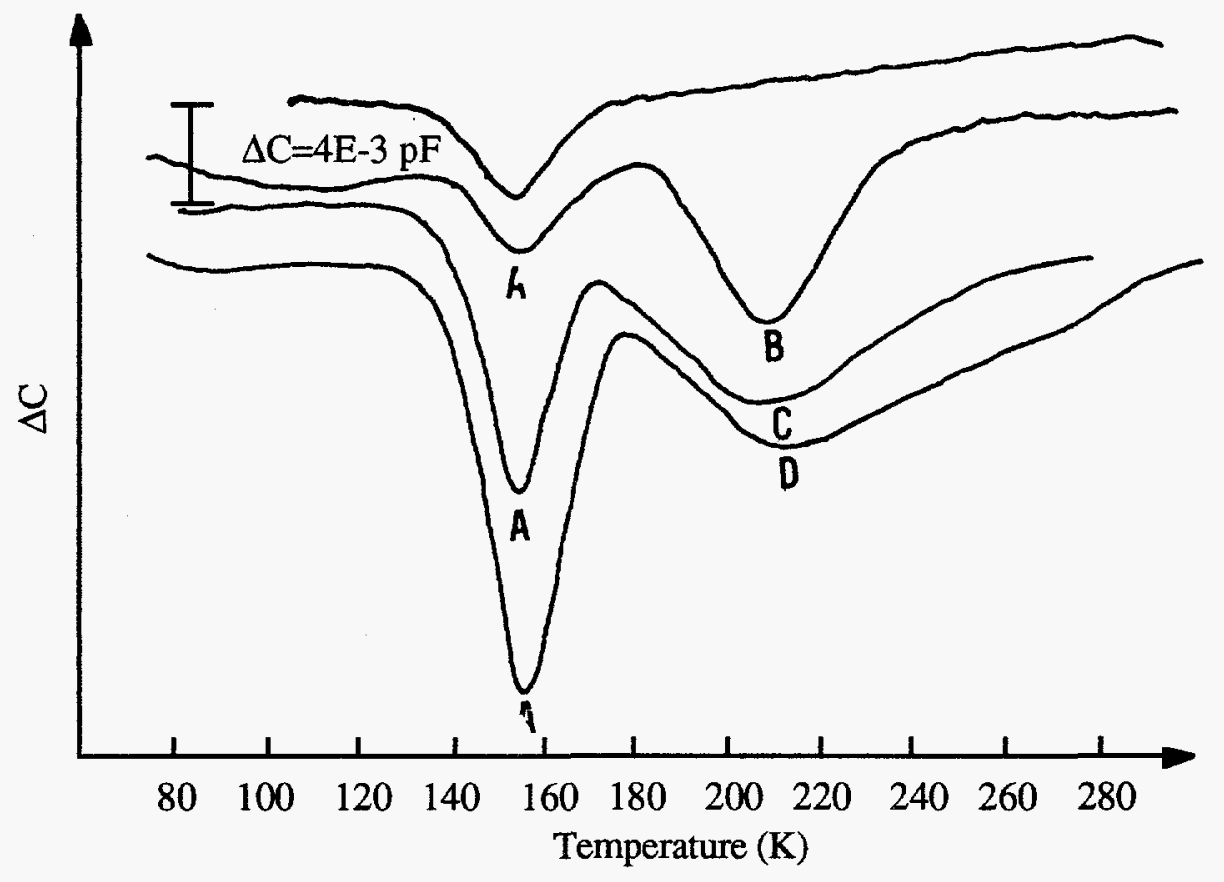

Fig. 9 DLTS spectra of Cr-doped, as-grown EFG materials. Peak A corresponds to an energy level at $E_{v}+0.27 \mathrm{eV}$ due to $\mathrm{CrB}$ pairs.

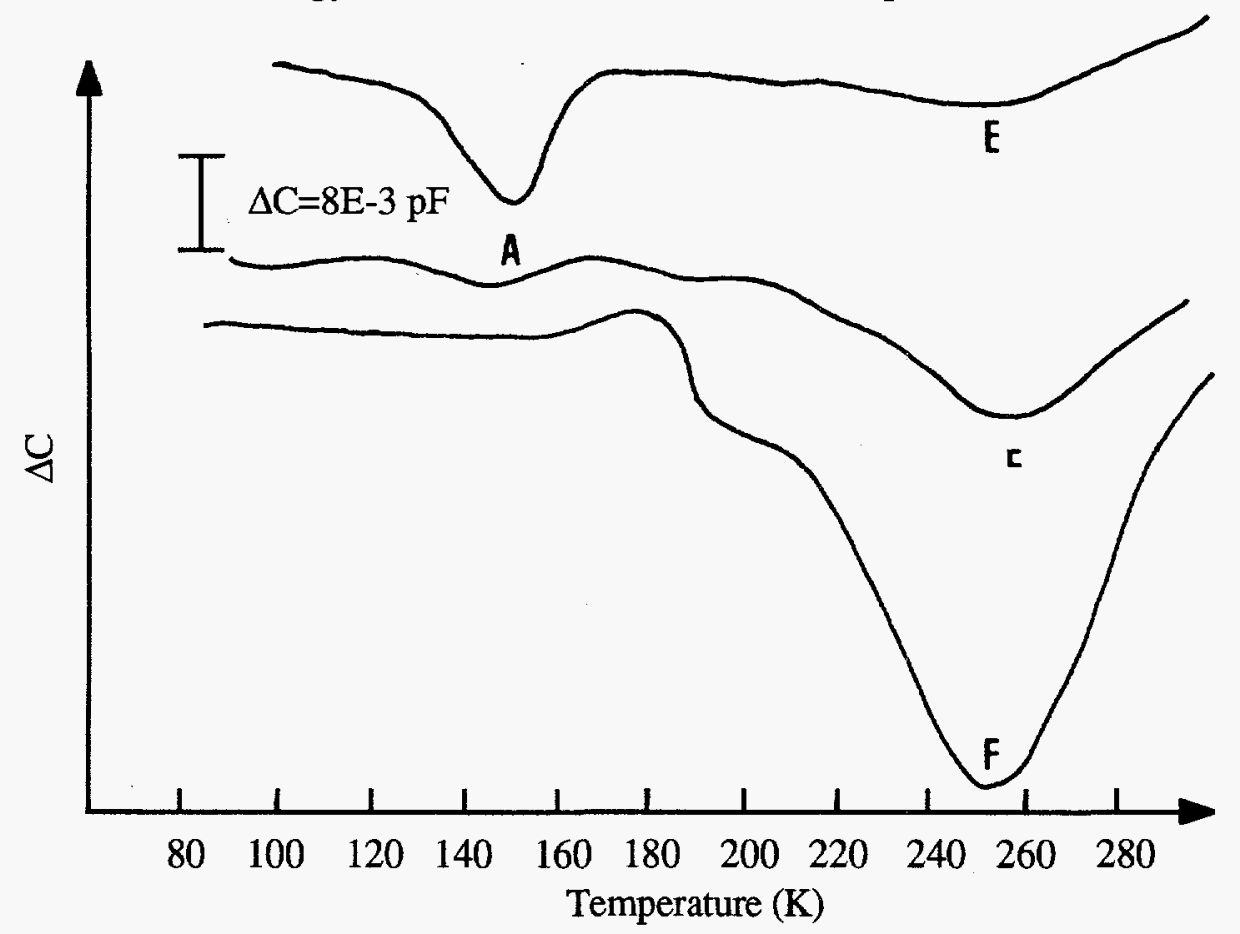

Fig. 10 DLTS spectra of two different energy states with a FWHM of $0.2 T_{\max }$. Each peak is generated by more than one deep-level impurity. Peak E: multi-energy states at $\mathrm{E}_{\mathrm{V}}+0.42 \mathrm{eV}$ with an effective capture cross section of $1 \times 10^{-16} \mathrm{~cm}^{2}$; peak $\mathrm{F}$ : multi-energy states at $E_{\mathrm{V}}+0.49 \mathrm{eV}$ with an effective capture cross section of $5 \times 10^{-15} \mathrm{~cm}^{2}$. 
has any information about the identity of the measured impurities. However, we are working on this aspect theoretically. Those DLTS peaks (E and F) are shown in Fig.10. Although the peaks are correlated to two different energy states, their FWHM are equal to $0.2 \mathrm{~T}_{\max }$.

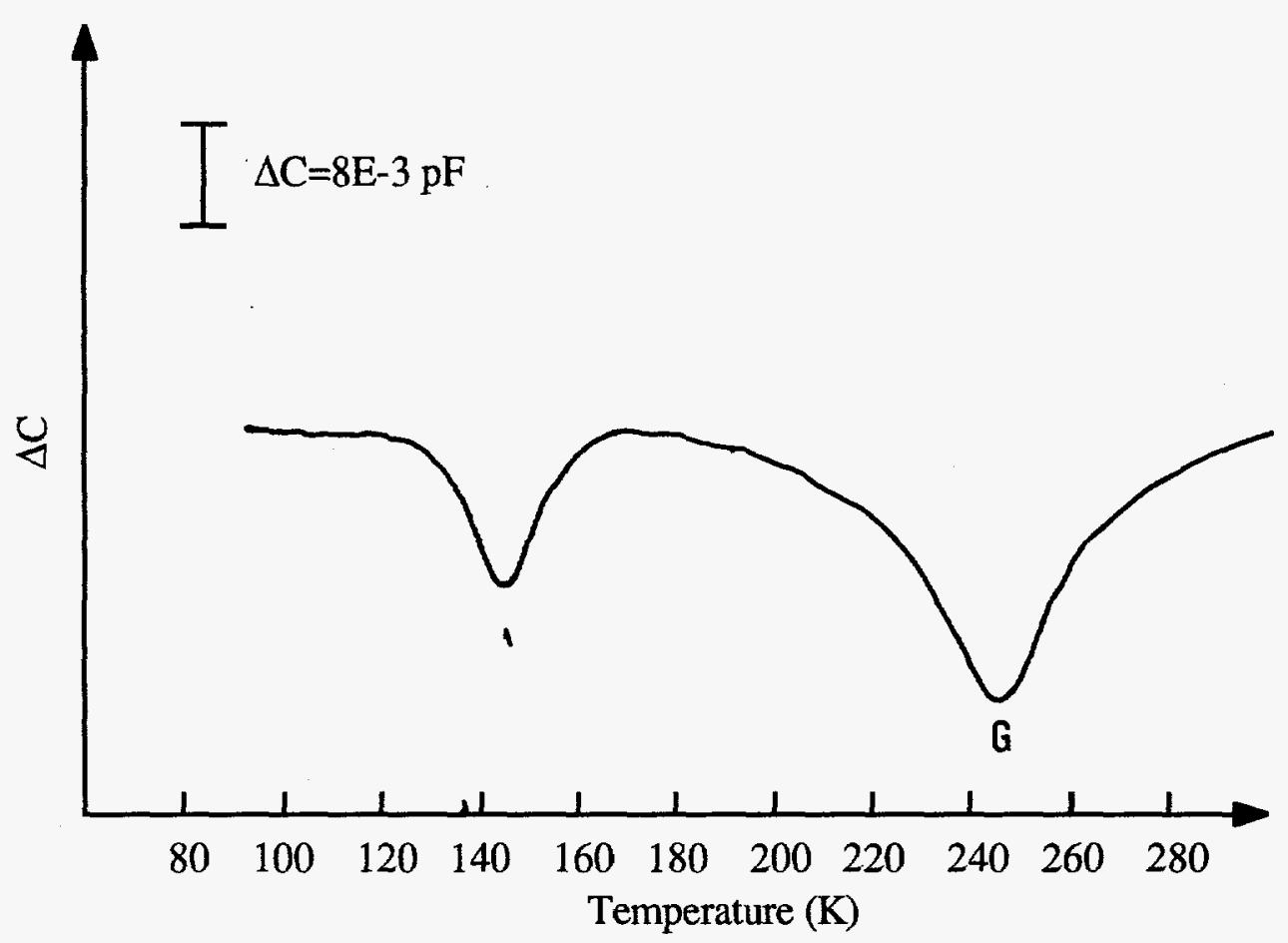

Fig. 11 DLTS spectrum of a sample with two similar energy levels but different capture cross sections. Peak G: single energy level at $\mathrm{E}_{\mathrm{v}}+0.27 \mathrm{eV}$ with capture cross section of $2 \times 10^{-19} \mathrm{~cm}^{2}$.

There is one energy level whose energy is very close to that of $\mathrm{CrB}$ pairs, but it is quite different in the capture cross section value so that the two peaks are separated in the DLTS spectrum. While the capture cross section of the energy level of $\mathrm{CrB}$ pairs is $\sim 10^{-15} \mathrm{~cm}^{2}$, the unknown energy level has a capture cross section of $\sim 10^{-19} \mathrm{~cm}^{2}$. The effectiveness of a deep-level impurity as a recombination and generation center is determined by the value of the capture cross section as well as by the location of energy level in the band gap. Fig.11 shows the DLTS spectrum of the sample with the two energy states.

It was reported by Cretella et al. that the segregation of precipitate phases to the midthickness of the sample generates a clean near-surface region of about $100 \mu \mathrm{m}{ }^{2}$ We could not detect any impurities at the sample surface until we etched the sample surface $10 \mu \mathrm{m}$. 
However, we are not certain that no impurities at the surface means really a clean surface. There is also a possibility that the high concentration of carbon at the surface may prevent the impurity from being measured by DLTS. The $\mathrm{CrB}$ pairs are relatively uniformly distributed through the sample thickness. The measured $\mathrm{CrB}$ concentration is shown in Fig.12 as a function of depth below the surface.

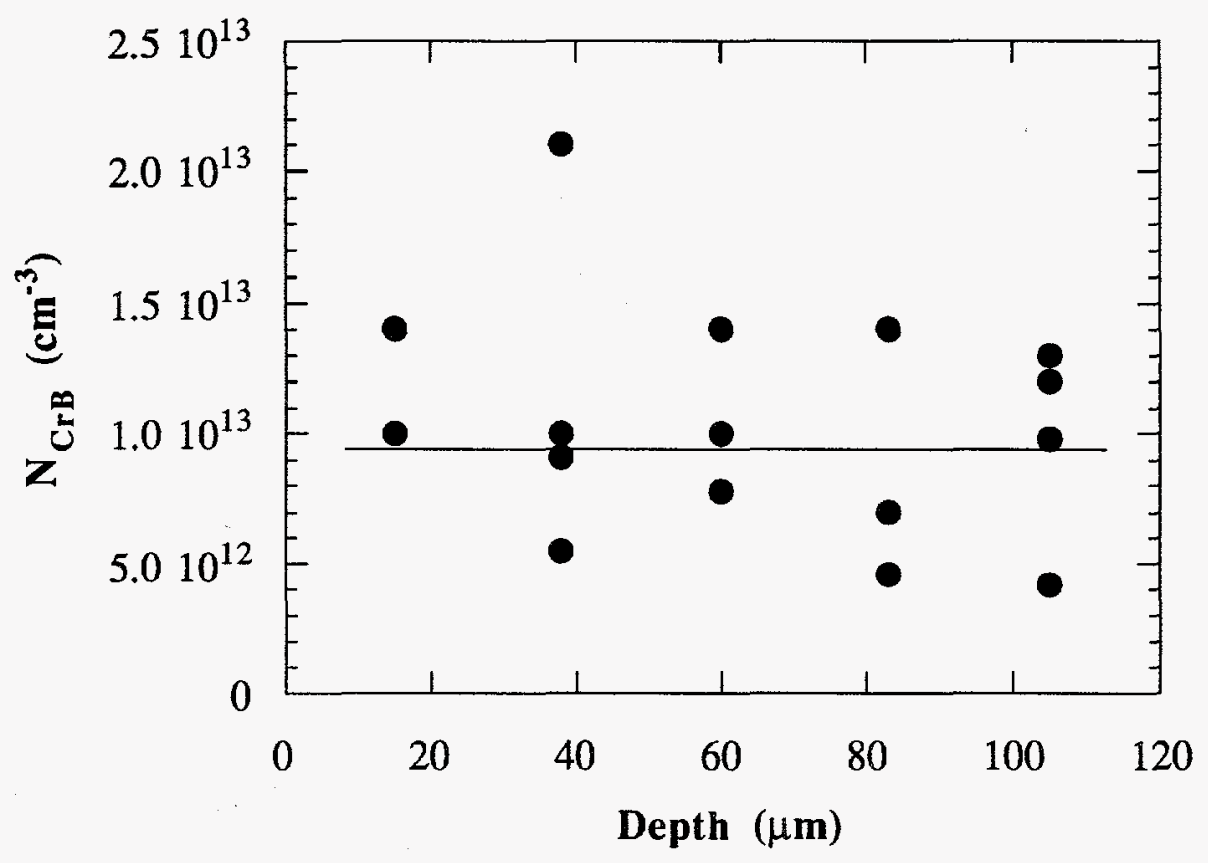

Fig. 12 The concentration of $\mathrm{CrB}$ pairs are relatively uniform through the sample thickness.

In solar cells, i.e. $n^{+} p$ junctions, we have used forward injection pulses to inject small concentrations of minority carriers to characterize minority carrier traps. We have not detected any $\mathrm{Cr}$-related peaks. We find only broad peaks which are hardly analyzable. The DLTS peaks, as shown in Fig.13, extend in temperature as wide as $\mathrm{T}=200 \mathrm{~K}$ and they are correlated with minority carrier traps. The peaks $\mathrm{I}, \mathrm{J}, \mathrm{K}$ and $\mathrm{L}$ are all minority carrier traps distributed over a certain energy range. Further, all the DLTS spectra show the possible energy states measurable only above room temperature. The majority trap, peak $\mathrm{H}$, was also detected at $\mathrm{E}_{\mathrm{c}^{-}} 0.3 \mathrm{eV}$ with a capture cross section of $2 \times 10^{-19} \mathrm{~cm}^{2}$. The broad peaks can not be analyzed by the single energy level theory. The movement of the broad peaks as the injection pulse period changes is not as clear as the movement of a single level peak. There is, however, a trend that these peaks are correlated with the measured diffusion lengths. Chromium is a very fast moving transition metal. It diffuses as much as $300 \mu \mathrm{m}$ 
in $30 \mathrm{~min}$. at $900{ }^{\circ} \mathrm{C}$. The major solar cell heat treatment is the $\mathrm{n}^{+}$diffusion for $30 \mathrm{~min}$. at $900{ }^{\circ} \mathrm{C}$. Hence, out-diffusion of $\mathrm{Cr}$ during solar cell processing is one of the reasons why neither $\mathrm{CrB}$ pairs nor $\mathrm{Cr}_{\mathrm{i}}$ are found in EFG solar cells. Another possible explanation of lack of $\mathrm{Cr}$ in solar cells is precipitates of $\mathrm{Cr}_{\mathbf{i}}$ in the grain boundaries or at the solar cell surface during solar cell processing due to the high mobility of $\mathrm{Cr}$. The active precipitation of $\mathrm{Fe}$ at $\mathrm{Si}$ surface has been reported. ${ }^{22} \mathrm{Cr}$ may behave in a similar manner.

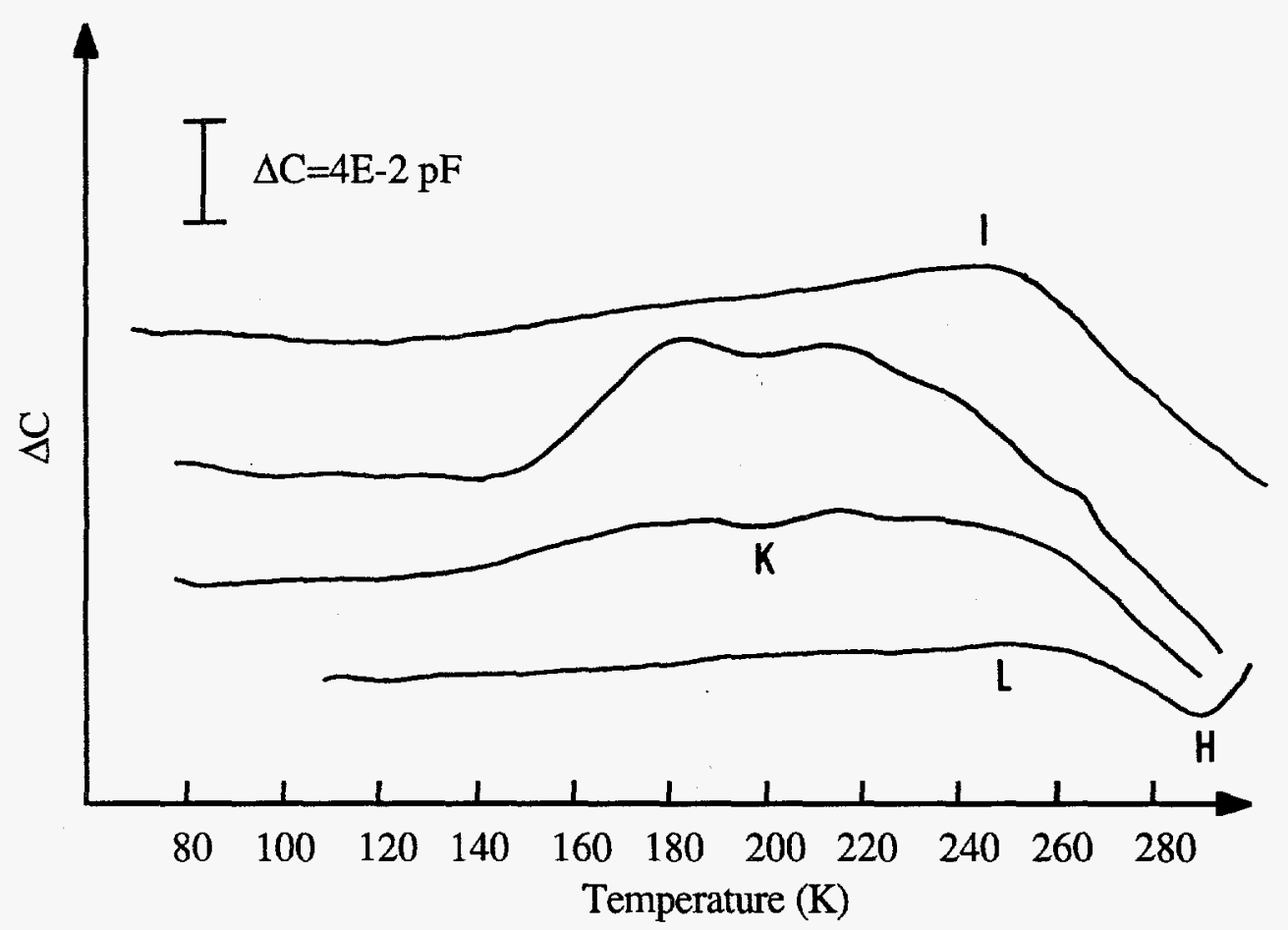

Fig. 13 DLTS spectra of Cr-doped EFG solar cells. The samples are pulsed with a small forward bias to characterize minority carrier traps.

DLTS measurements were also made on high-efficiency solar cells, on its as-grown material and on low-efficiency solar cells and on its as-grown material. The DLTS results on the as-grown, low-efficiency material, 36J61B1-1, are shown in Fig.14. The efficiency of solar cells made of contaminated, as-grown material is about $11 \%$. There are two kinds of DLTS peaks in low-efficiency, as-grown material. The first one is a peak due to a discrete impurity energy level. The second one is a broad feature with no prominent DLTS peak. 
The DLTS peaks of single energy levels, A and B, were found for Schottky diodes with twins or with defect-free regions as shown in Fig.14. Peak A corresponds to an energy state located at $E_{\mathrm{V}}+0.45 \mathrm{eV}$ with a capture cross section of $1 \times 10^{-15} \mathrm{~cm}^{2}$ and $B$ corresponds to an energy state located at $\mathrm{E}_{\mathrm{V}}+0.3 \mathrm{eV}$ with the capture cross section of $2 \times 10^{-14} \mathrm{~cm}^{2}$. Those single peaks are superimposed on a broad peak spectrum. The broad peaks were observed in all of the Schottky diodes measured on the low-efficiency, as-grown material.

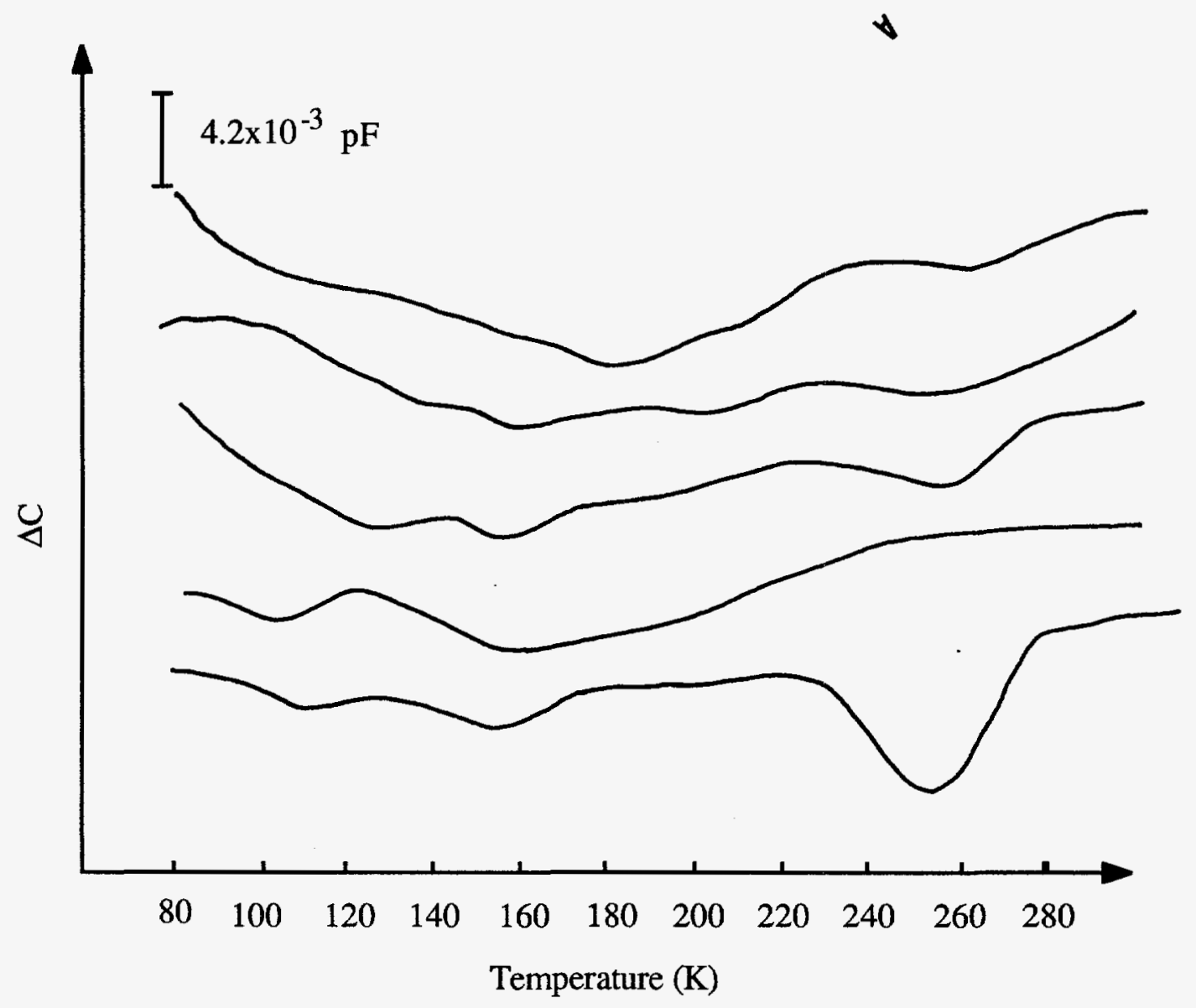

Fig. 14 DLTS spectra of low-efficiency, as-grown material, 36J61B1-1.

This very broad peak is unique for low-efficiency, as-grown material. The source of these continuous energy levels might be precipitates causing localized structural disruption. This kind of continuous energy level distribution was found in oxygen precipitates after gettering of impurities. 23 The unpurified die provides this sample with nuclei and/or high concentrations of impurities for precipitation of impurities. These precipitates are distributed throughout the wafer degrading the lifetime and the diffusion length. 
The DLTS spectra of as-grown, high-efficiency material are shown in Fig.15. The efficiency of solar cells made from high-efficiency material is about 13\%. The measured DLTS peaks have a peculiar property as concerns their FWHMs. The FWHM of all DLTS peaks of the high-efficiency, as-grown material is equal to $0.2 T_{\max }$ where $T_{\max }$ is the peak temperature. In Fig.15, peak $C$ corresponds to an energy state located at $E_{V}+0.44 \mathrm{eV}$ with a capture cross section of $6 \times 10^{-16} \mathrm{~cm}^{2}, D$ at $E_{V}+0.28 \mathrm{eV}$ with a capture cross section of $1 \times 10^{-18} \mathrm{~cm}^{2}, \mathrm{E}$ at $\mathrm{E}_{\mathrm{v}}+0.31 \mathrm{eV}$ with a capture cross section of $2 \times 10^{-17} \mathrm{~cm}^{2}$ and $\mathrm{F}$ at $E_{\mathrm{v}}+0.37 \mathrm{eV}$ with a capture cross section of $3 \times 10^{-17} \mathrm{~cm}^{2}$.

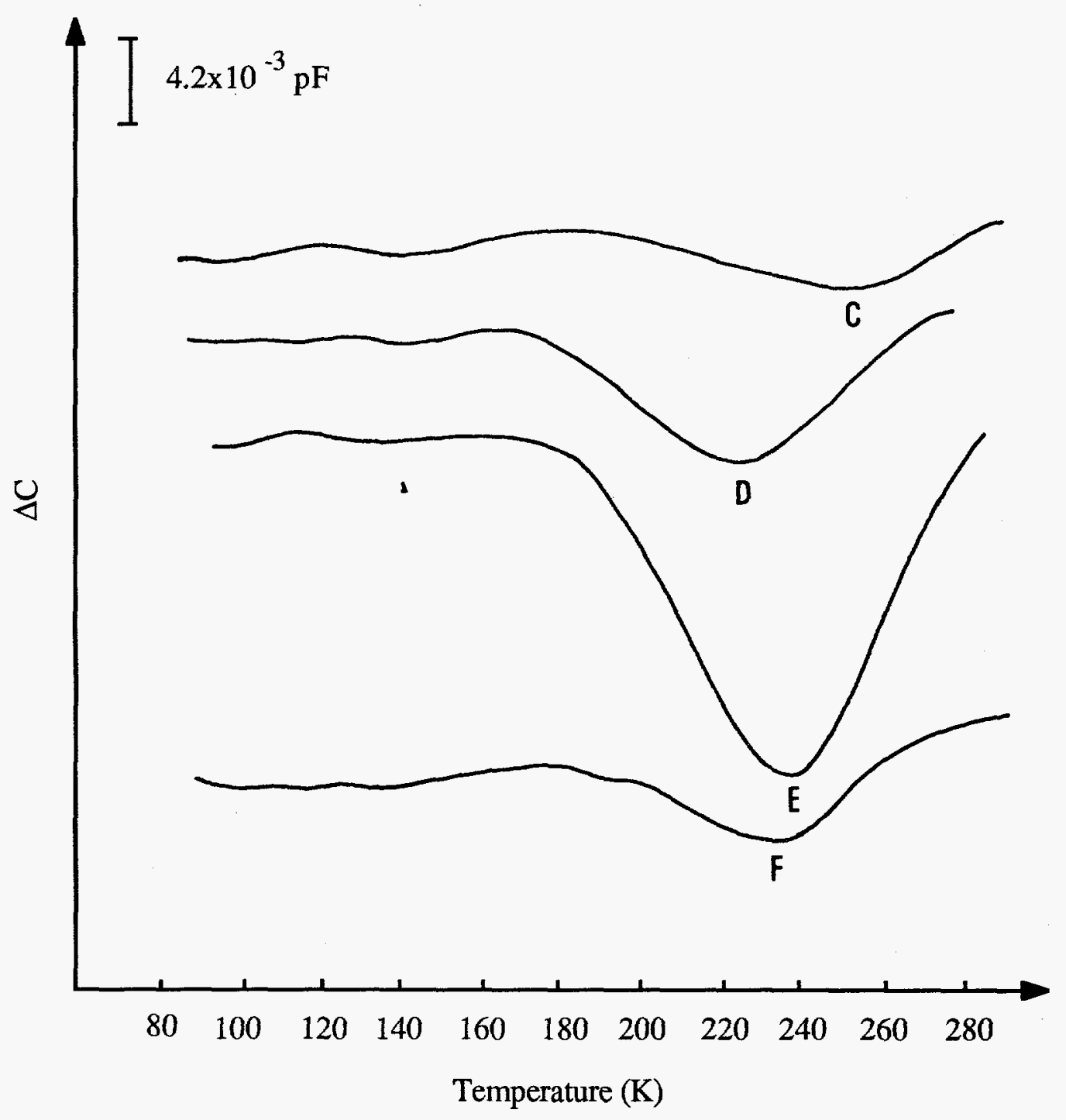

Fig. 15 DLTS spectra of high-efficiency, as-grown material, 19J81C2-1. 
For Schottky diodes with no visible structural defects, no prominent impurity levels were detected. Based on optical microscopic observation of each Schottky diode, impurities are preferentially distributed along grain boundaries in the high-efficiency, as-grown material. No impurity energy levels were detected in defect-free areas or in twinned region. The energy levels with their FWHM equal to $0.2 \mathrm{~T}_{\max }$ are also found in the Cr-doped EFG asgrown materials. Therefore, these energy levels are commonly found in the EFG as-grown material unless the graphite die is contaminated by impurities. The common energy states are mainly located around $\mathrm{E}_{\mathrm{V}}+0.33$ and $\mathrm{E}_{\mathrm{V}}+0.4 \mathrm{eV}$. Another thing to be pointed out is that all the common energy states are found only on Schottky diodes located on grain boundaries. Therefore we speculate that the crystal irregularities in the grain boundaries are responsible for the common energy states with their DLTS FWHM peaks of $0.2 \mathrm{~T}_{\max }$. DLTS measurements on low-efficiency and high-efficiency solar cells show similar features as Cr-doped cells. Only the broad peaks of minority carrier traps were detected on solar cells implying the existence of distributed energy states in the solar cells.

\section{Minority Carrier Diffusion Length}

We measure the minority carrier diffusion length by the surface photovoltage (SPV) technique ${ }^{24}$ using a fully-automated SPV system. We have used this system for a variety of $\mathrm{Si}$ and GaAs samples and find no problem when the samples are single crystalline semiconductors. However, we find unusual behavior for many polycrystalline Si samples. This unusual behavior manifests itself most commonly in the slopes of the relative photon flux density versus $1 / \alpha$ SPV plots. For many polycrystalline samples we find two very different slopes. This is especially noticeable for Solarex cast poly-Si but much less so for Mobil Solar EFG poly-Si samples. Although this section of the report deals primarily with EFG materials and cells, we digress at this point to discuss the SPV behavior of both cast and EFG poly-Si materials. In particular, we discuss nonlinear SPV curves that we observe at times.

SPV measurements were made on cast poly-Si materials, EFG poly-Si materials, and CZgrown single crystal Si. Materials were prepared by $3 \mathrm{H}_{2} \mathrm{SO}_{4}+\mathrm{H}_{2} \mathrm{O}_{2}$ cleaning, $\mathrm{HF}$ dip and RCA cleaning. After cleaning, Schottky diodes were made by depositing $200 \AA$ Al using electron beam evaporation. We use semitransparent Al Schottky diodes because capacitance pressure contacts, which we have used for other samples, are not suitable for poly-Si samples because their surfaces are not flat. SPV measurements were made on those Schottky diodes on the as-received material. After the measurements the cast poly-Si materials were polished removing about $10 \mu \mathrm{m}$. Schottky diodes were made on the same 
location where the first Schottky diodes were located. SPV measurements were made again. After these measurements the polished materials were etched in $4 \mathrm{HNO}_{3}+1 \mathrm{HF}$ to remove polishing damage. About $25 \mu \mathrm{m}$ of the material was removed. Schottky diodes were made again using the same procedure and the devices were remeasured. $\mathrm{CZ}$ single $\mathrm{Si}$ and EFG poly-Si materials were neither polished nor etched.

Figs.16-19 show the relative photon flux density (RFP) versus $1 / \alpha$ plots for highefficiency cast poly-Si materials, for medium-efficiency materials and for low-efficiency materials. The poly-Si material classification of "low, medium, or high-efficiency" refers to the efficiency of solar cells made on materials taken from very close in the ingot to the material we are studying. We have available to us both unprocessed wafers and completed cells. For conventional material, such RPF versus $1 / \alpha$ plot should be straight lines to give the correct diffusion length. The diffusion length is the intercept of an SPV plot at RFP=0 on the negative $1 / \alpha$ axis. However, measured RPF versus $1 / \alpha$ plots are frequently not straight lines for cast poly-Si materials and for EFG cells. For CZ single crystal Si and for EFG material we generally observe a straight line behavior. The curvature of SPV plots can be caused by several factors, including the surface reflectivity for rough-unpolished surfaces, the absorption coefficient which can vary due to stress in the material, and surface damage introduced during wafer processing.

For high-efficiency cast material the first SPV measurement gives a curved line in the low wavelength range ( $\lambda=8100 \AA$ - $9000 \AA$ or $1 / \alpha=12.6-31.8 \mu \mathrm{m}$ ), as shown in Fig.17. The entire measurement range shown as $1 / \alpha=12 \mu \mathrm{m}$ to $190 \mu \mathrm{m}$ corresponds to the wavelength range of $8100 \AA$ to $10100 \AA$. This curved line becomes almost linear after polishing the sample surface. Therefore, for this particular Schottky diode the surface roughness is most likely responsible for the curvature of the SPV plot. Over the entire measurement wavelength range the RPF of the rough surface is higher than the RPF of the polished surface. The rough surface has a higher reflectivity than a flat surface and the reflectivity is very likely wavelength dependent and not uniform. Fig. 20 shows the surface of the highefficiency material before polishing. Note the very rough surface features which obviously play an important role during SPV measurements. The reflectivity characteristics differ locally from region to region, since the surface conditions are very nonuniform. 


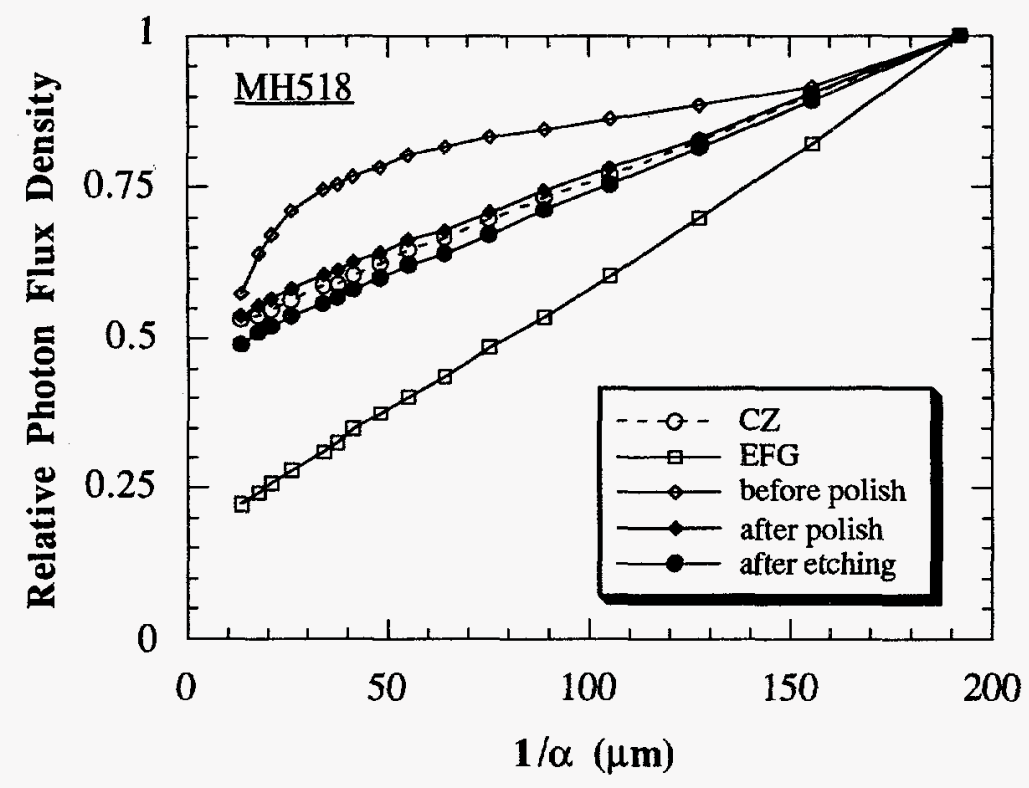

Fig. 16 Relative photon flux density versus $1 / \alpha$ for high-efficiency material. For $C Z$ and EFG only one data set, for cast poly-Si three data sets are shown.

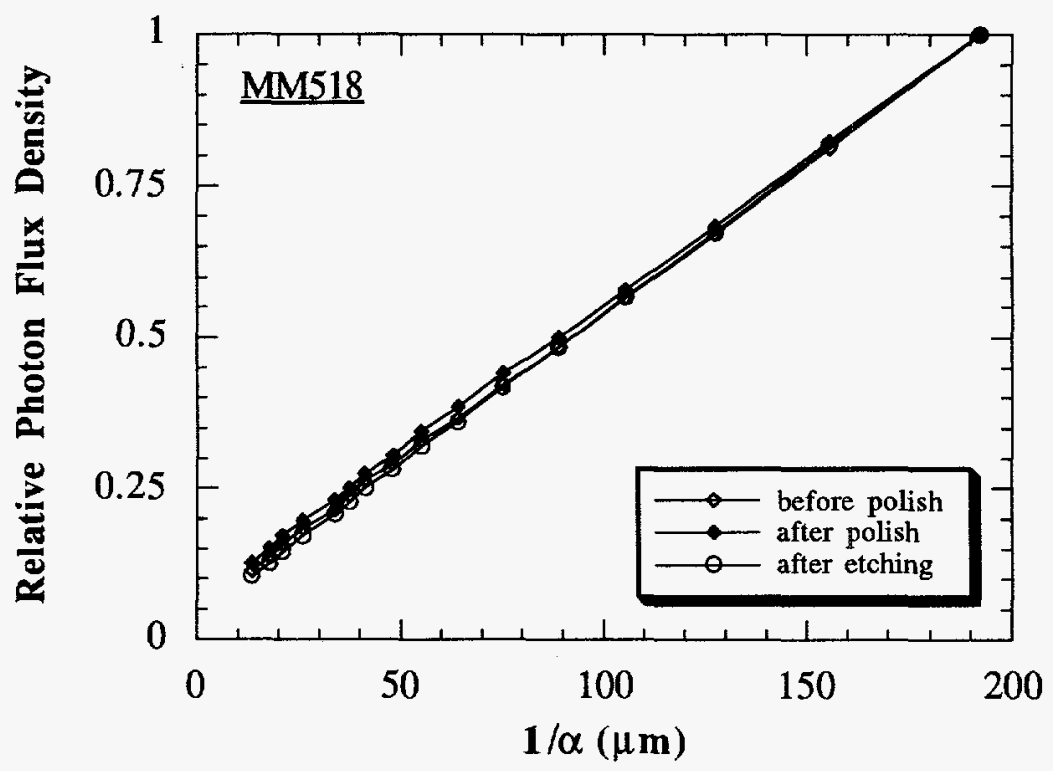

Fig. 17 Relative photon flux density versus $1 / \alpha$ for medium-efficiency cast poly-Si material. 


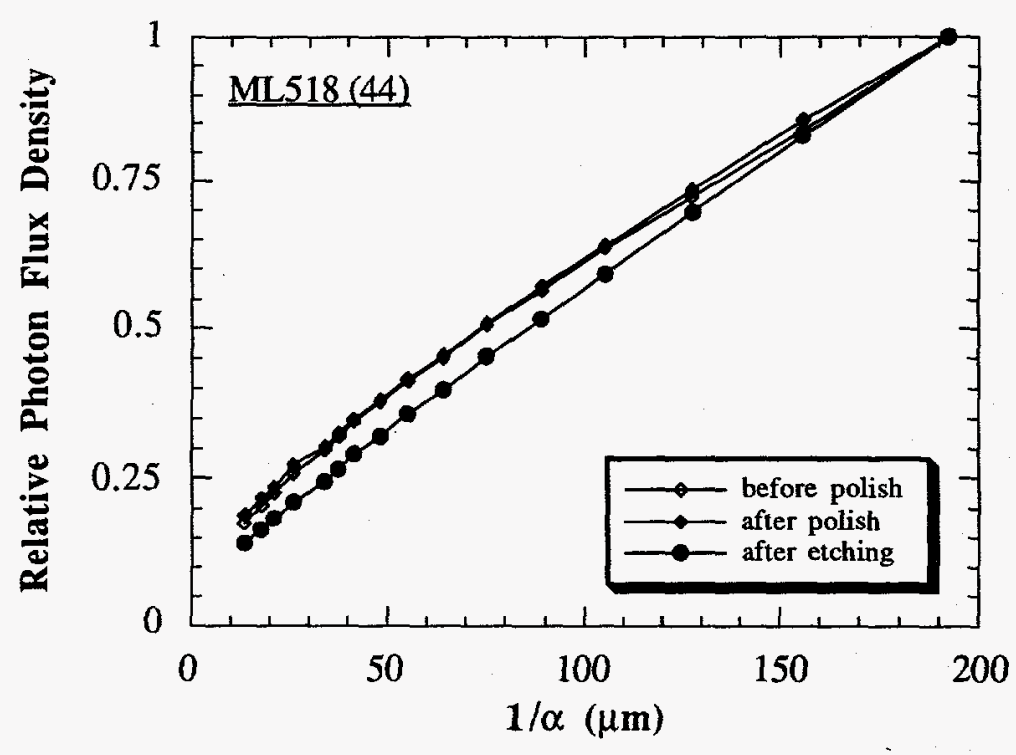

Fig. 18 Relative photon flux density versus $1 / \alpha$ for low-efficiency cast poly-Si material without precipitates.

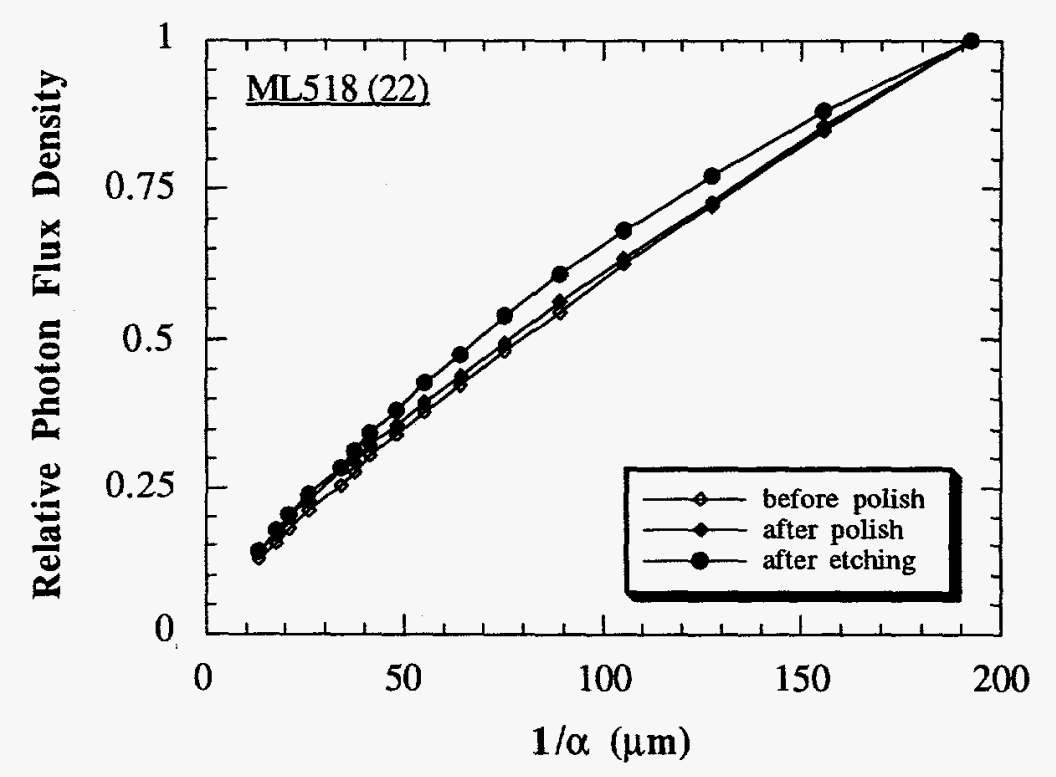

Fig. 19 Relative photon flux density versus $1 / \alpha$ for low-efficiency cast poly-Si material with precipitates. 

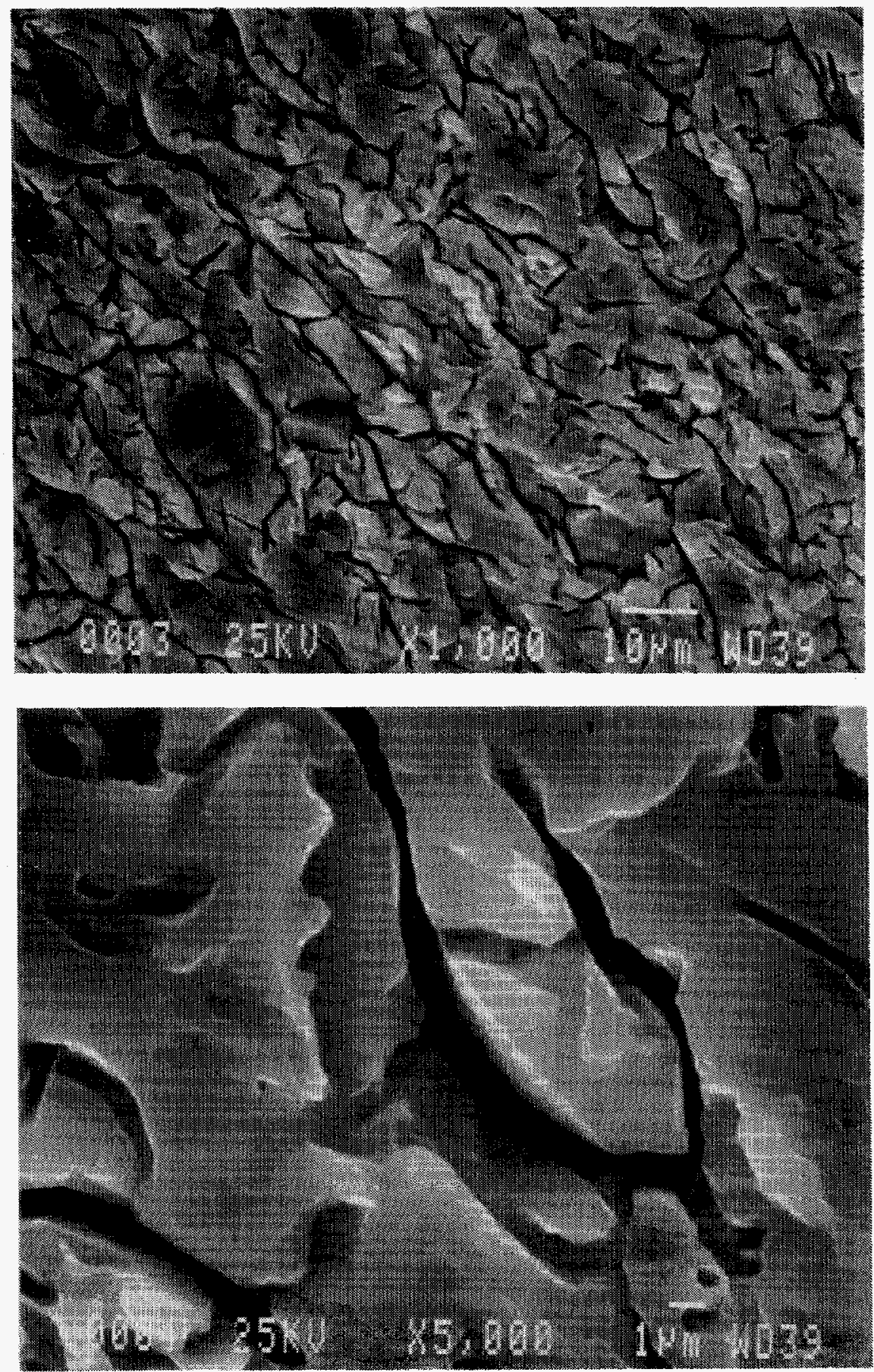

Fig. 20 High-efficiency cast poly-Si as received. 
Medium and low-efficiency materials also exhibit curvature in their SPV plots during the initial measurements prior to any polishing or etching, but the curvature is less than that of high-efficiency material as shown in Figs.17-19. For the low-efficiency cast poly-Si material samples, we investigated samples with and without precipitates. These precipitates, to be discussed in more detail later, are believed to be $\mathrm{SiC}$ precipitates. The initial measurements do not differ significantly from the measurements after polishing unlike the high-efficiency material, which does exhibit a significant change after polishing. This implies that the surface effect is reduced for medium and low-efficiency material. Because the diffusion lengths of the medium and low-efficiency materials are low the effect of surface is not as pronounced as in the high-efficiency material.

The RPF versus $1 / \alpha$ plot of high-efficiency material is almost a straight line after etching but a small curvature remains at the lower wavelength. This may be caused by absorption coefficients that differ from absorption coefficients of single-crystal Si. For mediumefficiency material there are no major differences among the three measurements. One of low-efficiency material Schottky diodes (ML518(22)) shows more curvature after etching than before. This Schottky diode has precipitates as shown in Fig.21(a). Another low efficiency Schottky diode (ML518(44)) shows a similar trend with medium and highefficiency material. Fig.21(b) shows this diode with no precipitates. Therefore, the curvature of SPV plots in the measurement after etching is mainly due to the absorption coefficient difference.

The absorption coefficients which yield a straight line in the RPF versus $1 / \alpha$ plot are determined by extrapolating the first 6 data points at low wavelengths to higher wavelengths. The calculated absorption coefficients are shown in Fig.22. The solid circles and the solid triangles are the ASTM absorption coefficients of the stress-relieved Si and nonstress-relieved $\mathrm{Si}^{25}$ The solid diamonds are the absorption coefficients used in our SPV system. This is one of the published data sets for stress-relieved Si. These absorption coefficients give a straight line for $\mathrm{CZ}$ single $\mathrm{Si}$ in our system as shown in Fig.16. Fig.22 shows that all the calculated absorption coefficients lie between the values used in our system and the nonstress-relieved $\mathrm{Si}$ absorption coefficients. The absorption coefficients for the regions which contain precipitates are closer to the nonstress-relieved Si absorption coefficients compared to the other regions. Although EFG material, prior to cell fabrication, exhibits almost straight SPV lines like CZ single crystal Si, EFG solar cells always show curvature in the SPV plots much like the high-efficiency cast material.

The measured diffusion lengths differ according to which portion of a nonlinear SPV curve is used in the diffusion length determination. Usually nonlinear SPV plots can be described 

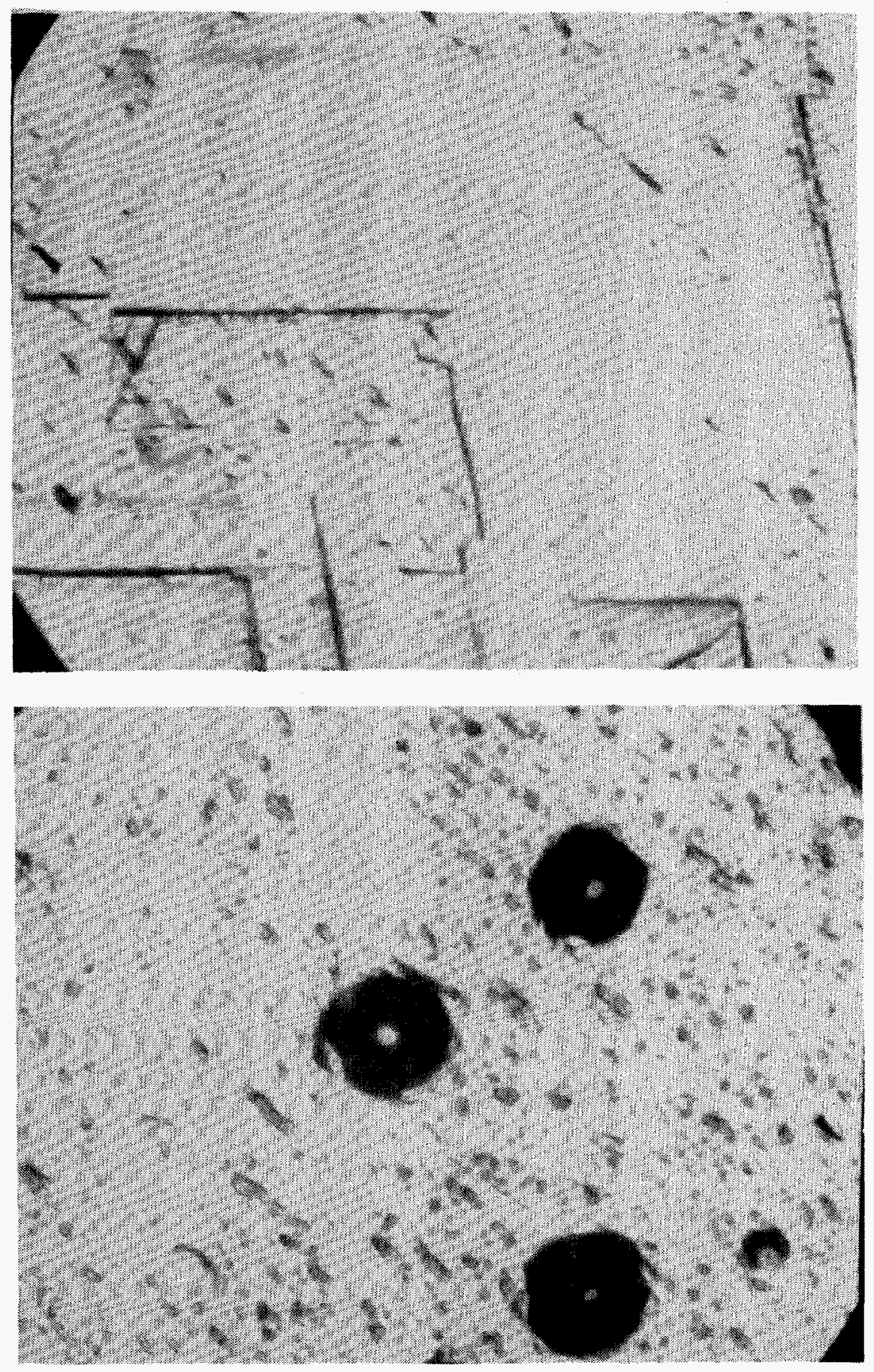

Fig. 21 Surface features of low-efficiency material after polishing and etching for samples upper without, and lower with precipitates. 
by two straight line portions, one occurring in the upper wavelength and the other in the lower wavelength region. The measured diffusion lengths for two such regions are given in Table 1. The lower wavelength region gives a more reasonable diffusion length than the high wavelength region. We base this on the observation that if the high-wavelength region is used to calculate the absorption coefficients which yield a straight line, the calculated absorption coefficients have negative values in the low wavelength region. This is clearly not physically real. Low-efficiency materials always have higher diffusion lengths than medium-efficiency material if the high-wavelength portion of the SPV plot is used. If the low-wavelength region is used then the low-efficiency material has lower diffusion lengths than medium-efficiency material. This implies the low-efficiency material is more highly stressed than the medium-efficiency material and the absorption coefficients of the lowefficiency material differ more from that of single crystal Si than those of mediumefficiency material.

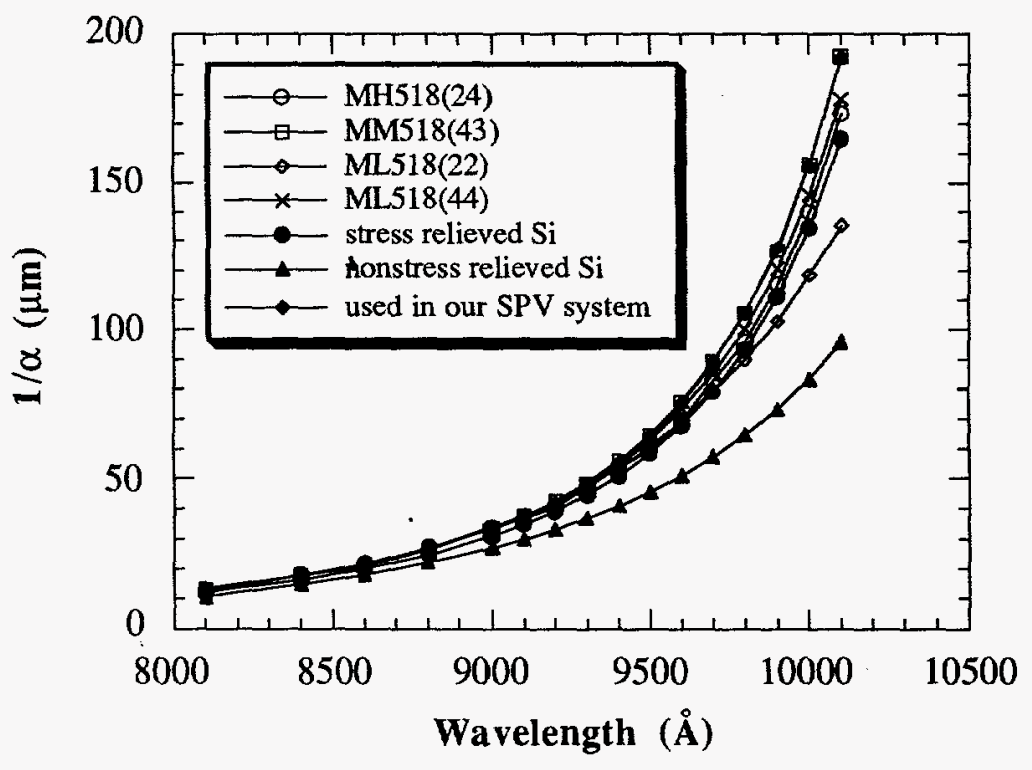

Fig. 22 Absorption coefficients versus wavelength.

Table 1 Diffusion length (in microns) determined from high-wavelength (WL) and low-wavelength regions of SPV plots

$\begin{array}{lccccc} & \text { CZ } & \text { MH518 } & \text { MM518 } & \text { ML518(44) } & \text { MM518(22) } \\ \text { High WL } & 193.1 & 169.3 & 8.8 & 20.4 & 52.4 \\ \text { Low WL } & & 142.7 & 7.9 & 14.5 & 7.3\end{array}$


We now continue our discussion of diffusion length measurements in Cr-doped EFG polySi. In particular, we wanted to know the dependence of the diffusion length on $\mathrm{Cr}_{\mathbf{i}}$ and $\mathrm{Cr}$ $B$ pair concentration. The dissociated $\mathrm{Cr}-\mathrm{B}$ pairs become $\mathrm{Cr}_{i}$ with an energy level at $\mathrm{E}_{\mathrm{c}}-0.2$ $\mathrm{eV}$ and substitutional boron. The energy level of $\mathrm{Cr}-\mathrm{B}$ is at $\mathrm{E}_{\mathrm{v}}+0.27 \mathrm{eV}$. The effect of an impurity on the recombination lifetime is dependent on the location of the energy level in the band gap and on the capture cross section. In terms of the location of the energy level, both impurities should have a similar effect on the recombination lifetime if their capture cross sections were identical, since both energy levels are about the same energy from the intrinsic energy level. Minority carrier diffusion lengths before and after annealing were measured by SPV to compare the effect of $\mathrm{Cr}-\mathrm{B}$ pairs and $\mathrm{Cr}$ interstitials on the minority carrier lifetime/diffusion length.

The results are shown in Fig.23. The diffusion lengths remain invariant with time as $\mathrm{Cr}_{\mathbf{i}}$ changes to $\mathrm{Cr}-\mathrm{B}$ pairs. Since we find no diffusion length change with conversion of chromium from $\mathrm{Cr}_{\mathrm{i}}$ to $\mathrm{Cr}-\mathrm{B}$, it is possible that both impurities have similar recombination properties. It is also obvious from Fig. 23 that as $N_{C r B}$ changes from $5 \times 10^{12} \mathrm{~cm}^{-3}$ to $2 \times 10^{13} \mathrm{~cm}^{-3}$, there is very little change in $L_{n}$. This leaves open the possibility that the diffusion length is governed by another recombination center. We have been unable, however, to find such a recombination center with DLTS measurements.

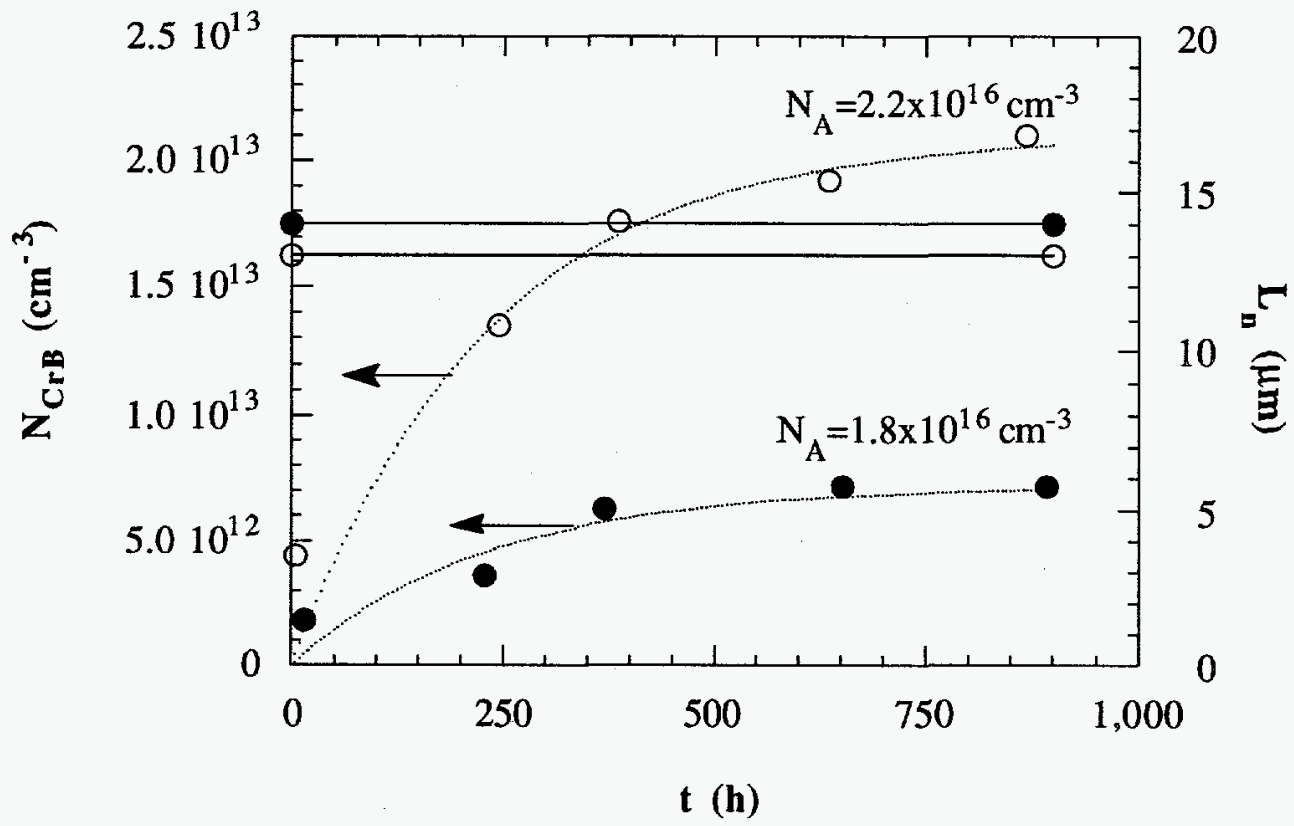

Fig. 23 Minority carrier diffusion lengths for two different $\mathrm{N}_{\mathrm{CrB}}$ concentrations as $\mathrm{Cr}_{i}$ is transformed into $\mathrm{Cr}$-B pairs. The diffusion lengths are shown by the straight lines. 


\section{Junction and Substrate Properties of Solar Cells}

The quality of p-n junctions is one of the most important factors in solar cell performance. The ideal p-n junction does not have any parasitic components so that the solar cell is an ideal device. However, in practice, there exist parasitic components which degrade the performance of solar cell. Among them, the shunt resistance, $\mathbf{R}_{\mathbf{s h}}$, and the series resistance, $\mathrm{R}_{\mathbf{S}}$, are most critical. The series resistance reduces the cell power output. The effect of the shunt resistance is shown by higher values of the diode ideality factor, $n$, than the ideal values which lie between 1 and 2 . It is also known that the solar cell efficiency usually decreases with increasing values of $n$. We have simulated the effect of the shunt resistance on the forward I-V characteristics using the device structure shown in Fig.24.

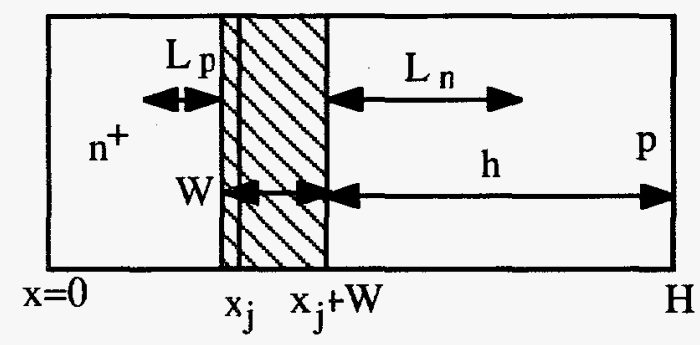

Fig. 24 Solar cell dimensions and minority carrier diffusion lengths $L_{n}$ and $L_{p}$.

\subsection{I-V Characteristics}

The dark I-V characteristic including $R_{S}$ and $R_{S h}$ is modeled by the equation

$$
I_{d}=\frac{q A n_{i}^{2} D_{n}}{N_{A} L_{n}} \exp \left[q\left(V-I R_{s}\right) / k T\right]+\frac{q A W n_{i}}{2 \tau_{s c r}} \exp \left[q\left(V-I R_{s}\right) / 2 k T\right]+\frac{V-I R_{s}}{R_{s h}}
$$

where $A$ is the junction area, $D_{n}$ the electron diffusion length, $n_{i}$ the intrinsic carrier concentration, $\mathrm{N}_{\mathrm{A}}$ the $\mathrm{p}$-substrate doping concentration, $\mathrm{W}$ the space-charge region width, $\tau_{\text {scr }}$ space-charge region recombination lifetime. In this expression some assumptions are made. The doping concentration of the $\mathrm{n}^{+}$region is sufficiently high to be able to neglect the current components from the $\mathrm{n}^{+}$side when compared to the current of the $\mathrm{p}$-side. The theoretical I-V and the $\mathrm{n}-\mathrm{V}$ curves are shown in Fig.25.

The ideality factor is calculated from the theoretical I-V curves using the equation 


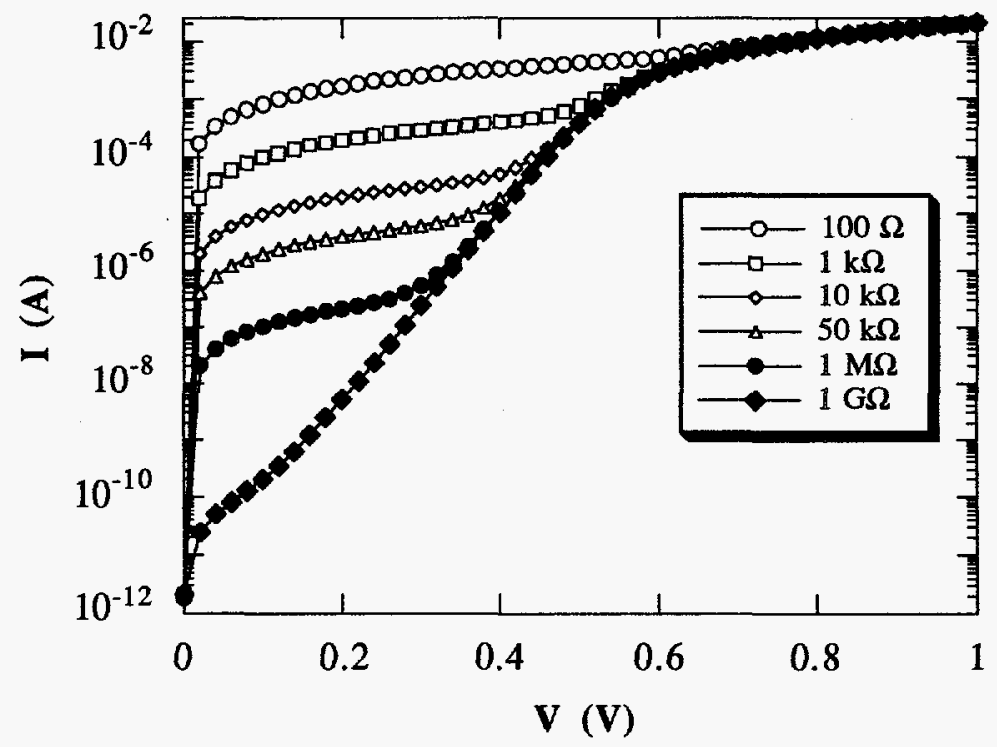

(a)

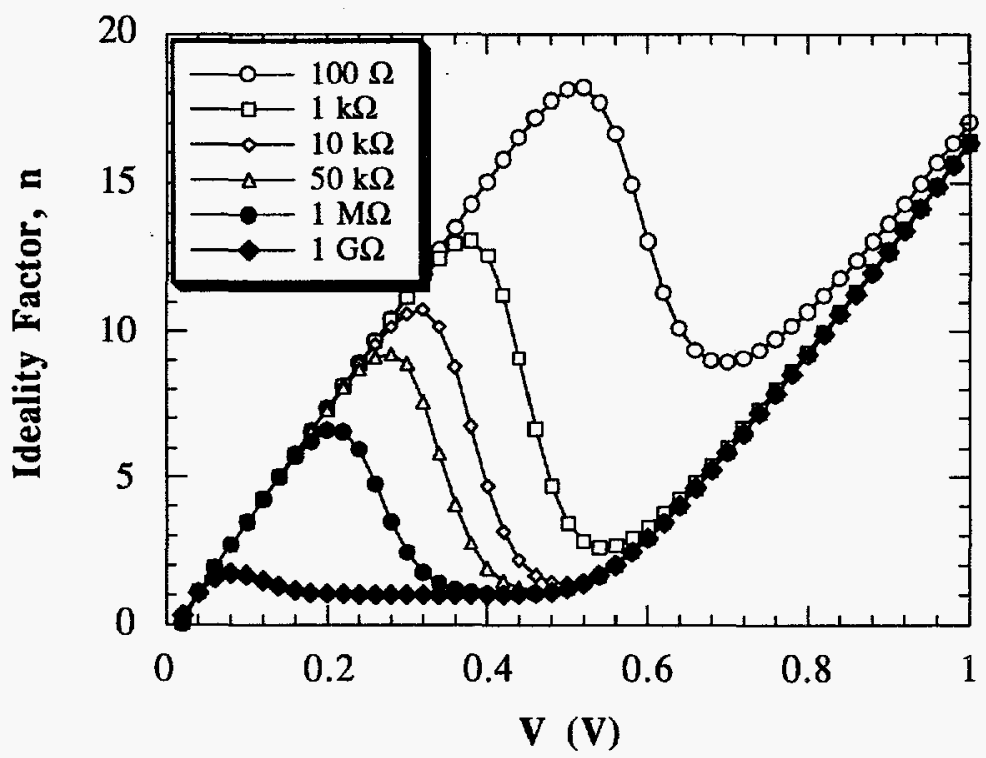

(b) 


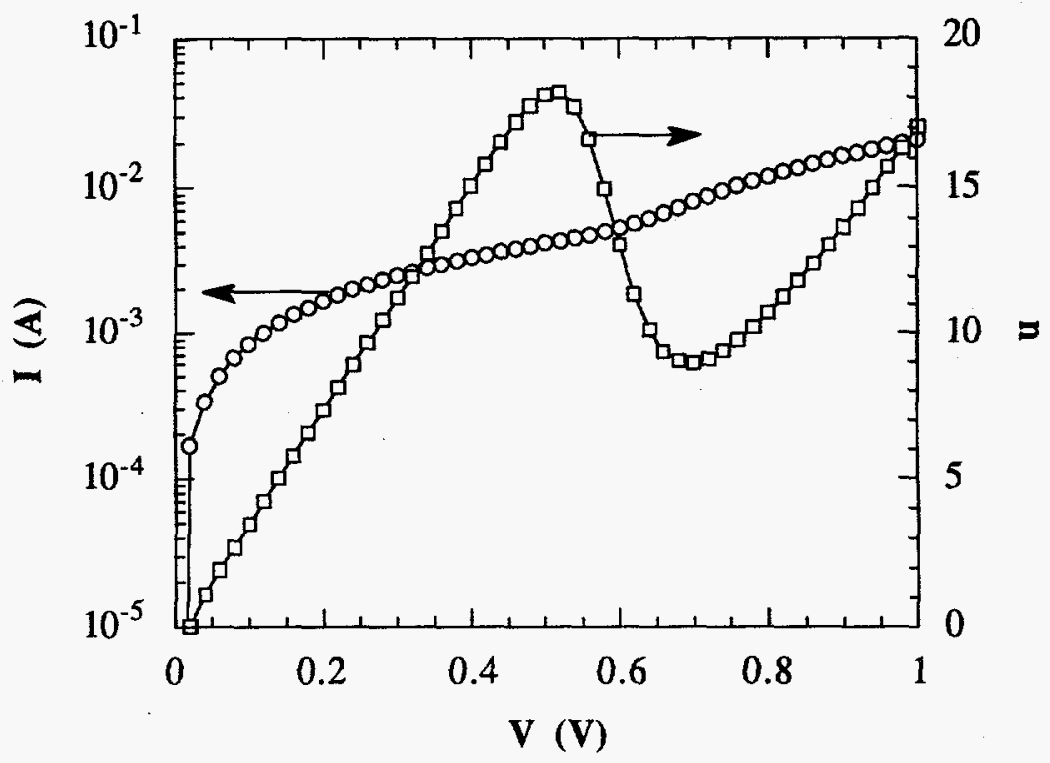

(c)

Fig. 25 Calculated (a) I-V characteristics, (b) $n-V$ characteristics versus voltage as a function of shunt resistance, (c) I-V and $n-V$ for $R_{\text {sh }}=100 \Omega$. $A=0.196 \mathrm{~cm}^{2}, D_{n}=32 \mathrm{~cm}^{2} / \mathrm{s}$, $\mathrm{N}_{\mathrm{A}}=1 \times 10^{16} \mathrm{~cm}^{-3}, \mathrm{~W}=0,34 \mu \mathrm{m}, \tau_{\mathrm{scr}}=\mathrm{L}_{\mathrm{n}}^{2} / \mathrm{D}_{\mathrm{n}}, \mathrm{R}_{\mathrm{s}}=20 \Omega, \mathrm{L}_{\mathrm{n}}=100 \mu \mathrm{m}$.

$$
n=[(k T / q) m]^{-1}
$$

where $m=d \ln (I) / d V$ is the slope of the $\ln (I)$ versus $V$ curve. The shunt resistances, $R_{\text {sh }}$, are used as parameters ranging from $100 \Omega$ to $1 \mathrm{G} \Omega$.

The diode ideality factor $\mathrm{n}$ is known to be $\mathrm{n}=1$ for pure diffusion current and $\mathrm{n}=2$ for $\mathrm{SRH}$ recombination current in the space charge region. ${ }^{26}$ High quality, single-crystal Si diodes usually have ideality factors between 1 and 2 . However, the pn junctions of low-cost solar cells usually have higher $n$ values. Ideality factors can range as high as 6 to 8 for such cells with low shunt resistances. The high impurity concentration and the high density of crystalline defects from low-cost raw materials and growth processes lead to the poor junctions. Various reasons have been suggested as possible causes of the high ideality factors including micro-plasma breakdown, 27 surface leakage by metallic precipitates, 28 surface channeling, ${ }^{29}$ and tunneling. ${ }^{30}$ 
There are two things to be pointed out in Fig.25. First, the maximum diode ideality factor increases as the shunt resistance decreases. Second, the diode ideality factor also varies with applied bias voltage. The $\mathrm{n}$ value increases monotonically to a maximum at a bias voltage, $V_{\max }$, and then decreases to a minimum at $V_{\min }$. $V_{\max }$ increases as the shunt resistance decreases because the effect of the shunt resistance on the current grows as the shunt resistance decreases. Beyond $V_{\max }$, the diffusion current component dominates thereby decreasing $\mathrm{n}$. The diode ideality factor reaches a minimum from which it increases again due to series resistance. The measured ideality factors of Cr-doped EFG mesa diodes in Fig.26 show the effect of the shunt resistance. The EFG solar cells have a variety of conducting paths along the shunt resistance caused by grain boundaries and precipitates.

To examine the effect of the shunt resistance on the ideality factor in detail, $\mathrm{n}$ is calculated and drawn as a function of shunt resistance in Fig.27 with the minority carrier diffusion length as a parameter ranging from $50 \mu \mathrm{m}$ to $200 \mu \mathrm{m}$ using Eqs.(7) and (8). The ideality factors in this figure are calculated at $\mathrm{V}=0.45 \mathrm{~V}$. The diode ideality factors are insensitive at extremely low $\left(\mathrm{R}_{\mathrm{Sh}}<200 \Omega\right)$ and high $\left(\mathrm{R}_{\mathrm{Sh}}>100 \mathrm{k} \Omega\right.$ ) shunt resistances. Between these extremes, however, $n$ depends on the diffusion length. It increases as the diffusion length increases. Later this graph will be useful for the determination of the shunt resistance from the measured ideality factors.

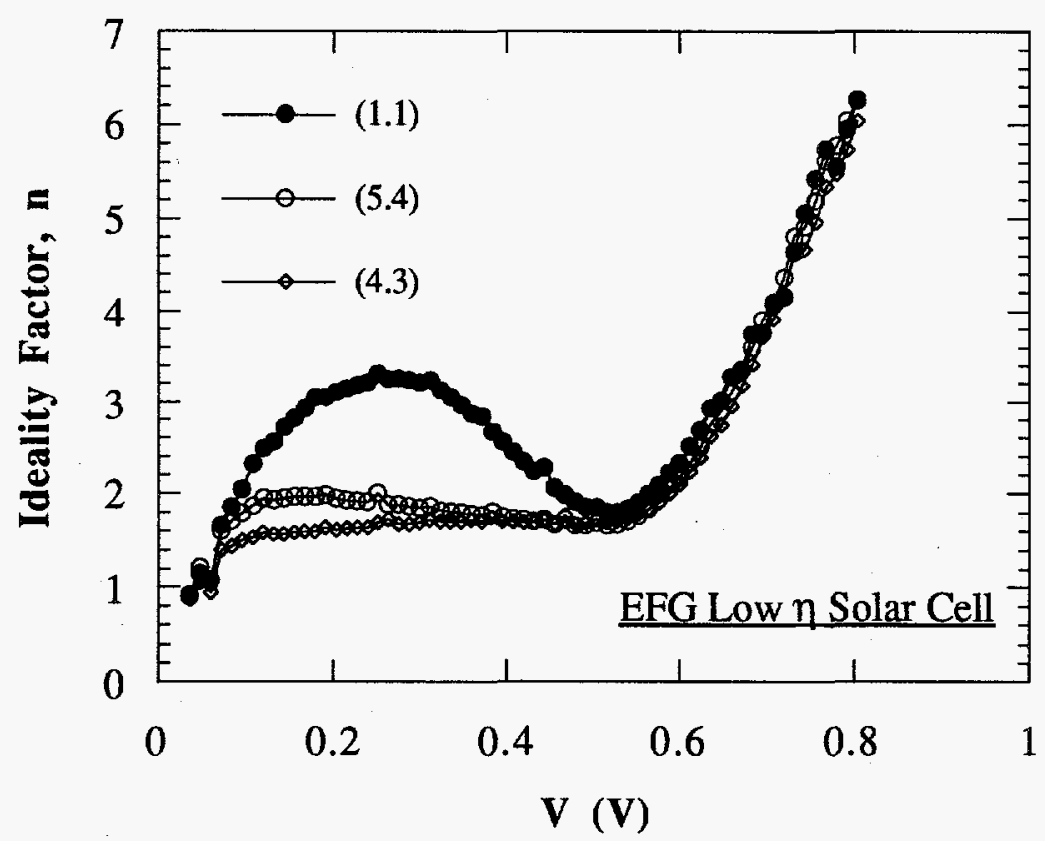

Fig. 26 Measured diode ideality factor versus voltage for EFG solar cells. 


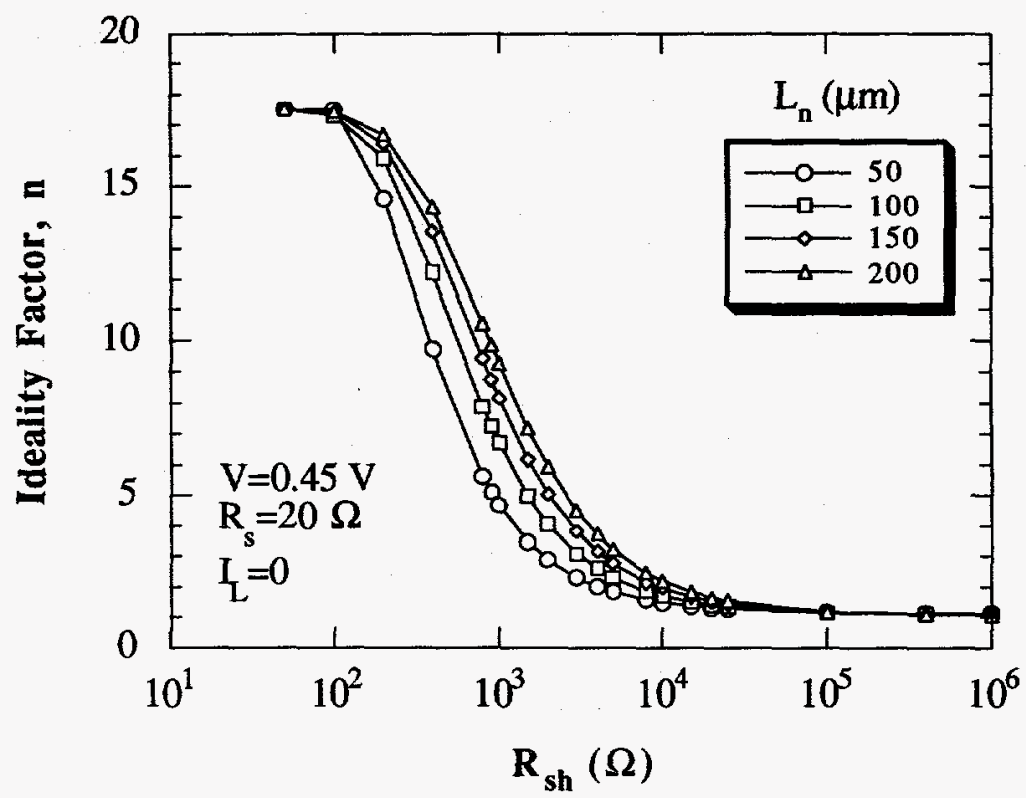

Fig. 27 Variation of the ideality factor $\mathrm{n}$ as a function of the shunt resistance with the diffusion length as parameters for $\mathrm{V}=0.45 \mathrm{~V}$.

\subsection{Surface Photovoltage and Diffusion Length Dependence on Diode Ideality Factor}

We have seen from ideality factor and surface photovoltage or open circuit voltage measurements that the open circuit voltage decreases as $n$ increases and the diffusion length is relatively independent of $\mathrm{n}$ as shown in Fig.28.

To calculate the open circuit voltage under illumination, we have to add the photocurrent component, $\mathrm{I}_{\mathrm{L}}$, to the dark current component of Eq.(7). The photocurrent, $\mathrm{I}_{\mathrm{L}}$, consists of the photocurrent due to electrons from the $p$-substrate collected at the space-charge region edge, $\mathrm{x}=\mathrm{x}_{\mathrm{j}}+\mathrm{W}$, and the photocurrent generated within the space-charge region. We neglect the small photocurrent collected from the $\mathrm{n}^{+}$region. The photocurrent collected at the edge of the space charge region from the $p$-substrate, $I_{n}$, is given by

$$
I_{n}=A q \frac{F(1-R) \alpha L_{n}}{\alpha^{2} L_{n}^{2}-1} \exp \left[-\alpha\left(x_{j}+W\right)\right]\left[\alpha L_{n}-Y\right]
$$

where 


$$
Y=\frac{\left(S_{n} L_{n} / D_{n}\right)\left[\cosh \left(h / L_{n}\right)-\exp (-\alpha h)\right]+\sinh \left(h / L_{n}\right)+\alpha L_{n} \exp (-\alpha / h)}{\left(S_{n} L_{n} / D_{n}\right) \sinh \left(h / L_{n}\right)+\cosh \left(h / L_{n}\right)}
$$

Here $\mathrm{F}$ is the photon flux density, $\mathrm{A}$ the area, $\alpha$ the absorption coefficient, and $\mathrm{S}_{\mathbf{n}}$ the surface recombination velocity at the back surface. The photocurrent generated within the space-charge region, $I_{g}$, is given by

$$
I_{g}=A q F(1-R) \exp \left(-\alpha x_{j}\right)[1-\exp (-\alpha W)]
$$

The total photocurrent, $I_{L}$, is

$$
I_{L}=I_{n}+I_{g}
$$

The total current is

$$
I=I_{d}-I_{L}
$$

where $I_{d}$ is the dark current given by Eq.(7).

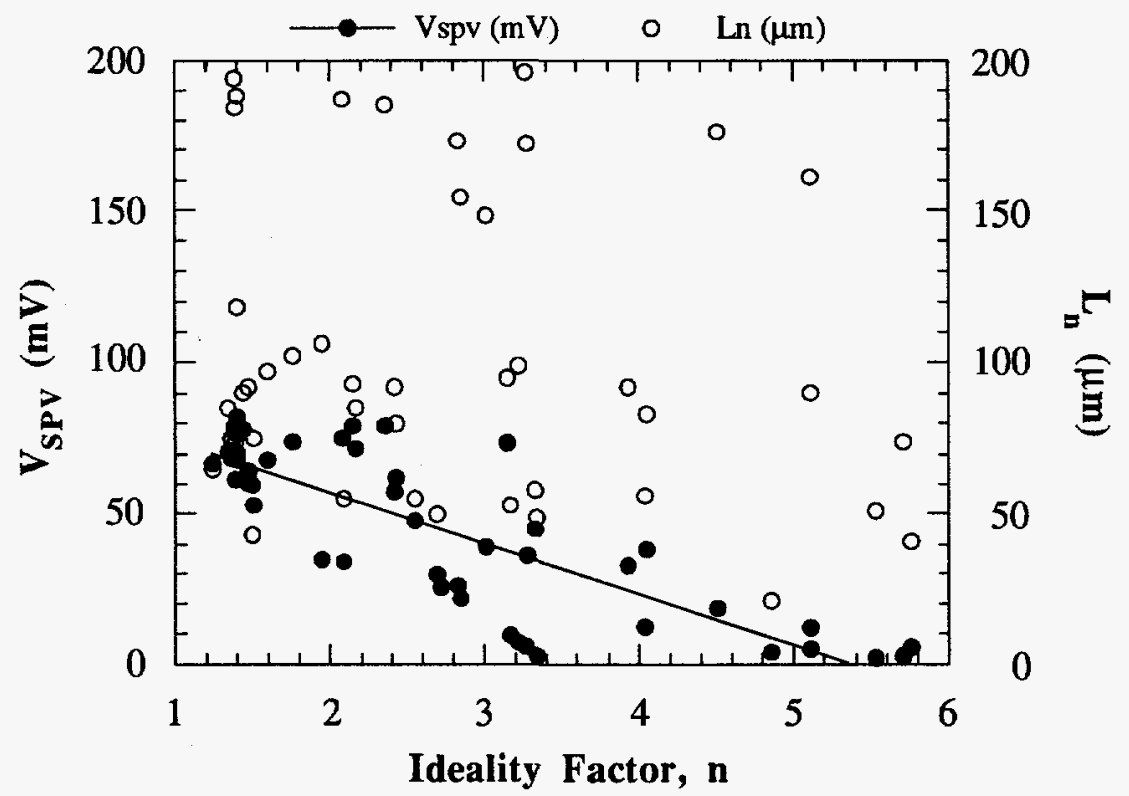

Fig. 28 Open circuit voltage decreases as the diode ideality factor increases while the diffusion length is relatively independent of the diode ideality factor. 
The open circuit voltages, $V_{o c}$, are calculated with Eqs.(7) and (9)-(12) for various shunt resistances. To calculate the total photocurrent, we used $F=3 \times 10^{15}$ photons $/ \mathrm{cm}^{2} \cdot \mathrm{s}, \alpha=52$ $\mathrm{cm}^{-1}, \mathrm{~S}_{\mathrm{n}}=50 \mathrm{~cm} / \mathrm{sec}, \mathrm{h}=399 \mu \mathrm{m}, \mathrm{W}=0.34 \mu \mathrm{m}, D_{\mathrm{n}}=32 \mathrm{~cm}^{2} / \mathrm{sec}, \mathrm{A}=0.196 \mathrm{~cm}^{2}, \mathrm{R}_{\mathrm{s}}=20 \Omega$. The diffusion length is used as a parameter. For each shunt resistance, there is a corresponding diode ideality factor calculated with Eq.(7). The diode ideality factor and the corresponding open circuit voltage are calculated using identical diffusion length. The calculated open circuit voltages and the corresponding diode ideality factors are shown together with measured data from $\mathrm{Cr}$-doped EFG solar cells for several different diffusion lengths in Fig.29 and 30. Fig.29 shows the open circuit voltage versus $\mathrm{n}$ for the various diffusion lengths considered. Fig. 30 compares theory with experimental data. From these graphs, we find the experimental diode ideality factors of the measured data to be distributed up to $n \approx 7$. According to Fig. 27 this corresponds shunt resistances above $1 \mathrm{k} \Omega$. The diode ideality factors of a large portion of the data points are distributed in the range of $\mathrm{n}=1$ to $\mathrm{n}=3$. The corresponding shunt resistance lie above $5 \mathrm{k} \Omega$ according to Fig. 27 which is consistent with the shunt resistance measurements of $\mathrm{Cr}$-doped solar cells.

The variation of the ideality factor with diffusion length is shown in Fig.31. When the shunt resistance is above $5 \mathrm{k} \Omega$, the diode ideality factor is relatively immune to variations in diffusion length. This is consistent with the data shown in Fig.27.

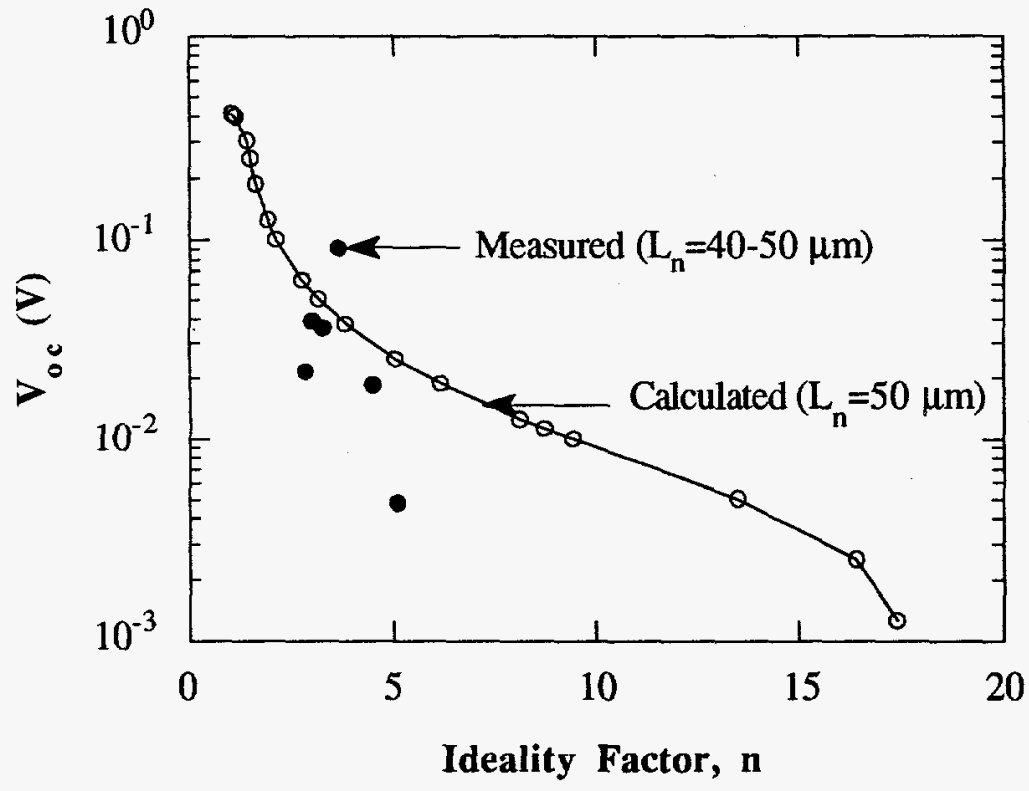

Fig. 29-1 Calculated open circuit voltages versus $n$ at $V=.45 \mathrm{~V}$ and diffusion length of 50 $\mu \mathrm{m}$. Open circles: theory; closed circles: measured data. 


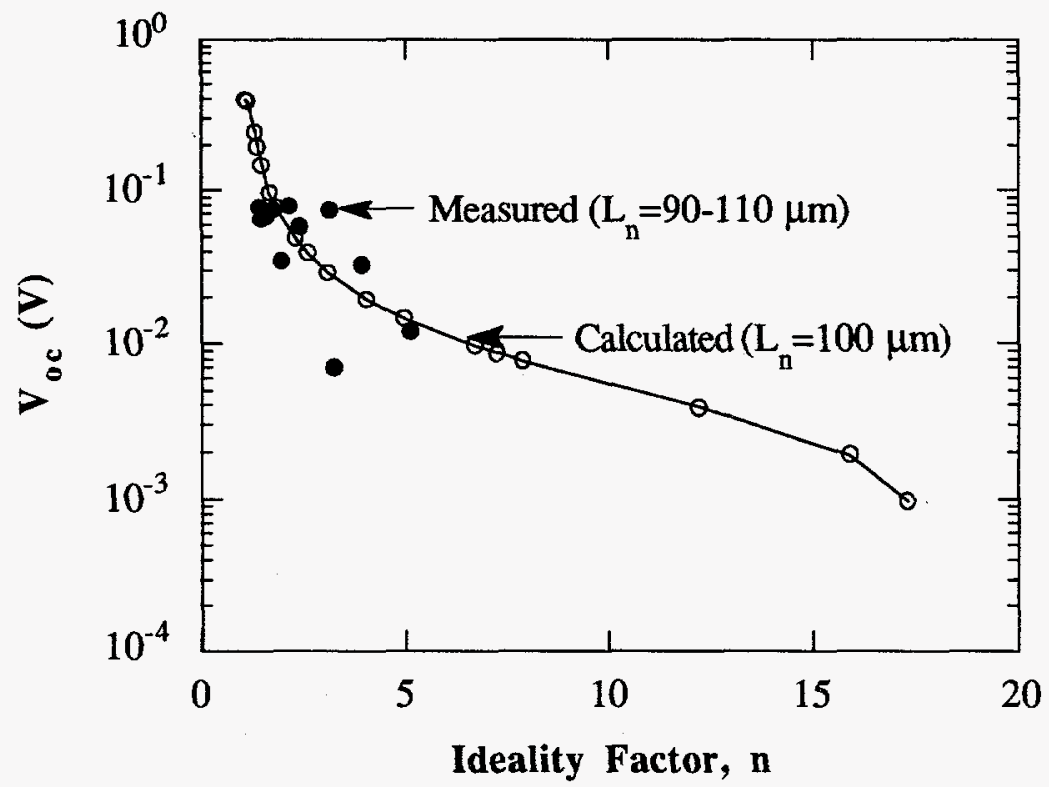

Fig. 29-2 Calculated open circuit voltages versus $n$ at $V=.45 V$ and $L_{n}=100 \mu m$. Open circles: theory; closed circles: measured data.

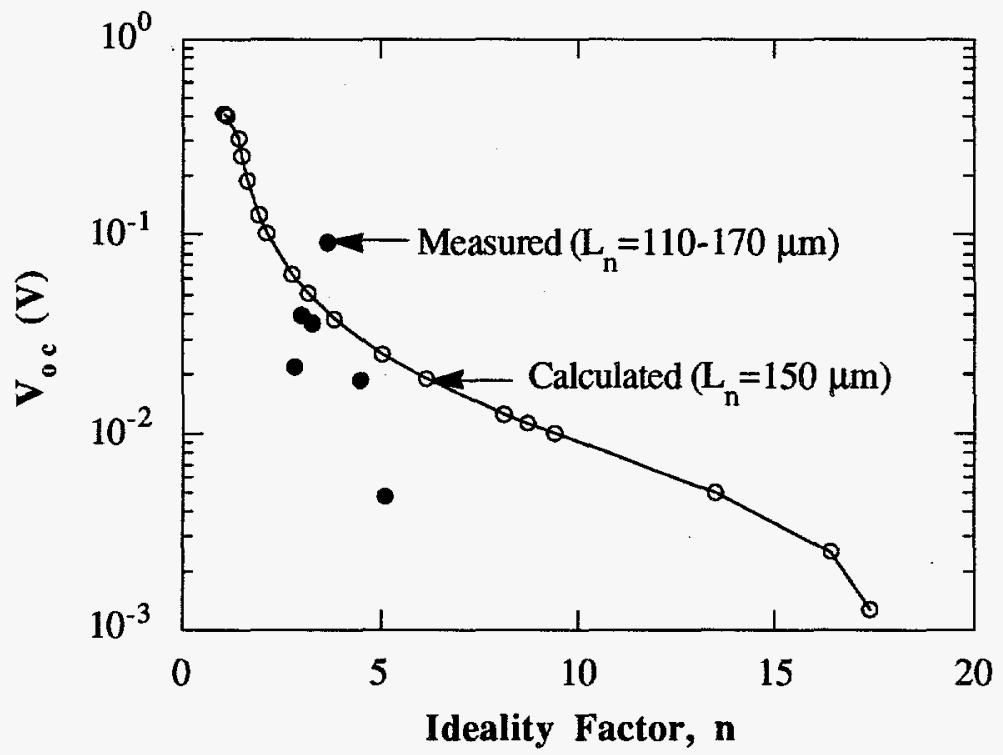

Fig. 29-3 Calculated open circuit voltages versus $n$ at $V=.45 \mathrm{~V}$ and $\mathrm{L}_{n}=150 \mu \mathrm{m}$. Open circles: theory; closed circles: measured data. 


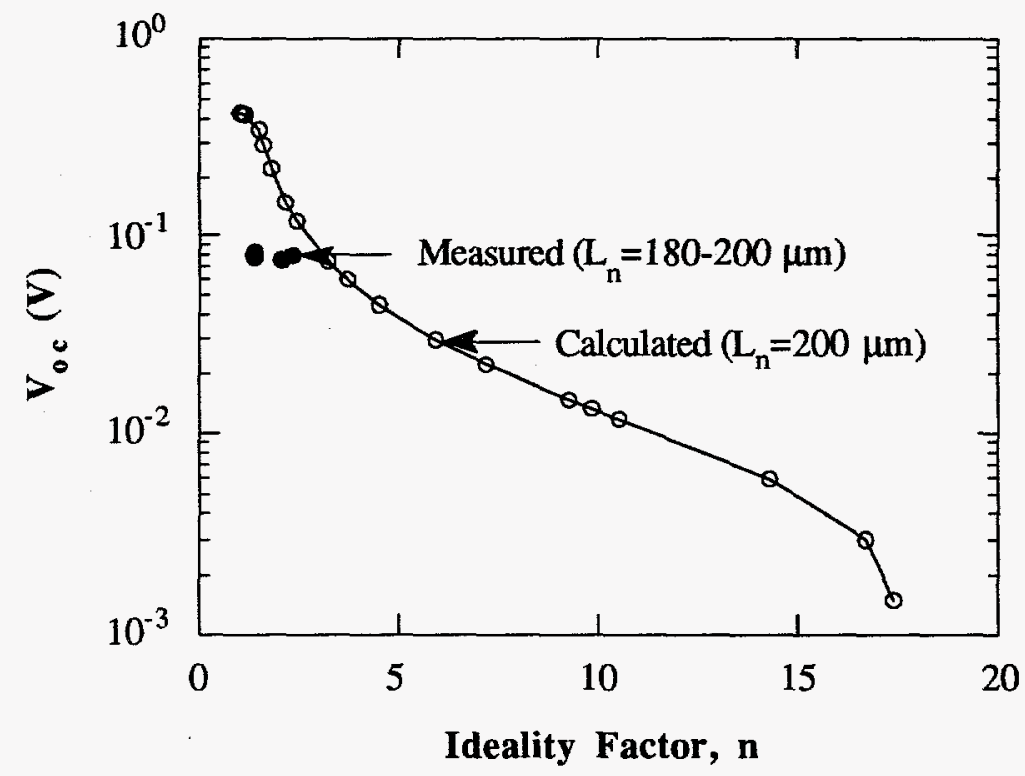

Fig. 29.4 Calculated open circuit voltages versus $n$ at $V=.45 V$ and $L_{n}=200 \mu m$. Open circles: theory; closed circles: measured data.

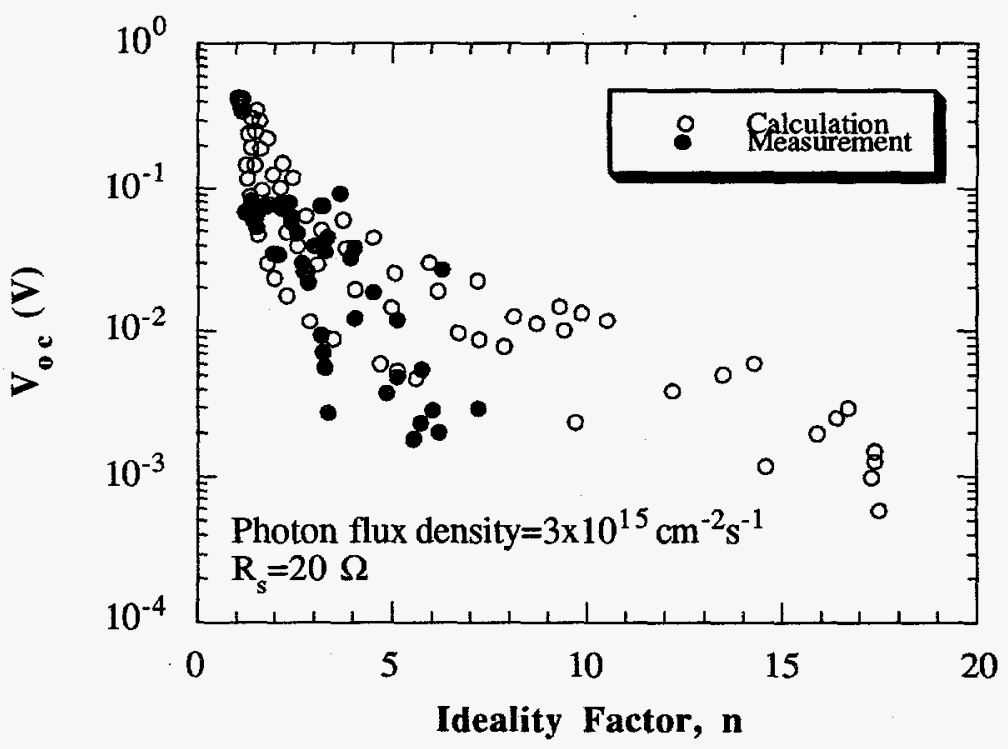

Fig. 30 Calculated open circuit voltages at $V=.45 \mathrm{~V}$ and several diffusion lengths. Open circles: theoretical calculations; closed circles: measured data. 


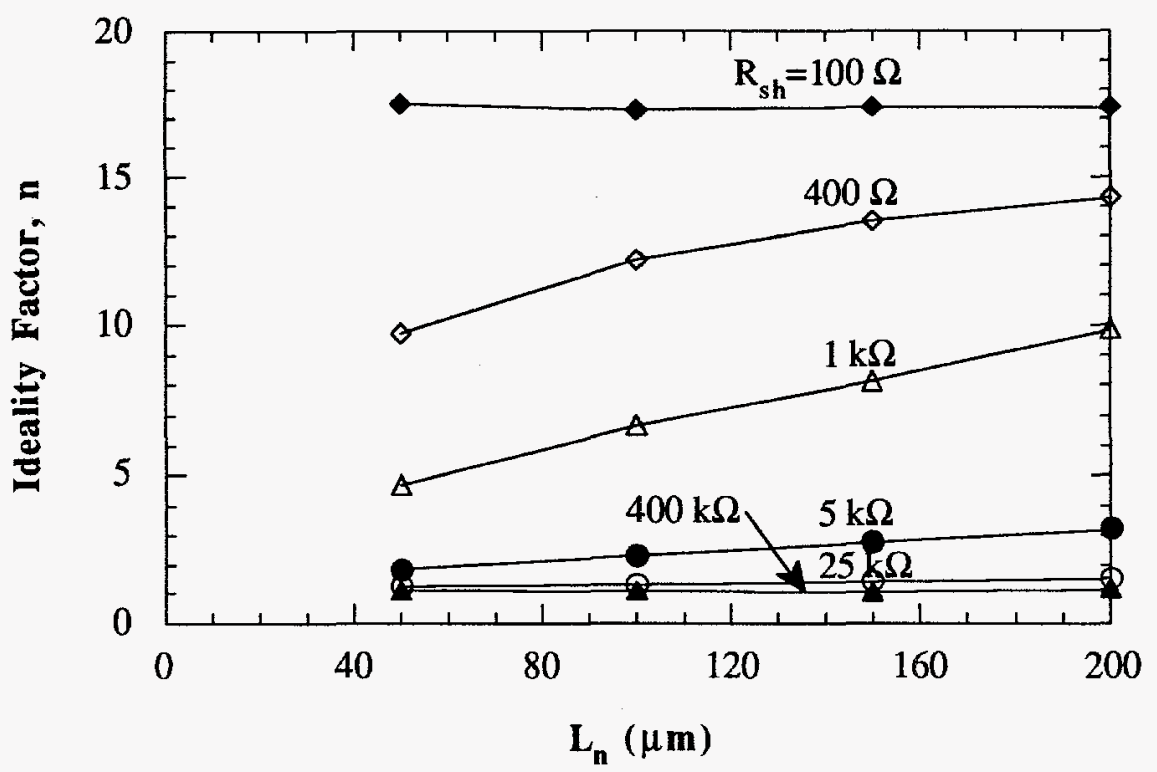

Fig. 31 Ideality factor, $\mathbf{n}$, is not dependent on the shunt resistance at very low or high value Between them, the ideality factor increases as the diffusion length increases.

Solar cell performance depends, among other device parameters, on the quality of the junction and on the substrate minority carrier lifetime. Junction quality is very dependent on recombination in the space-charge region and on shunting effects due to structural imperfections like dislocations and grain boundaries propagating through the space-charge region. The quality of the junction and the substrate can be separately determined by combining current-voltage (I-V), surface photovoltage (SPV), and open-circuit voltage decay (OCVD) measurements. I-V measurements give the diode saturation currents and the ideality factor n. SPV gives the minority carrier diffusion length, but it also yields the surface photovoltage which is related to the cell open circuit voltage if the SPV measurements are made on solar cells. In addition we measure the minority carrier lifetime by OCVD. We use mesa diodes etched from solar cells. The mesa diodes, with diameters ranging from $1 \mathrm{~mm}$ to $3 \mathrm{~mm}$, are convenient devices to observe the effect of specific defects or impurities on the electrical parameters such as $\mathrm{L}_{\mathrm{n}}, \mathrm{V}_{\mathrm{oc}}, \tau_{\mathrm{n}}$, and $\mathrm{n}$. In some cases we have used electron beam induced current (EBIC) to map the defect distributions across the samples and have tried to correlate these defects with I-V, SPV, and OCVD measurements. The cell efficiencies for these devices range from $11 \%$ to $13 \%$.

OCVD and SPV diffusion length characterization techniques both probe the bulk. OCVD measurements require pn junctions, of course. Diffusion lengths measured on EFG Cr- 
doped poly-Si cells, Solarex cast poly-Si cells, and on single crystal diodes by both techniques are compared in Fig.32. There is a variation in $L_{n}$ measured with these two methods. OCVD is a transient method whereas SPV is a steady-state technique. One might, therefore, expect a difference between the lifetimes or the diffusion lengths determined by these two methods. Furthermore, extraction of the minority carrier lifetime from opencircuit voltage decay is not unique. We find that frequently such a curve changes continuously with time with no unique slope. This makes the choice of voltage or time at which to take the slope difficult.

We find reasonable agreement between $\mathrm{L}_{\mathrm{n}}$ determined by OCVD and by SPV over a good part of the range covered in Fig.32. The diffusion length is calculated from the OCVDdetermined lifetime using an electron diffusion coefficient of $30.8 \mathrm{~cm}^{2} / \mathrm{s}$, consistent with the substrate doping concentration of our samples. The extraction of the lifetime from the open circuit voltage decay curve is difficult for devices with low lifetimes, because the curve does not exhibit the classical two slopes observed on high lifetime devices. Instead, it is typically a continuously varying decay curve with no unique slope, making lifetime determination uncertain. We chose the slope at $\mathrm{V}=0.4 \mathrm{~V}$.

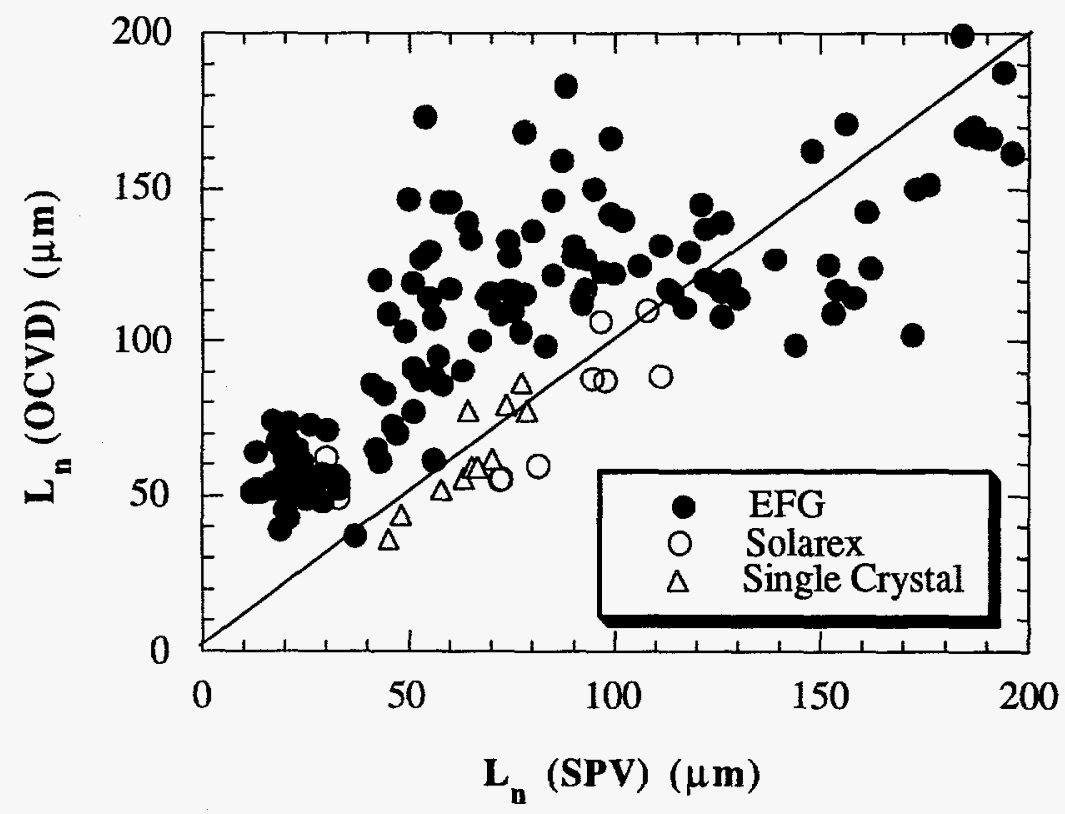

Fig. 32 Comparison of diffusion lengths by OCVD and SPV for EFG Cr-doped EFG-Si, Solarex cast poly-Si solar cells, and single crystal diodes. 


\section{Impurity Segregation}

In this section we discuss our measurements on impurity segregation in Cr-contaminated EFG silicon. Due to the highly degenerate crystal structure in the "rash" areas of the chromium-contaminated material it seems appropriate to discuss the "rash" regions separately from the "non-rash" areas.

\section{1 "Non-rash" EFG Silicon}

The "non-rash" areas of chromium-contaminated EFG Si provide an opportunity to study impurity segregation under "normal" equilibrium defect growth conditions. We used three techniques. SIMS and transmission electron microscopy (TEM) were used to find chromium concentration gradients and precipitation directly. EBIC was used to look for changes in electrical activity indirectly which could be inferred to be due to chromium segregation.

\subsubsection{EBIC Mapping}

Investigators from Mobil Solar Energy Corporation suspected a chromium concentration gradient across the ribbon width as shown in Fig.33(a), due to impurity segregation caused by the capillary position in the growth die. EBIC measurements were made across the entire ribbon width on a strip from blank 01c61-2-R to determine if a reduction in EBIC current could be used to locate regions where the chromium had segregated. An aluminum Schottky barrier was evaporated across the strip using the standard process. Then the strip was broken in half to fit the EBIC SEM stage. We made contact to the samples using a parallel connection as shown in Fig.34. The parallel connection allows the effect of any junction shunting to be shared by both samples as they would be in a cell. A series of EBIC linescans at $15 \mathrm{x}$ magnification, using a $35 \mathrm{keV}$ beam energy at $75 \mathrm{pA}$ beam current was made spanning the cell width. The data have been redrawn to indicate percent change from the highest EBIC current measured. As shown in Fig.33(b) the EBIC current as a function of distance does have a bimodal distribution with local aberrations due to defects superimposed on the distribution. The EBIC minima of the distribution were found at the ribbon center and edges thus lending support to the impurity segregation theory.

\section{EBIC Across Ribbon Thickness}

Similar EBIC measurements were made across the ribbon thickness to determine if there was a general trend of reduced EBIC current in the center of the ribbon thickness. Such a trend might provide some indirect support to the model that the impurity concentration should be higher in the middle of the ribbon thickness. Again, the measurement conditions were identical to those used in the ribbon width measurement. Fig. 35 shows the result of 
seven traces in which the variations in ribbon width were normalized then the data from all the traces were averaged to make the resultant trace.

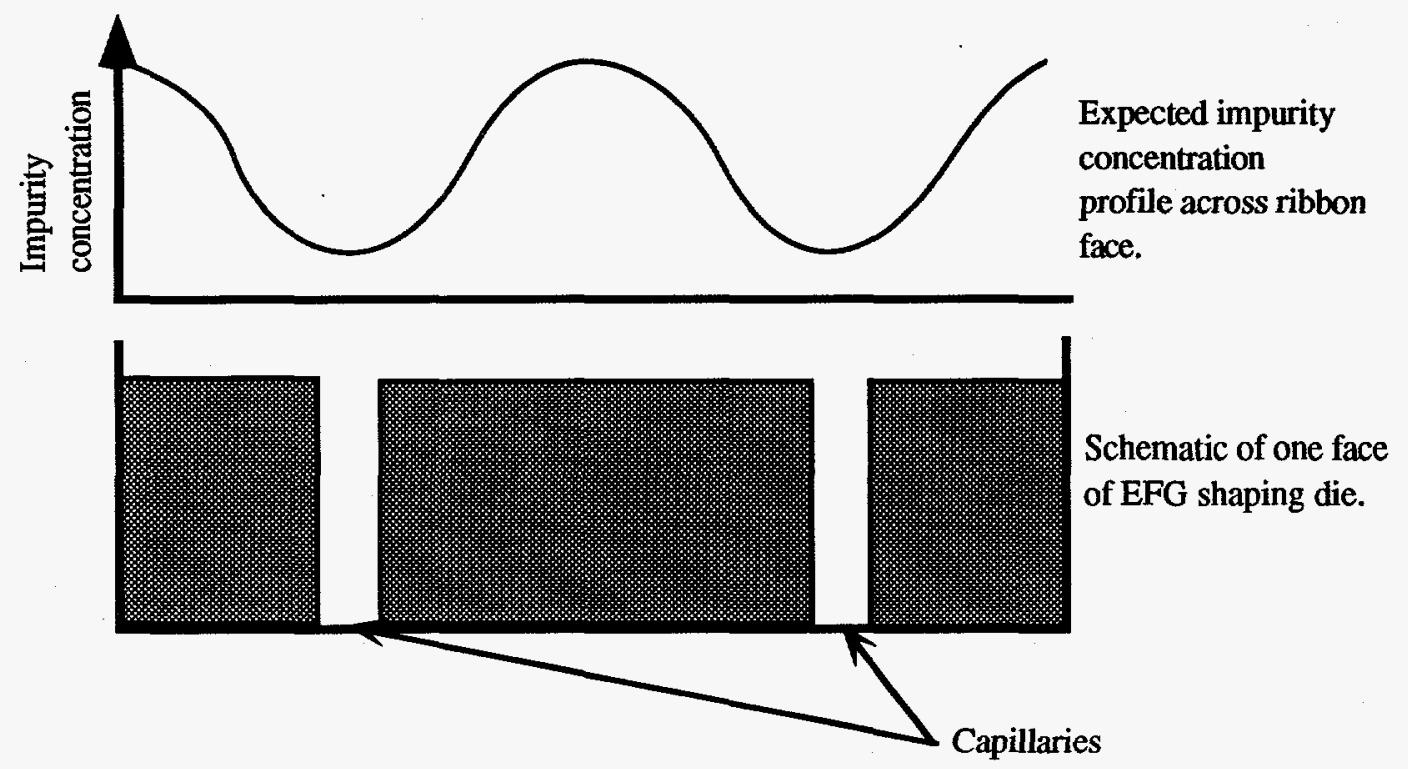

(a)

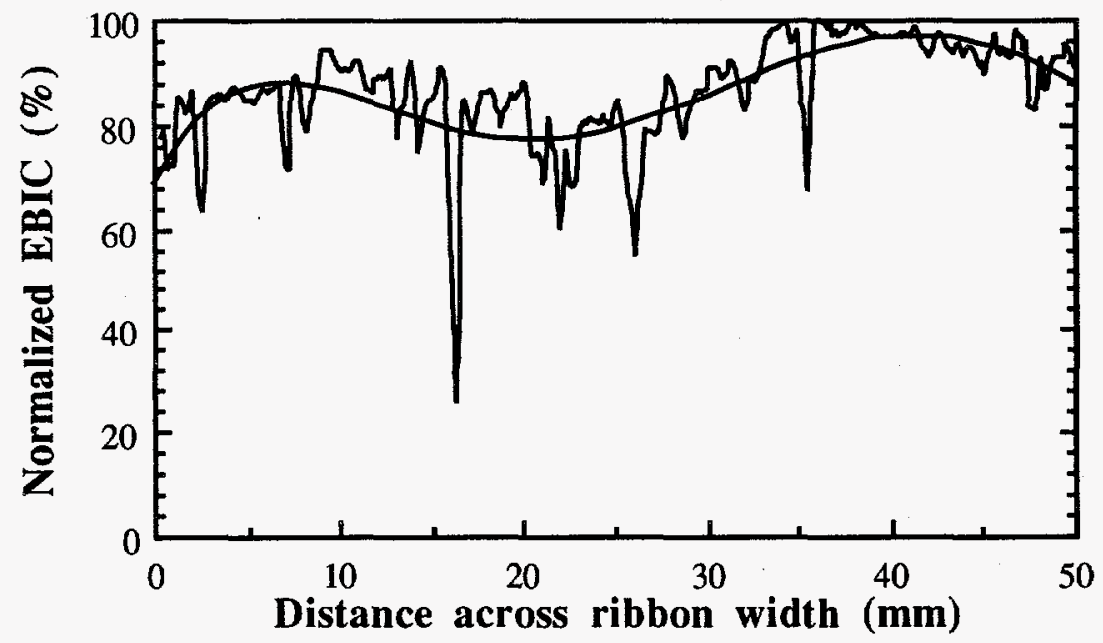

(b)

Fig. 33 Results of EBIC measurements across the face of chromium contaminated EFG ribbon. (a) Schematic of one face of EFG shaping die and a plot showing the expected impurity concentration across ribbon face, (b) normalized EBIC current across the ribbon face. 


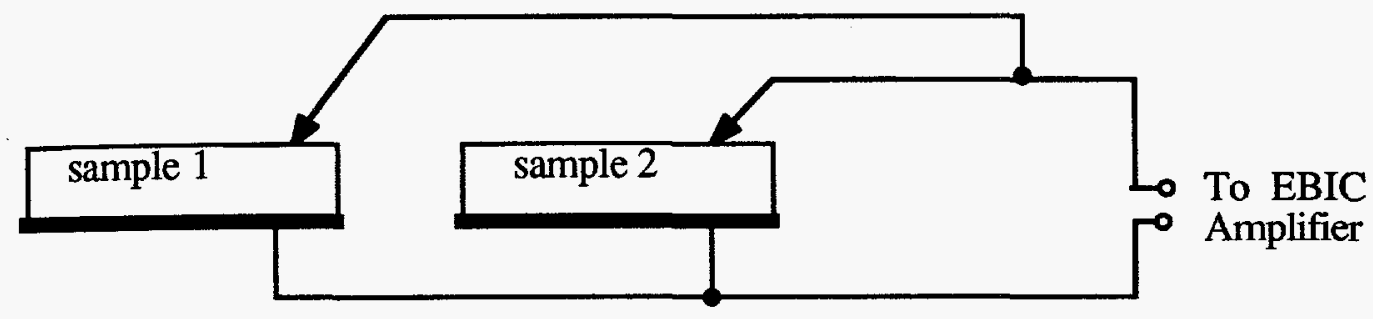

Fig. 34 Schematic of parallel connection of ribbon samples to make EBIC measurements across the ribbon face.

The EBIC linescans (Fig.33(b)) across the ribbon width bore a remarkable qualitative resemblance to the impurity profile modeled for EFG ribbon growth in the width direction. If one assumes the EBIC current to be inversely proportional to the electrically active impurities, the location of the EBIC linescan peaks would correspond to impurity minima and using the EFG segregation model, the impurity minima should correspond to the region immediately above the die feeder capillaries. This behavior was in fact observed as shown by comparison of Fig.33(a) and 33(b). The large spikes of reduced EBIC current are due to grain boundaries in most cases.

While making this EBIC measurement we noticed that junction shunting could cause misleading EBIC data. Although shunting may occur only at a very small point in the junction, EBIC current generated anywhere on the diode will be shunted causing less current to be measured than is really generated in a particular local region. This operation was verified when the EBIC current was excessively small over a large area junction but after this piece of silicon was broken into quarters, we found normal EBIC currents on three of the pieces and low current on one quarter which was shunted. The shunting occurs at some grain boundaries and especially in "rash" areas. For this reason, if EBIC currents are to be compared between two large area junctions (as was done in this measurement) the junctions must be connected in parallel so the effect of any shunting is equally shared by the junctions. A better alternative would be to use a line of very small isolated junctions in the form of dots where shunting in any one dot would not affect its neighbor. This method is impractical when very long linescans are desired since it would take excessively long to move the contact probe to each dot.

The EBIC as a function of ribbon thickness (Fig.35) also indicates the expected trend of less EBIC current from the ribbon center where the impurity concentration of chromium should be higher due to segregation as the ribbon faces solidify before the center, forcing impurities to the center. There are two artifacts on this composite linescan which should be discussed. The sharp peak of EBIC current near the front surface is probably due to 
enhanced carrier collection since the diode junction is wrapped around the corner of the sample as shown in Fig. 36 allowing carriers produced deep in the sample but close to the front surface to be collected. The abrupt drop-off of EBIC very close to the front and rear surface is probably due to high surface recombination.

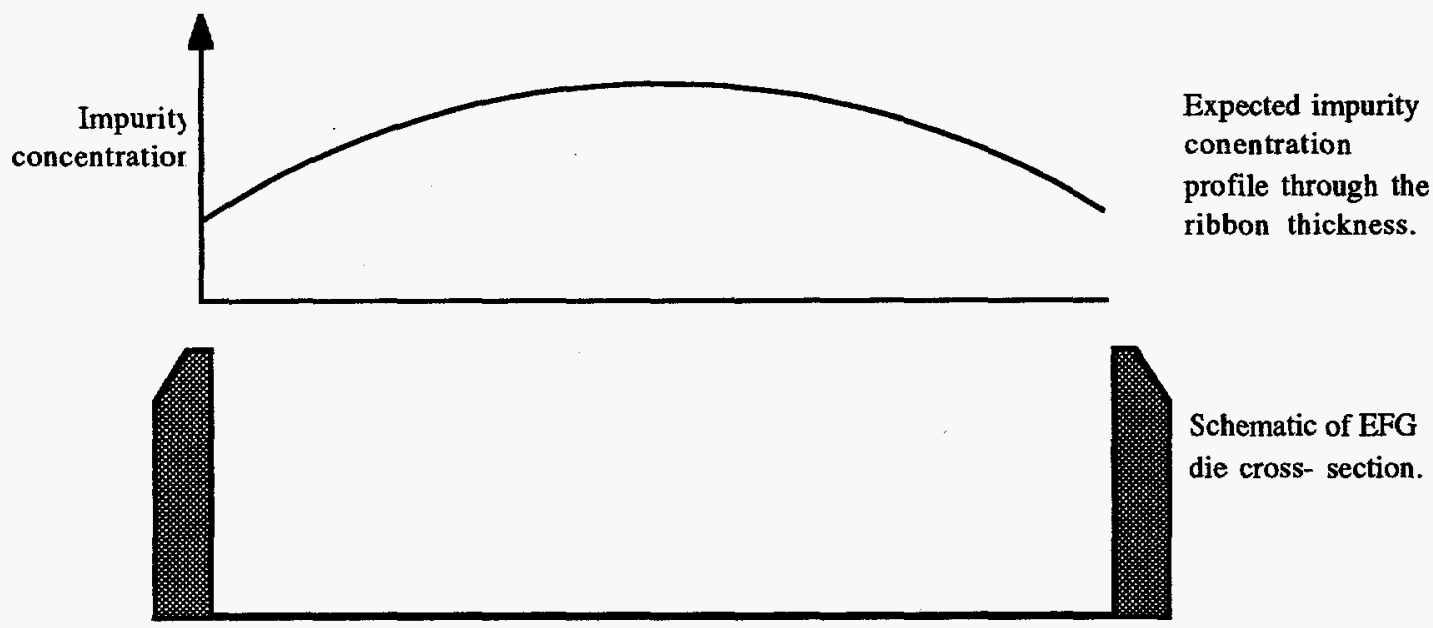

(a)

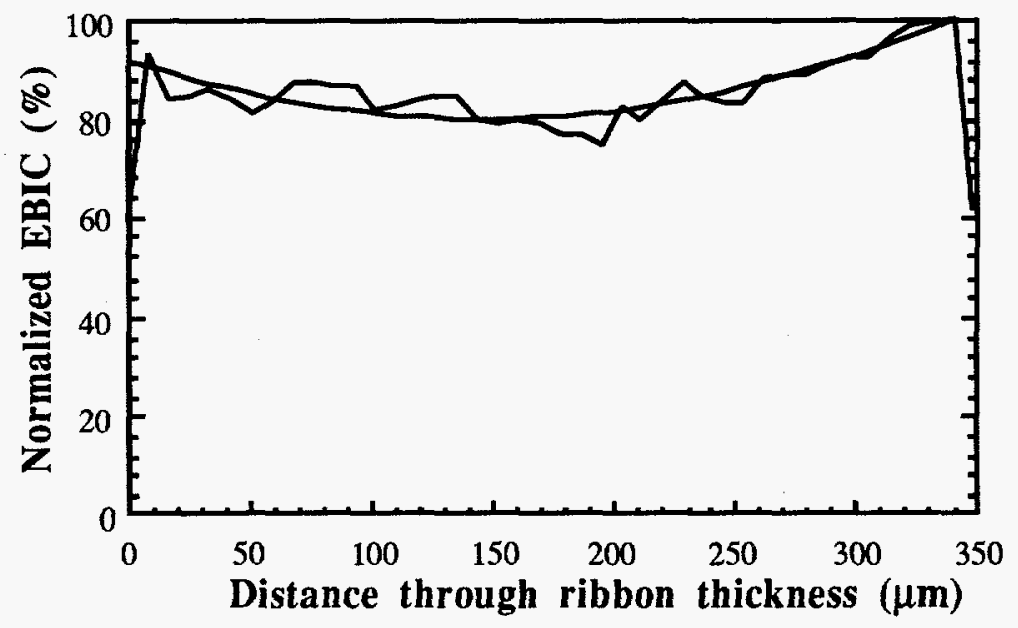

(b)

Fig. 35 Results of EBIC measurements through thickness of chromium contaminated EFG ribbon. (a) Schematic of EFG shaping die through the ribbon thickness and a plot showing the expected impurity concentration through the thickness, (b) normalized EBIC current through ribbon thickness. 


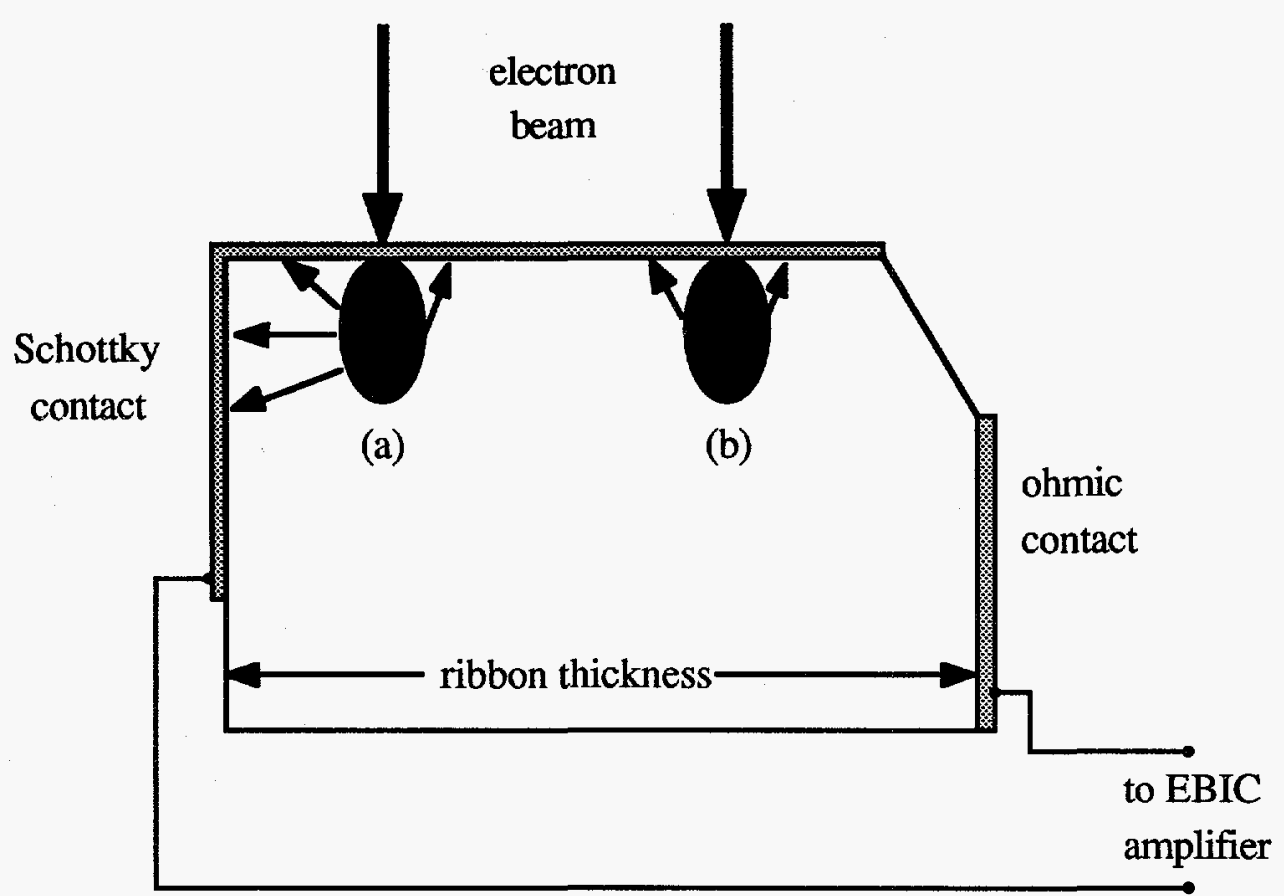

Fig. 36 Schematic of sample used to measure EBIC through the ribbon thickness. Note enhanced carrier collection by the Schottky contact wrapped around the corner when the electron beam is in position (a) as compared to position (b).

\subsubsection{SIMS Depth Profiles Through Electrically Active Grain Boundaries}

Our attempt to measure chromium concentration gradients in the ribbon cross section through electrically active grain boundaries is probably invalid due to the difficulty of preparing a sample such that the boundary is parallel to the sputtered crater floor. It is reiterated that we selected only isolated electrically active twin boundaries for SIMS profiling. Unfortunately the poor spatial resolution of EBIC does not permit determination of whether the electrically active boundary is truly isolated or whether it is part of a series of boundaries which may extend $1-3 \mu \mathrm{m}$ in width. Additionally, any electrically active boundary which was straight enough to apply this preparation technique was invariably part of a twin band which although not electrically active, often had sub-micron separation between boundaries. We have thought about the problem of trying to determine if the electrically active boundaries are active because chromium has segregated to them or whether chromium segregates to all boundaries or no boundaries regardless of their electrical activity. Table 2 list possible scenarios and the expected results from the SIMS profiling. From this exercise we conclude scenario 3, where the boundary contains chromium but is tilted with respect to the sputter crater bottom so we detect a small but constant amount of chromium, to be the most likely explanation for our results. 
Table 2 Possible Explanation for No Cr Detection by SIMS in Grain Boundaries

\begin{tabular}{|c|c|c|c|}
\hline Scenario & Condition & Detectability & $\begin{array}{l}\text { uled out by } \\
\text { is Analysis }\end{array}$ \\
\hline 1 & $\begin{array}{l}\text { Cr not segregated } \\
\text { to boundary }\end{array}$ & Would detect no Cr signal & NO \\
\hline 2 & $\begin{array}{l}\text { Cr segr. to bound. } \\
\text { parallel to surface and } \\
\text { less than } 1.5 \mu \mathrm{m} \text { below it }\end{array}$ & $\begin{array}{l}\text { Boundary should be easily } \\
\text { detected by SIMS profiling }\end{array}$ & Probably \\
\hline 3 & $\begin{array}{l}\text { Cr is segr. only to isolated } \\
\text { bound., but bound. was } \\
\text { tilted with respect to the } \\
\text { surface by } \geq 1^{\circ}\end{array}$ & $\begin{array}{l}\text { SIMS sputter crater intersects } \\
\text { only a small band of bound. at } \\
\text { one time. Probably below detect. } \\
\text { limit and no gradient detected }\end{array}$ & NO \\
\hline 4 & $\begin{array}{l}\text { Cr is segr. to a series of } \\
\text { bound., each separated by } \\
<1 \mu \mathrm{m} \text { but tilted w.r.t. the } \\
\text { surface } \geq 1^{\circ}\end{array}$ & $\begin{array}{l}\text { SIMS sputter crater intersects } \\
\text { only a small band of the bound. } \\
\text { at any one time. This would be } \\
\text { below det. limit and no gradient } \\
\text { would be detected }\end{array}$ & NO \\
\hline 5 & $\begin{array}{l}\text { Cr segregates to many } \\
\text { parallel microtwins with a } \\
\text { total contaminated bound. } \\
\text { width of } 1-2 \mu \mathrm{m}\end{array}$ & $\begin{array}{l}\text { Would see this in SIMS images } \\
\text { of the plan view surface. May not } \\
\text { detect a Cr gradient in a depth profilec } \\
\text { if the profile started and ended in a } \\
\text { contaminated region. }\end{array}$ & $\begin{array}{l}\text { YES } \\
\text { ed }\end{array}$ \\
\hline
\end{tabular}

\subsubsection{Lack of Precipitation at Grain Boundaries and Dislocations}

Despite a careful search, we found no evidence of chromium precipitates, second phases, or detectable chromium concentration gradients in any of the boundaries or dislocations using EDS in the JEOL 2000FX AEM. While lack of detection is certainly not a definitive proof for nonexistence, we will discuss the EDS detection limit for the analysis. We point out that a residue in some very faint water spots was easily detected and shown to contain $\mathrm{Ca}, \mathrm{K}$, and $\mathrm{Na}$. The detection limit for sodium is poor (being a light element) compared to that of chromium. Therefore we are confident that the equipment was operating properly.

\section{TEM/EDS Detection Limit Calculation}

The detection limit is basically the application of Poisson statistics to determine the size of the smallest peak, with a chosen degree of statistical certainty, which can be identified on the background continuous spectrum. The Poisson distribution applies to counting events in which the period between events is much longer than the event. ${ }^{31}$ The variance of the Poisson distribution is $\sigma^{2}=\bar{N}$, but since the Poisson distribution becomes identical to the Gaussian distribution for $N>30$ (always the case in X-ray analysis) we can use the parameters of the Gaussian distribution to define our statistical certainty. We could be $95 \%$ 
certain that an X-ray peak was real and not a random fluctuation of the background spectrum if the number of counts in the peak is more than two standard deviations greater than the mean of the background. We can be $95 \%$ confident that a peak is real (detected) if

$$
I_{A}-I_{b}^{A} \geq 2 \sqrt{I_{b}^{A}}
$$

where $I_{A}$ is the total integrated count under peak $A$ and $I_{b}^{A}$ is the total integrated background count under peak A (see Fig.37).

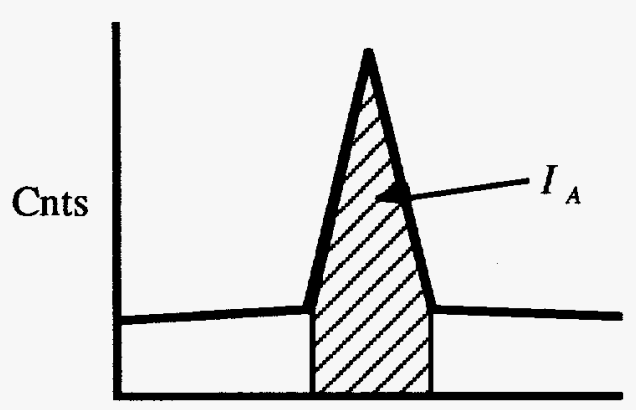

Energy (keV)

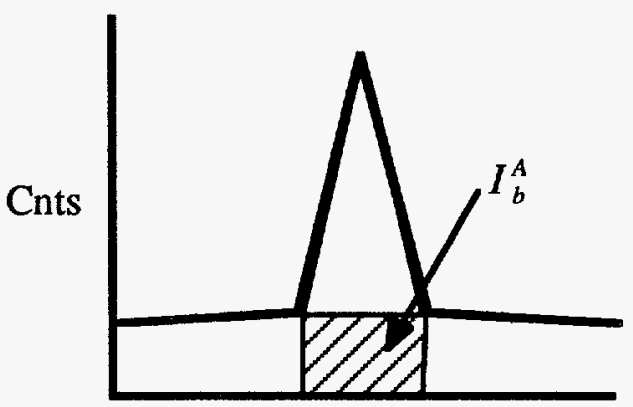

Energy (keV)

Fig. 37 Schematic representation of the definition of total integrated peak count $I_{A}$ and total integrated background count under peak $\mathrm{I}_{\mathrm{b}}^{\mathrm{A}}$.

This states that the net peak counts, $\mathrm{I}_{\mathrm{A}}-\mathrm{I}_{\mathrm{b}}^{\mathrm{A}}$ should be at least two times larger than the standard deviation, $\left(I_{b}^{A}\right)^{1 / 2}$, of the background counts over the same energy interval. It is clear that a large peak to background ratio improves the detection sensitivity limit. There are two types of detection sensitivity formulae. The minimum detectable mass, MDM, is used to calculate the minimum mass of a particle that can be detected located on an extremely thin support. MDM calculations assume there is no X-ray contribution from the thin support which would "dilute" the X-rays detected from the particle. Our samples are modeled to contain a thin plane of impurities in a silicon matrix and therefore do not meet the MDM criteria. We must use the minimum mass fraction, MMF, to calculate the minimum impurity mass detectable in a matrix which contributes a large X-ray signal and Bremsstrahlung of its own. Finally, the equations assume the sample is sufficiently thin that $\mathrm{X}$-rays generated in the film undergo negligible absorption as they leave the film and that these $X$-rays cause negligible fluorescence. This is called the thin film approximation and the criteria for its validity developed by Tixier and Philibert, state that absorption is negligible, if for each element ${ }^{32}$ 


$$
\chi_{A} \rho \mathrm{t}<0.1
$$

where:

$$
\chi_{A}=(\mu / \rho)_{\text {spec }}^{A} \csc (\alpha)
$$

and, $\left.{ }^{\frac{\mu}{\rho}}\right)_{\text {spec }}^{A}$, is the mass absorption coefficient for X-ray, $A$, in a matrix, spec., $\rho$ is the matrix density, and $t$ is the film thickness. $t \cdot \csc (\alpha)$ is the distance the $X$-ray travels through the film to the detector in our geometry.

The value of $\chi_{\mathrm{A}} \rho t$ has been calculated for $\mathrm{K}$-shell $\mathrm{X}$-rays of elements with atomic number between 5 and 30 as shown in Fig.38. The $1000 \AA$ or thinner films we use, easily meet this criterion for elements with atomic number greater than $10(\mathrm{Ne})$.

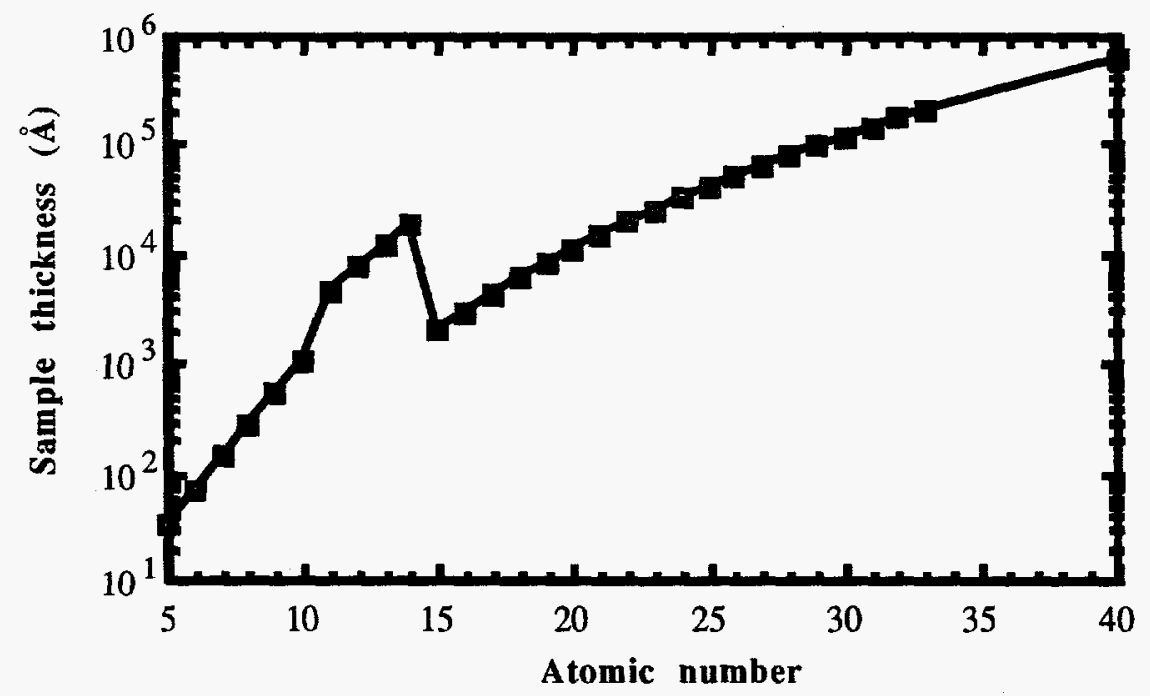

Fig.38 Graph of maximum sample thickness which satisfies the "thin film limit" under our conditions, requiring negligible $\mathrm{X}$-ray absorption as defined by Tixier and Philibert. ${ }^{32}$

The simplest MMF formula is due to Ziebold ${ }^{33}$

$$
\mathrm{MMF}=\left(\frac{\mathrm{P}}{\mathrm{B}} \mathrm{P} \tau\right)^{-1 / 2}
$$


where $\frac{P}{B}$ is the peak to background ratio for the characteristic peak, $P$, due to a foil composed of only the element of interest. $P$ is the count rate (counts/s) into the pure element peak, and $\tau$ is the $\mathrm{X}$-ray counting time (i.e. livetime).

Since our samples are essentially pure silicon, $P_{\text {silicon }}$ and $\frac{P}{B}$ silicon are easily found. $\frac{P}{B}$ is a function of the atomic number and beam energy. To estimate MMF for chromium we normalized the $200 \mathrm{keV}$ peak to the background data to $\frac{P}{B}$ silicon $=65$ found in our system. ${ }^{34}$ Fig. 39 shows we can expect MMF in the range of $2 \%$ to $0.02 \%$ under typical operating conditions.

From a more fundamental viewpoint the MMF is dependent on the ionization cross section for production of both the characteristic and Bremsstrahlung X-rays at the energy of interest. Additionally, the systems background and detector efficiency must be considered for the X-rays of interest. Joy and Maher have proposed a formula which accounts for these fundamental parameters. 35

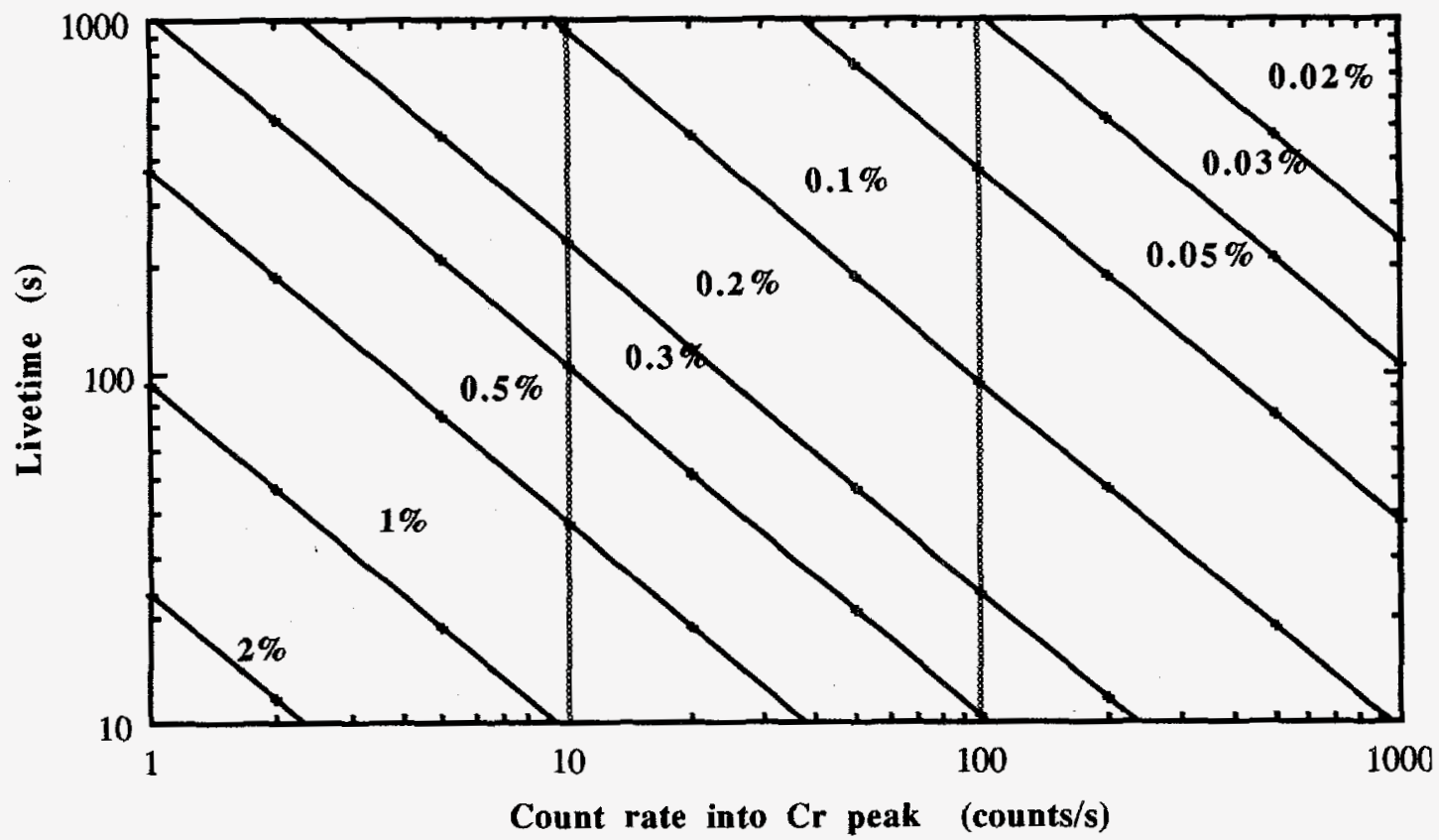

Fig. 39 Count rate and livetime required to achieve the specified MMF for $\mathrm{Cr}$ in our system.

Their expression for the integrated characteristic peak counts is: 


$$
P=J Q_{k}^{1} \omega_{k} M_{k} F T \tau
$$

where $P$ is the integrated characteristic peak counts, $Q_{k}^{1}$ is the ionization cross-section for characteristic peak in mass units, and $\omega_{k}$ is the fluorescent yield of characteristic peak. $M_{k}$ is the total irradiated mass of element causing characteristic peak, and $F$ is the yield fraction of characteristic peak - we use $K_{\alpha}$ peaks so:

$$
F=\frac{K \alpha}{(K \alpha+K \beta)}
$$

where $\mathrm{T}$ is the detector efficiency, and $\tau$ is the $\mathrm{X}$-ray counting time (i.e. livetime).

The expression for the integrated background under the characteristic peak is ${ }^{35}$

$$
B=J \frac{Q_{B}^{1}}{E_{K}} \Delta E M_{B} T \tau
$$

where $B$ is the integrated background count under the characteristic peak, $Q_{B}^{1}$ is the ionization cross-section for background at energy, $E_{K}$, where $E_{K}$ is the energy of the characteristic peak. $\Delta \mathrm{E}$ is the width of the characteristic peak in energy, and $\mathrm{M}_{\mathrm{B}}$ is the mass of the irradiated matrix.

To be $95 \%$ confident that a peak is not a statistical fluctuation in the background intensity, the peak intensity must be two standard deviations greater than the mean background count. This will be the criterion for the minimum detection limit. Accounting for the statistics and rearranging the terms, the minimum mass fraction is

$$
M M F=\frac{M_{k}}{M_{B}}=\frac{2\left(Q_{B}^{1} \Delta E / E_{K}\right)^{1 / 2}}{Q_{k}^{1} \omega_{k} F T\left(J \tau M_{B}\right)^{1 / 2}}
$$

All the terms in this expression can be easily measured, calculated, or found in tables except, $Q_{B}^{1}$, the ionization cross-section for the continuous background. $Q_{B}^{1}$ was determined using the measured $\frac{P}{B}$ silicon ratio for the JEOL $2000 \mathrm{FX}$ then adjusting it as was done previously using Zaluzec's $\frac{P}{B}$ data to get $a \frac{P}{B}$ chromium $=107$ for our system. $Q_{B}^{1}$ was then calculated using the formula 


$$
\frac{P}{B}=\frac{Q_{k}^{1} \omega_{k} E_{K} F}{Q_{B}^{1} \Delta E}
$$

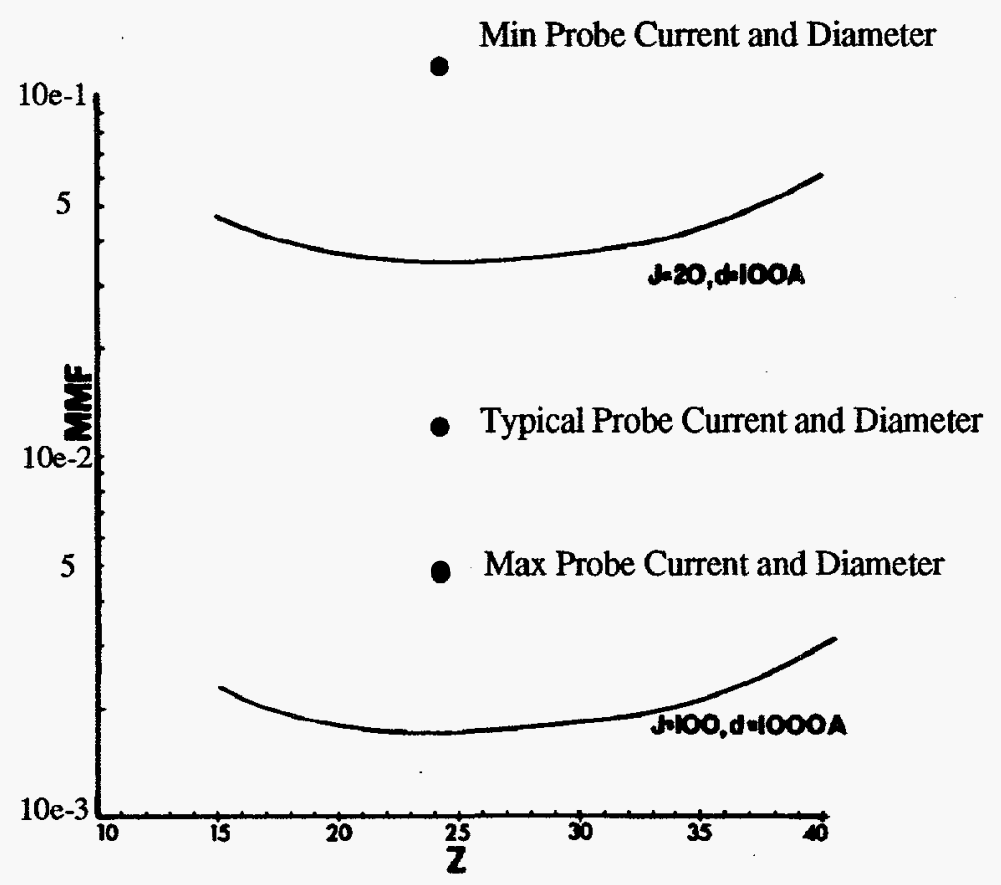

Fig. 40 Calculated MMF for element with atomic number, $Z$, in a Si matrix. We have superimposed the calculated MMF for our system assuming typical, minimum, and maximum probe sizes. Adapted from: [35] p.331.

Fig.40, due to Joy and Maher, shows the MMF for the elements with atomic number 15 to 40 in a silicon matrix. Our MMF calculations for chromium in the JEOL 2000FX are superimposed on the figure assuming a $500 \AA$ thick sample. We always used $500 \mathrm{~s}$ livetime for X-ray acquisition. Our typical operating conditions were $300 \AA$ diameter probe and $200 \mathrm{~A} / \mathrm{cm}^{2}$ beam current density giving an MMF for chromium of:

$$
\mathrm{MMF}=\frac{\mathrm{M}_{\mathrm{Cr}}}{\mathrm{M}_{\mathrm{Si}}} \approx 0.01
$$

The same conditions at a higher beam current of $350 \mathrm{~A} / \mathrm{cm}^{2}$ (but a larger beam diameter of $600 \AA)$ are: 


$$
\mathrm{MMF}=\frac{\mathrm{M}_{\mathrm{Cr}}}{\mathrm{MSi}_{\mathrm{i}}} \approx 0.005
$$

Using the minimum useful beam diameter of $\approx 80 \AA$, but only $30 \mathrm{~A} / \mathrm{cm}^{2}$ the MMF is:

$$
\mathrm{MMF}=\frac{\mathrm{MCr}_{\mathrm{C}}}{\mathrm{M}_{\mathrm{Si}}} \approx 0.1
$$

As an example of our detection sensitivity, we can calculate the width of a plane of $\mathrm{CrSi}_{2}$ that would contain the MMF of $\mathrm{Cr}$ under the given sample volume. Assuming the $\mathrm{CrSi}_{2}$ plane extends through the thickness and entirely across the sampled diameter as shown in Fig.41, we can detect a $9 \AA$ wide $\mathrm{CrSi}_{2}$ plane under our typical analysis conditions. In the worse case (low beam current density) the boundary would need to be $25 \AA$ wide for detection.

We found a condenser lens 1 setting of 1 and a $200 \mu \mathrm{m}$ condenser lens aperture to be the typical operating conditions and have acquired many EDS spectra of twin boundaries, low angle grain boundaries, and dislocations, both in boundaries and isolated and have found no detectable impurities.

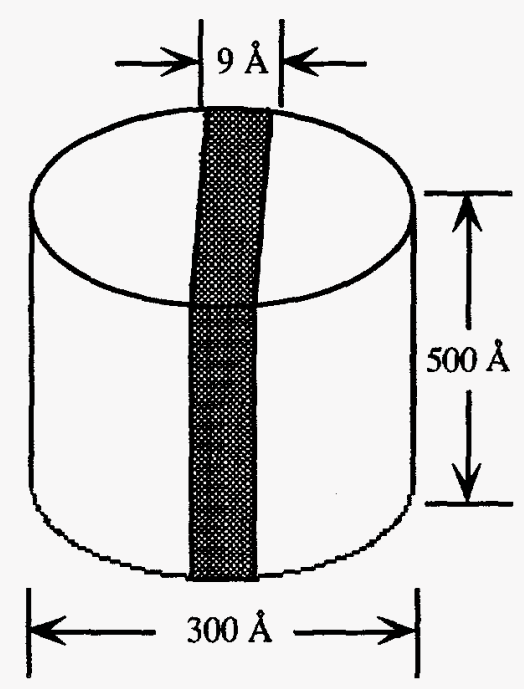

Fig. 41 Model of a $9 \AA$ wide plane of $\mathrm{CrSi}_{2}$ which should be detectable assuming MMF $\approx 0.01$ under our typical operating conditions in a thin film sample.

There are two equipment parameters ultimately limiting our detection sensitivity which could be improved by use of different equipment. Use of a field emission STEM 
instrument could increase the beam current density about 800 times while maintaining an 80 $\AA$ diameter beam, improving detection sensitivity by 70 times assuming an $80 \AA$ diameter beam on the 2000FX. ${ }^{36-37}$ The collection solid angle of the "Quantum" X-ray detector is restrictive compared to conventional detectors. SiLi X-ray detectors require the SiLi crystal to be chilled to $\mathrm{LN}_{2}$ temperatures to reduce electrical noise and prevent redistribution of the Li dopant. The chilled crystal must be protected from moisture condensation when the instrument is vented to air thus the crystal is located in a vacuum isolated chamber with an $\mathrm{X}$-ray "transparent" window at one end.

In the past, windows were made of $8 \mu \mathrm{m}$ thick beryllium foil which was physically strong enough to withstand the pressure cycling during everyday use. However the window absorbs low energy $\mathrm{X}$-rays from elements with atomic number less than 11 . The "Quantum" detector uses a proprietary window material which passes X-rays down to carbon (atomic number 6) but the window material is very fragile and cannot span as large an entrance aperture as the stouter beryllium windows. The microscope objective lens prevents moving the detector closer to the sample. Under our conditions, the solid angle of the "Quantum" detector is $0.011 \mathrm{sr}$ compared to $0.033 \mathrm{sr}$ of a standard detector. This degrades our sensitivity limit by 3 times. Since we were not interested in X-rays from light elements the "Quantum" detector had no particular advantage and the loss of solid angle is a disadvantage.

\section{2 “Rash" Silicon}

It has been proposed that the "rash" areas are due to interface breakdown modelled as follows. ${ }^{11}$ The large segregation coefficient of chromium allows most of it to be rejected from the solidifying ribbon across the solid/liquid interface into the melt above the EFG shaping die. The die prevents mixing of the increasingly chromium rich liquid at the growth interface with the melt bulk below the die. Nucleation of chromium disilicide precipitates begins when a critical chromium concentration is reached. The precipitates continue to grow until at a certain size, the precipitates become trapped in the interface and subsequently are incorporated into the solidifying ribbon. It is not known what determines the critical precipitate size but it may occur when the viscous drag of the liquid flowing over the precipitate into the growth interface overcomes the opposing segregation force on the precipitate.

A quantitative model of impurity segregation, due to Kalejs, can explain the observed patches of "rash" in the center and edges of the ribbon width and the presence of few precipitates outside the "rash" area. ${ }^{17}$ Fresh silicon is fed to the growth interface through capillaries in the shaping die. Melt exiting the capillaries must flow laterally to supply the 
entire interface with silicon. Chromium rejected from the ribbon is concentrated into pockets along the ribbon width midway between feed capillaries by the lateral flow of silicon above the die. Precipitates are thus formed in these areas of high impurity concentration.

\subsubsection{SIMS Grain Boundary Imaging}

One might expect segregation of chromium to the subsurface grain boundaries associated with the rash since grain boundaries ordinarily favor accumulation of impurities. The SIMS detection limit is on the same order as the $4 \times 10^{15}$ atoms $/ \mathrm{cm}^{3}$ solubility limit for chromium in silicon. Although the SIMS spatial resolution limit is about $1 \mu \mathrm{m}$, therefore much wider than the expected $\approx 100 \AA$ width of an impurity zone segregated to a grain boundary, the high sensitivity of SIMS often allows detection of grain boundary segregation, albeit with an image broadened to the $1 \mu \mathrm{m}$ resolution limit. 40 The lack of chromium segregation was unexpected. Precipitate growth may consume much of the chromium in the liquid phase and in effect offer some melt purification before it becomes ribbon.

\subsubsection{EBIC Evidence of Gettering}

We have clearly identified very large $\mathrm{CrSi}_{2}$ precipitates in EFG ribbons. The EBIC signatures of these precipitates and surrounding region are very similar for as-grown material and for material annealed at $950^{\circ} \mathrm{C}$ for 4 hours. But for completed cells, we find a significantly different EBIC signal showing clearly defined denuded zones with enhanced EBIC collection surrounding the precipitates for distances of around $25 \mu \mathrm{m}$ as shown in Fig.42.

The chief difference between these samples is the cell fabrication sequence in one case and annealing history in the other. The phosphorous diffusion necessary for the cell $\mathrm{n}^{+}$layer formation may hold the key to this behavior. It is well known that phosphorus diffusion is a very effective getter agent. ${ }^{38}$ Its getter efficiency has been attributed to enhanced solubility of the gettered metals in the heavily doped $\mathrm{n}^{+}$layer and to the role of Si self interstitials. Hydrogenation is likely also to play a role in these measurements, since hydrogen is known to passivate the dangling bonds at the grain boundaries.

Additionally, the $\mathrm{CrSi}_{2}$ precipitate itself may act as a getter agent, much as $\mathrm{SiO}_{2}$ precipitates in Czochralski Si have been shown to produce effective internal gettering. It is not necessary that dislocations be associated with precipitates. The strain surrounding the precipitate appears to be sufficient for effective gettering. 39 When the EFG Si surface is etched, generally we find some etch pits associated with grain boundaries, dislocations and 
other structural defects. When $\mathrm{CrSi}_{2}$ precipitates are within the etched region, we find a much larger etch rate in the Si immediately surrounding the precipitates than in the bulk. This is illustrated in Fig. 6 where etched "moats" surround each precipitate, indicative of highly strained regions at the precipitate/Si interface. Such strained interfaces are likely sinks for impurities during gettering.

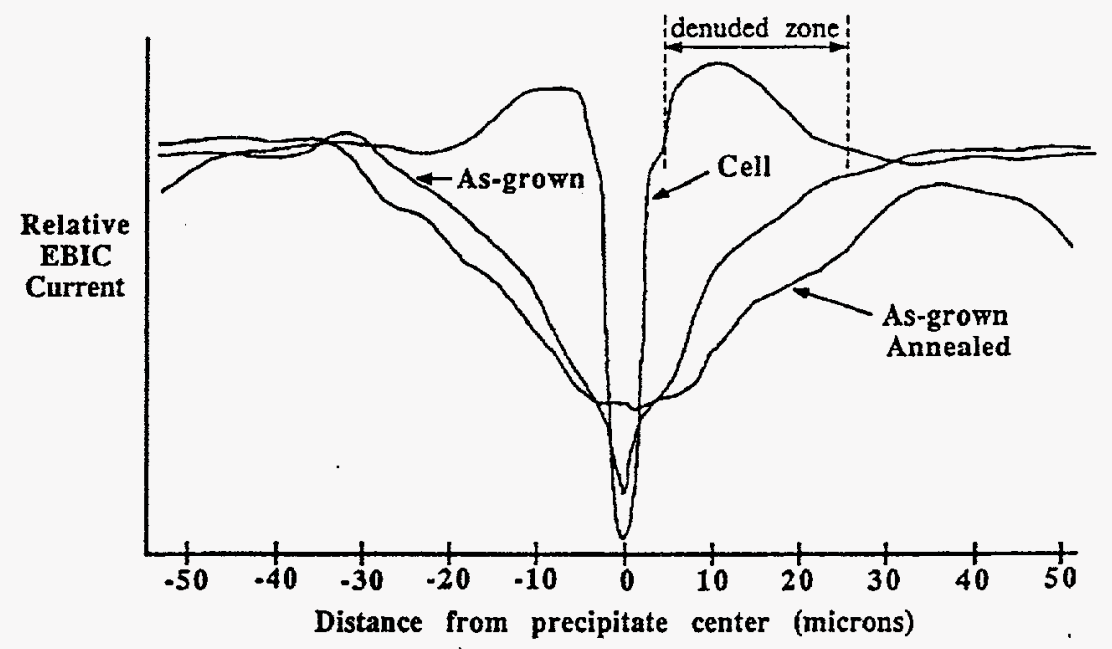

Fig. 42 EBIC linescans across precipitates.

The denuded zone width of typically $25 \mu \mathrm{m}$ does not correspond to the diffusion distance of dissolved chromium atoms in the $\mathrm{Si}$ lattice. The diffusion coefficient for chromium in $\mathrm{Si}$ is given by 14

$$
\mathrm{D}=0.01 \exp (-1 / \mathrm{kT})
$$

For $\mathrm{T}=900^{\circ} \mathrm{C}$ this gives a diffusion coefficient of $\mathrm{D}=5 \times 10^{-7} \mathrm{~cm}^{2} / \mathrm{sec}$, resulting in a diffusion distance $(\mathrm{Dt})^{1 / 2}$ of $300 \mu \mathrm{m}$ for $\mathrm{t}=30 \mathrm{~min}$. This is much larger than the $25 \mu \mathrm{m}$ denuded zone width observed in EBIC plots. This points to a more complex picture than this first order analysis. The fact that gettering must be occurring is seen from the relatively high conversion efficiencies of 11 to $15 \%$ for these cells that are heavily contaminated with chromium. ${ }^{4}$ We believe the $\mathrm{CrSi}_{2}$ precipitates to be gettering sites that reduce the dispersed chromium concentration. 


\section{Discussion}

$\mathrm{Cr}$ doped EFG as-grown material has an energy level caused by $\mathrm{CrB}$ pairs located at $\mathrm{E}_{\mathrm{V}}+0.27 \mathrm{eV}$. On grain boundaries, energy levels were detected with their FWHM equal to $0.2 \mathrm{~T}_{\max }$. Low-efficiency, as-grown materials grown through a contaminated graphite die have distributed energy levels represented by broad peaks. The broad peaks are a unique feature of low-efficiency, as-grown materials. They are caused by a high density of impurities from the contaminated graphite die. The high-efficiency, as-grown material has peaks with their FWHM equal to $0.2 \mathrm{~T}_{\max }$ only on the grain boundaries. No discrete energy levels were detected.

The common feature between Cr-doped and high-efficiency, as-grown material is that the two samples show DLTS peaks with their FWHM equal to $0.2 \mathrm{~T}_{\max }$. The peaks are probably caused by the irregular crystal structure in the grain boundaries. Solar cells have distributed energy states represented by broad peaks in the DLTS spectra. This is likely due to precipitates or other types of structural defects that introduce energy levels over a wide portion of the band gap in contrast to isolated metallic impurities that introduce discrete energy levels in the band gap. We have, in an earlier study on the effects of oxide precipitates in $\mathrm{Cz} \mathrm{Si}$, found that oxide precipitates give broad DLTS spectra. When these spectra are deconvolved, they result in a distributed energy band in the band gap. We believe that such a broad energy spectrum is caused by interface states at the silicon/oxide precipitate interface in that case. When precipitates are formed in poly-Si, as in $\mathrm{Cr}$ contaminated EFG Si, for example, similar interface states may form at the precipitate/Si interface. It has, of course, also been postulated that due to dangling bonds at grain boundaries, an energy spectrum of distributed states should exist at such structural defects.

Using the metallurgical concentration of $\mathrm{N}_{\mathrm{Cr}} \approx 5 \times 10^{18} \mathrm{~cm}^{-3}$ measured in the "rash" area by glow discharge mass spectroscopy $y^{4}$ the ratio of electrically active $\mathrm{Cr}$ to the total chromium in the ribbon is about $0.2 \%$. Rohatgi found the electrically active chromium to range between $0.1-4 \%$ and noted a much higher electrically active concentration in grain boundary free areas than in polycrystalline areas and proposed that the boundaries enhance metal precipitation to a benign state. ${ }^{41} \mathrm{EFG}$ material cannot be grown in single crystal form but the relatively low level of electrically active chromium is in keeping with Rohatgi's observation that polycrystalline areas contain less electrically active chromium. However, the observation of no preferential segregation of precipitates to the EFG grain boundaries and the lack of SIMS evidence of grain boundary segregation, raise the question of whether the grain boundaries cleanse the silicon of chromium or if the grain boundaries are a result of the precipitates and are just coincidental with gettering actually due to the precipitates. 


\section{References}

1. J.R. Davis, Jr., A. Rohatgi, R.H. Hopkins, P.D. Blais, P. Rai-Choudhury, J.R. McCormick, and H.C. Mollenkopf, IEEE Trans. Electron Devices, ED-27, 677 (1980).

2. M.C. Cretella, B.R. Bathey, and N.W. Marr, Sixth European Communities Photovoltaic Solar Energy Conference, W. Palz and F.C. Treble (Ed.), D. Reidel Publishing, 929 (1985).

3. B.R. Bathey, R.O. Bell, C.E. Dubé, J.P. Kalejs, and F.V. Wald, 4th International Photovoltaic Science and Engineering Conf., Sydney (IREE Austratlia, Edgecliff), 117 (1989).

4. R.R. Bathey, C.E. Dubé, J.P. Kalejs, and F.V. Wald, 21st IEEE Photovolt. Spec. Conf., Kissimee, FL, 687 (1990).

5. A. Rohatgi, W.A. Doolittle, A.W. Smith, F.V. Wald, R.O. Bell, and C.E. Dubé, 21st IEEE Photovolt. Spec. Conf., Kissimee, FL, 581 (1990).

6. H. Führer and P. Wagner, Proc. Polycryst. Semicond., Malente, Germany, 191 (1988).

7. N.T. Bendik, V.S. Garnky and J.S. Milevskii, Sov. Phys.-Solid State 12, 150 (1970).

8. H. Conzelmann and J. Weber, Physica 116B, 291 (1983).

9. H. Conzelmann, K. Graff, and E.R. Weber, Appl. Phys. A30, 169 (1983).

10. E.R. Weber, Appl. Phys. A30, 7 (1983).

11. J.P. Kalejs, B. Bathey and C. Dubé, J. Crystal Growth 109, 174 (1991).

12. J.B. Mohr, S.H. Park, S.N. Schauer, D.K. Schroder and J. Kalejs, 21st IEEE Photovolt. Spec. Conf., Kissimee, FL, 711 (1990).

13. H. Reiss, C.S. Fuller, and F.J. Morin, Bell Syst. Tech. J. 35, 535 (1956).

14. E.R. Weber and D. Gilles, in Semiconductor Silicon 1990 (H.R. Huff, K.G. Barraclough, and J.I. Chikawa, eds.), Electrochem. Soc., Pennington NJ, 585 (1990).

15. E.R. Weber, in: Properties of Silicon (IEE, London ), 437 (1988).

16. G. Zoth and W. Bergholz, J. Appl. Phys. 67, 6764 (1990).

17. J.P. Kalejs, Silicon Processing for Photovoltaics II, C.P. Khattack and K.V. Ravi (Ed.), Elsevier Science Publishers, 185 (1985).

18. K.V. Ravi, J. Cryst. Growth, 39, 1-16 (1977).

19. F.V. Wald, In: Crystals: Growth, Properties, and Applications, Vol. 5: Silicon, H.C. Freyhardt (Ed.), Springer-Verlag, 147 (1981).

20. W. Kern and D.A. Puotinen, RCA Review, June, 187 (1970).

21. R.G. Wilson, F.A. Stevie, and C.W. Magee, Secondary Ion Mass Spectrometry, (New York: John Wiley and Sons, 1989) p. App.F.4.

22. S. Yee, Appl. Phys. Lett. 59, 17 (1991).

23. J.M. Hwang, "Recombination Properties of Oxygen-Precipitated Silicon", Ph.D. Dissertation, Arizona State University, 1986.

24. A.M. Goodman, J. Appl. Phys. 32, 2550 (1961).

25. ASTM Standard F391-87, 1987 Annual Book of ASTM Standards, Am. Soc. Test. Mat., Philadelphia, 1987.

26. C.T. Sah, R.N. Noyce, and W. Shockley, Proc. IRE 45, 1228 (1957).

27. A. Goetzberger and C. Stephen, J. Appl. Phys. 32, 2646 (1961). 
28. H.J. Queisser, Solid-State Electron. 5, 1 (1962).

29. C.T. Sah, IRE Trans. Electron. Dev. ED-9, 94 (1962).

30. M. Wolf, Proc. IRE 48, 1246 (1960).

31. K.F.J. Heinrich, Electron Beam X-Ray Microanalysis, Van Nostrand Reinhold, New York, 156 (1981).

32. J.I. Goldstein, "Principles of Thin Film X-Ray Microanalysis", in Introduction to Analytical Electron Microscopy (J.I. Goldstein and D.C. Joy, eds.), 95 (1979).

33. T.O. Ziebold, Anal. Chem. 39, 858 (1967).

34. N.J. Zaluzec, "Quantitative X-Ray Microanalysis: Instrumental Considerations and Applications to Material Science", in Introduction to Analytical Electron Microscopy (J.I. Goldstein and D.C. Joy, eds.), 95 (1979).

35. D.C. Joy and D.M. Maher, "Sensitivity Limits for Thin Specimen X-Ray Analysis", in Scanning Electron Microscopy (I.O. Johari, ed.), A.M.F., O'Hare, IL:SEM Inc., 581 (1979).

36. J.K. Weiss, R.W. Carpenter, W. Braue, and A.A. Higgs, Proc. 47th Ann. EMSA Meet., 226 (1989).

37. H. Murakoshi, M. Ichihashi, T. Komoda, S. Isakozawa, and T. Kubo, Proc. 47th Ann. EMSA Meet., 10 (1989).

38. J.S. Kang and D.K. Schroder, J. Appl. Phys., 65, 2974 (1989).

39. D. Gilles, E.R. Weber, S.K. Hahn, O.R. Monteiro, and K.H. Cho, In: Semiconductor Silicon 1990, H.R. Huff, K.G. Barraclough, and J.I. Chikawa (Ed.), Electrochemical Society, 697 (1990).

40. G.A. Pollock, V.R. Deline, and B.K. Furman, In: Grain Boundaries in Semiconductors, Pike, Seager, and Leamy (Ed.) Elsevier Science Publishers, 71-76 (1982).

41. A. Rohatgi, J.R. Davis, R.H. Hopkins and P.G. McMullin, Solid-State Electronics, 26, 1039 (1983). 


\section{MICROSTRUCTURE AND ELECTRICAL CHARACTERIZATION OF SILICON CARBIDE PRECIPITATES IN CAST POLYCRYSTALLINE SILICON}

\section{Introduction}

Cast silicon, an important material for solar cell fabrication, was physically and electrically characterized to increase the basic understanding of defect and impurity incorporation into the polycrystalline structure. Wafers and cells from both a low stress, high efficiency $(\eta=12 \%)$ portion of the ingot and a high stress, low efficiency $(\eta=7 \%)$ portion of the ingot were used. The high stress material is formed because of a crucible release problem during the ingot cooling which produces an inordinate amount of lattice stress in that region of the ingot due to the different thermal expansions of the ingot and the crucible. The high stress is believed to trap many of the impurities that would normally segregate to the discarded top portion of the ingot. Large crystallographic SiC precipitates were discovered in the low efficiency material. These precipitates act both as strong recombination centers and as nucleation sites for defect generation. The physical characteristics and effects of these structures were investigated using scanning electron microscopy (SEM) techniques including secondary imaging, electron beam induced current (EBIC), and energy dispersive $x$-ray spectrometry (EDS). Deep level transient spectroscopy (DLTS) was used to investigate the impurity and defect trap levels near the inclusions and in the bulk material, while Fourier transform infrared spectroscopy (FTIR) was used to give impurity concentrations over both the material with and without the SiC precipitates.

\section{Physical Characterization}

The high efficiency and low efficiency materials have a similar grain structure, grain size and defect distribution, yet there is a large difference in the performance of the two materials. EBIC measurements revealed large $(10 \mu \mathrm{m}$ to $100 \mu \mathrm{m}$ in diameter) structures on the low efficiency cells and wafers. These inclusions appear as high recombination areas with a halo of defects surrounding them and are randomly distributed throughout the low efficiency material. The defect halo disappears if the sample is heavily etched, as the silicon around the inclusion is severely preferentially etched, indicating the large amount of stress induced by the structure. Secondary SEM images reveal that the inclusions are of many different shapes but are all crystallographic in nature. They are located in broad, shallow etch pits of up to $50 \mu \mathrm{m}$ in depth and $300 \mu \mathrm{m}$ across depending on the degree of etching. 


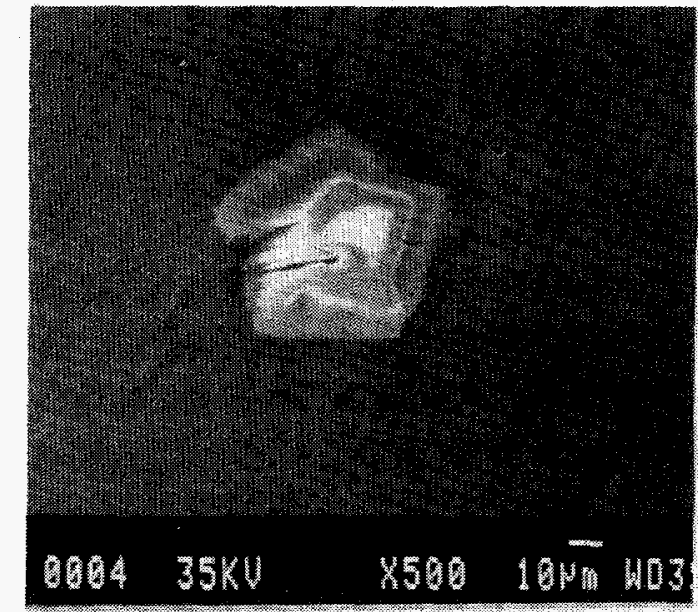

(a)

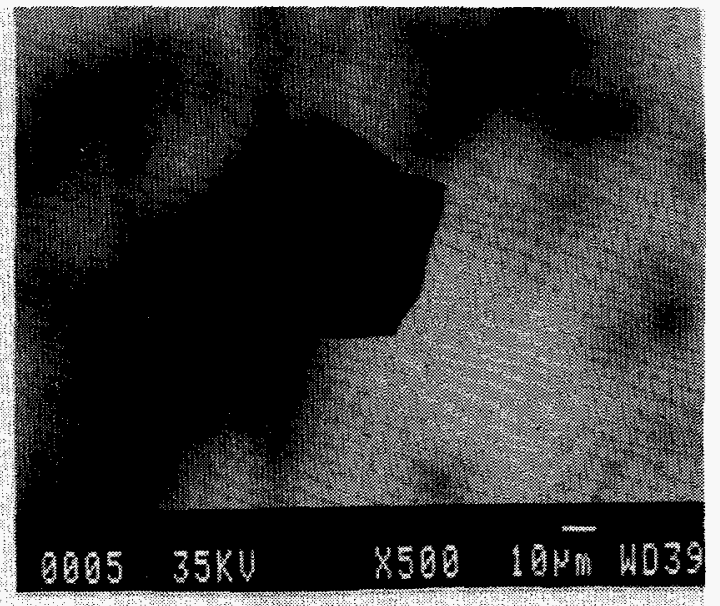

(b)

Fig. 1 Image of a typical SiC precipitate using (a) secondary SEM imaging and (b) EBIC.

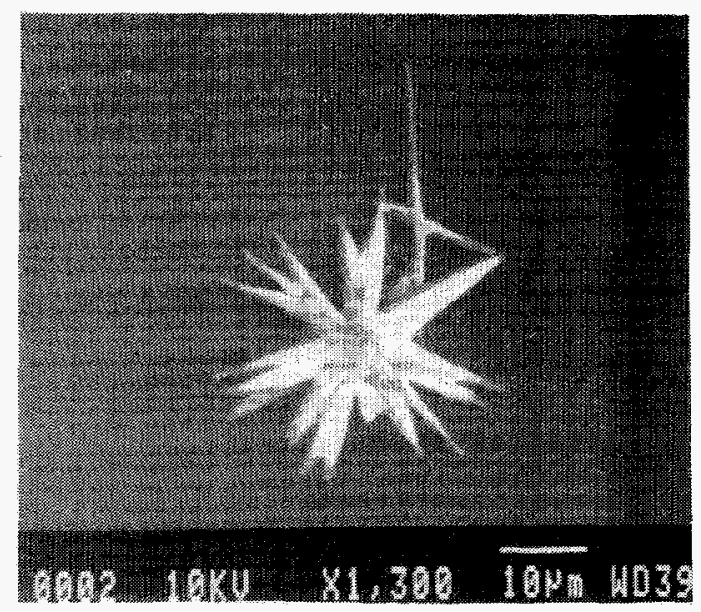

Fig. 2 Secondary SEM image of a "morningstar" SiC precipitate.

Figure 1 is a secondary SEM image and accompanying EBIC image of a typical inclusion while Figure 2 is a secondary SEM image of a "morningstar" structure. Many of the precipitates have this type of appearance but only on heavily etched samples because the mechanical polishing required for EBIC destroys the spikes on the top and sides of the structures near the surface. EDS analysis of these inclusions revealed a concentration of silicon only half that of the bulk silicon (the EDS detector cannot detect low $\mathrm{Z}$ materials) 
and it was concluded from this and the appearance of the structures that the structures are composed of $\mathrm{SiC}$. Similar $\mathrm{SiC}$ precipitates have been reported for silicon ribbon pulled through a carbon die $(1,2)$. These $\mathrm{SiC}$ precipitates appear equally in both the low efficiency wafers and cells but not in any of the high efficiency material; also, the heat treatment and diffusion involved in the cell formation process does not affect the precipitate's structure or the occurrence of "morningstar" structures.

FTIR analysis was used on the bulk wafer material to determine the interstitial oxygen and the substitutional carbon concentrations in the starting material. The low efficiency wafer showed an oxygen concentration of $19.8 \mathrm{ppm}$ and a carbon concentration of $0.69 \mathrm{ppm}$ while the high efficiency wafer had $12.2 \mathrm{ppm}$ of oxygen and $4.4 \mathrm{ppm}$ of carbon using the new ASTM standards $(3,4)$. These results indicate a higher oxygen concentration in the low efficiency material but a lower carbon concentration. The lower substitutional carbon concentration indicates that in the low efficiency material, the expected higher carbon content is incorporated into the SiC precipitates (which are not included in the FTIR count) leaving a lower carbon concentration in the bulk. By estimating the amount of carbon incorporated into the $\mathrm{SiC}$ precipitates based on the observed density of the precipitates, even a very conservative estimate would indicate the presence of much more total carbon in the low efficiency material than in the high efficiency material.

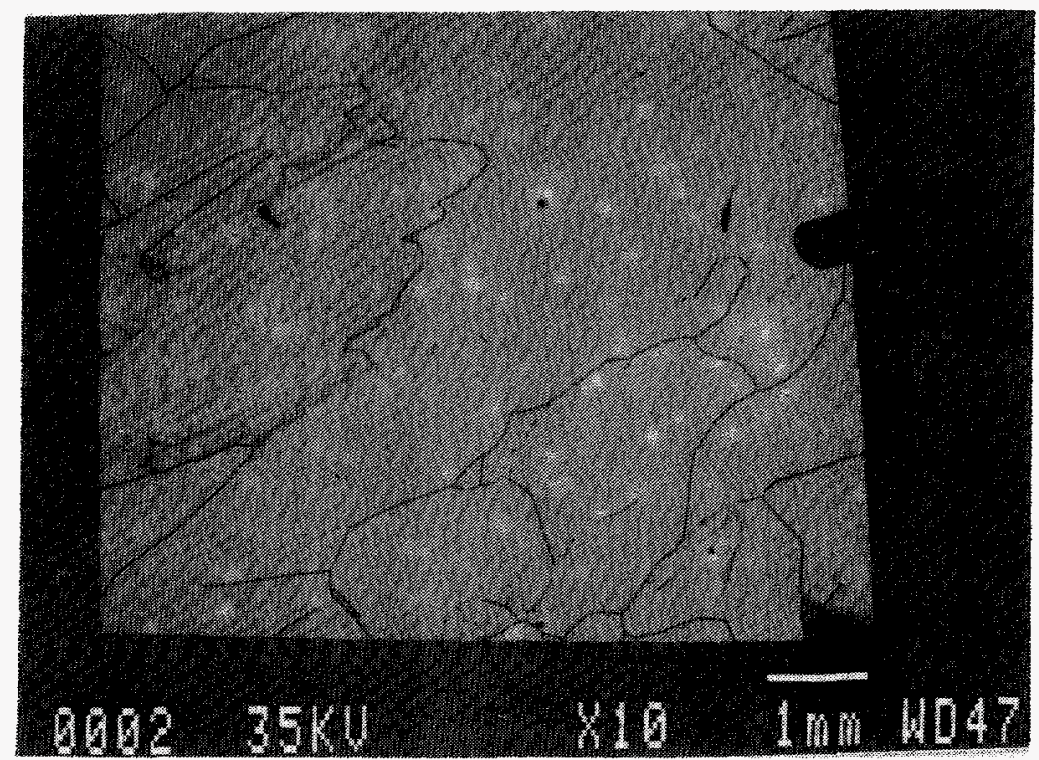

Fig. 3 EBIC image of a low efficiency cell sample.

EBIC measurements on low efficiency cells showed bright areas of higher EBIC current collection surrounding many of the defects and grain boundaries in the sample. Figure 3 is 
an EBIC image of a low efficiency cell sample showing the higher EBIC current. Higher EBIC current collection was especially prominent around the $\mathrm{SiC}$ precipitates and whereas bright areas occurred sporadically about some of the defects and grain boundaries in a sample, all of the SiC inclusions had increased EBIC current collection with increased current compared to other areas; this can be seen in Figure 4 which is an EBIC image of a $\mathrm{SiC}$ precipitate in a low efficiency cell sample. The bright areas, or denuded zones, appear to be due to the intrinsic or internal gettering of metal impurities. Intrinsic gettering occurs when crystalline imperfections attract mobile impurities since they are of a higher free energy than the normal silicon lattice (5). Samples of the low efficiency wafer were annealed or phosphorus diffused at $900^{\circ} \mathrm{C}$ for thirty minutes to simulate the diffusion step in the cell formation process. These samples showed the same gettering effects as the cell samples, irrespective of whether phosphorus was used or not, indicating that the gettering is not phosphorus gettering but is intrinsic in nature. Samples of high efficiency wafer material were subjected to the same heat treatments as the low efficiency samples but like the high efficiency cells, no change of any kind was observed.

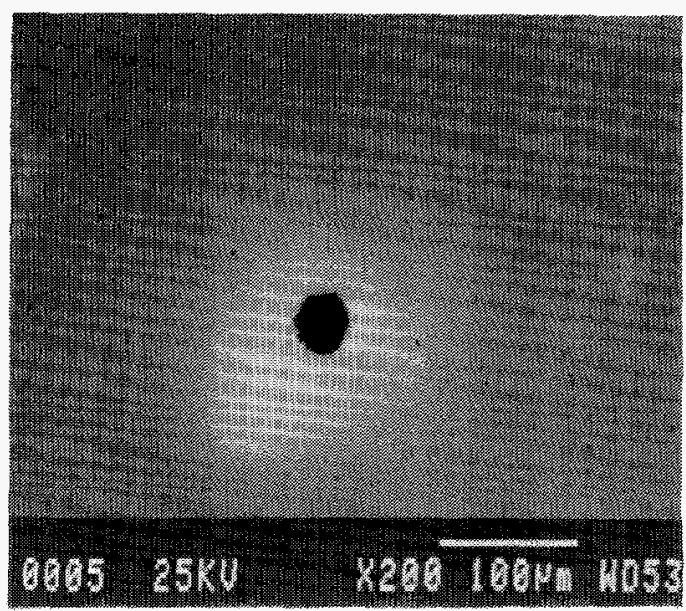

Fig. 4 EBIC image of a SiC precipitate and its surrounding denuded zone.

\section{Electrical Characterization}

DLTS measurements were made on the low efficiency and high efficiency cell and wafer samples as well as on the low efficiency wafer samples that had been annealed. Measurements were made using $800 \AA$ titanium $+2000 \AA$ aluminum Schottky contacts with a diameter of $0.5 \mathrm{~mm}$. Some of the Schottky contacts covered $\mathrm{SiC}$ precipitates but unfortunately the precipitates are so large that there is a break in the Schottky contact between the precipitate and the surrounding silicon. This causes the $\mathrm{SiC}$ precipitate to not be connected to the rest of the Schottky diode so that the DLTS measurements do not 
include the precipitates but do include all of the surrounding silicon up to the edge of the precipitate so that measurements could be made on the etch pit and the area of bulk silicon affected by the $\mathrm{SiC}$ precipitate. Measurements were made on Schottky diodes both on the bulk material and near the $\mathrm{SiC}$ precipitates to discover if there are any measurable effects of the inclusion of the $\mathrm{SiC}$ precipitates or differences between the two areas.

Table 1 DLTS Results

\begin{tabular}{|c|c|c|c|c|}
\hline Sample & Position & $\begin{array}{c}\text { Number of } \\
\text { Measurements }\end{array}$ & $\begin{array}{c}\text { Trap } \\
\text { Energy } \\
(\mathrm{eV})\end{array}$ & $\begin{array}{c}\text { Trap } \\
\text { Concentration } \\
\left(\mathrm{cm}^{-3}\right)\end{array}$ \\
\hline $\begin{array}{l}\text { Low Efficiency } \\
\text { Cell }\end{array}$ & $\begin{array}{c}\text { Bulk } \\
\text { Near SiC }\end{array}$ & $\begin{array}{l}2 \\
1\end{array}$ & $\begin{array}{l}\text { Broad } \\
\text { Broad }\end{array}$ & \\
\hline $\begin{array}{l}\text { Annealed Low } \\
\text { Efficiency Wafer }\end{array}$ & $\begin{array}{c}\text { Bulk } \\
\text { Near SiC }\end{array}$ & $\begin{array}{l}1 \\
1\end{array}$ & $\begin{array}{l}\text { Broad } \\
\text { Broad }\end{array}$ & \\
\hline $\begin{array}{l}\text { High Efficiency } \\
\text { Cell }\end{array}$ & & 2 & Broad & \\
\hline $\begin{array}{l}\text { Low Efficiency } \\
\text { Wafer }\end{array}$ & $\begin{array}{c}\text { Bulk } \\
\text { Near SiC } \\
\text { Near SiC }\end{array}$ & $\begin{array}{l}2 \\
1 \\
1\end{array}$ & $\begin{array}{c}E_{v}+0.35 \\
E_{v}+0.351 \\
E_{v}+0.292\end{array}$ & $\begin{array}{c}3.2 \times 10^{12} \\
3.14 \times 10^{12} \\
1.64 \times 10^{12}\end{array}$ \\
\hline $\begin{array}{l}\text { High Efficiency } \\
\text { Wafer }\end{array}$ & & $\begin{array}{l}2 \\
1 \\
1 \\
1\end{array}$ & $\begin{array}{c}\text { Broad } \\
E_{v}+0.358 \\
E_{v}+0.30 \\
E_{v}+0.26\end{array}$ & $\begin{array}{c}1.8 \times 10^{12} \\
1.88 \times 10^{12} \\
1.96 \times 10^{12}\end{array}$ \\
\hline
\end{tabular}

Table 1 shows the results of all of the DLTS measurements. The low efficiency cell, high efficiency cell and low efficiency annealed wafer samples all had a very similar DLTS spectra that did not show any distinct trap peaks but instead showed a broad DLTS peak which indicates a trap with continuous energy levels. Broad trap levels were also found on some of the high efficiency wafers, that are different from those found on the various heat treated samples but these broad spectra were found on older samples that had been through several processing treatments (though not any anneals). New high efficiency wafer samples that were cut from a different part of the same wafer showed distinct trap peaks instead of a broad trap peak. These traps are at $E_{\mathrm{V}}+0.358 \mathrm{eV}, \mathrm{E}_{\mathrm{V}}+0.30 \mathrm{eV}$ and $\mathrm{E}_{\mathrm{V}}+0.26 \mathrm{eV}$ and all have approximately the same trap concentration. All measurements taken on the low efficiency wafer material showed a single distinct peak that was at about $E_{\mathrm{v}}+0.35 \mathrm{eV}$ with a trap concentration of around $3.2 \times 10^{12} \mathrm{~cm}^{-3}$ except for one measurement which gave 
$\mathrm{E}_{\mathrm{V}}+0.292 \mathrm{eV}$ with a trap concentration of $1.6 \times 10^{12} \mathrm{~cm}^{-3}$. Except for this one measurement, the low efficiency material gave uniform results and did not show any dependence on whether $\mathrm{SiC}$ precipitates were present or not.

\section{Discussion}

$\mathrm{SiC}$ has a larger coefficient of thermal expansion than silicon and sublimates at a much higher temperature than silicon melts so that the $\mathrm{SiC}$ inclusions are likely to form by precipitation from a liquid phase (1). The high stress during the cooling of the low efficiency material traps many of the impurities that would otherwise segregate during solidification, and the combination of high stress and a high carbon concentration causes precipitation of the carbon into $\mathrm{SiC}$ precipitates. The inclusion of these $\mathrm{SiC}$ precipitates into the silicon matrix and the thermal expansion of the two materials would cause defects to nucleate about the structure forming a high stress, high recombination region not only at the precipitate itself but also in a surrounding region. In the high efficiency material, the lower stress allows the segregation of more of the impurities and the lower impurity concentration and stress are not conducive to the precipitation of $\mathrm{SiC}$.

Intrinsic gettering occurs when the metal impurities or even oxygen and carbon (6) are drawn to damaged sites or defect sites, such as dislocations, stacking faults or surface damage; thus an area denuded of these impurities is left surrounding the defect. Gettering and the amount of gettering is highly dependent upon the temperature and duration of the gettering anneal as well as upon the diffusivities and concentrations of the impurities involved. The dependence on these could lead to gettering not being observed in the high efficiency material since it does not contain as high a concentration of impurities as does the low efficiency material; also the high efficiency material is grown with less stress so that all defect structures would also have lower stress and the gettering seems to be dependent upon the degree of stress involved since the highest degree of gettering is observed around the $\mathrm{SiC}$ precipitates which are the areas of highest stress in the material. Oxygen precipitates have been shown to be involved in intrinsic gettering in Czochralski silicon $(7,8)$ but this involves nucleation of oxygen precipitates to induce defects and high stress areas to act as gettering sites (9). The $\mathrm{SiC}$ precipitates would act in much the same way by creating a region of stress much higher than in the surrounding material and nucleating defects. Metal impurities are present in the cast polysilicon, since less than pure silicon is used to grow the material, and a high concentration of these impurities is trapped in the low efficiency material. 
During the gettering process, metal impurities located in the high stress field of defects diffuse to the defect/gettering site to be gettered. Only fast diffusing metal impurities are likely to be gettered since other impurities such as carbon and oxygen diffuse too slowly to be substantially gettered for the temperature and duration of the annealing/diffusion cycle. The resulting denuded zone is only in the gettered site's high stress region so that some defects and grain boundaries have small denuded zones surrounding them but the largest and most intense denuded zones surround the SiC precipitates. After gettering, the collected EBIC current (which is locally proportional to the diffusion length) in the denuded zone surrounding a $\mathrm{SiC}$ precipitate is proportional to that of the high efficiency material, indicating that the increased concentration of impurities in the low efficiency material could be a determining factor in the reduced performance of cells made from material grown under exceptionally high stress.

The DLTS results indicate that for the most part there are no measurable traps induced in the material surrounding the $\mathrm{SiC}$ precipitates since all measurements gave the same results whether near a precipitate or not except for the one measurement that gave a $E_{v}+0.292 \mathrm{eV}$ peak. This result is not conclusive since DLTS using Schottky diodes on p-type material can only measure traps in the lower half of the band gap and DLTS measurements were taken over a large area, only a small part of which was adjacent to a SiC precipitate. According to Endrös and Krühler (10), substitutional carbon has been shown to induce deep trap levels at $\mathrm{E}_{\mathrm{Y}}+0.355 \mathrm{eV}, \mathrm{E}_{\mathrm{Y}}+0.290 \mathrm{eV}$ and $\mathrm{E}_{\mathrm{Y}}+0.216 \mathrm{eV}$ in p-type Czochralski silicon depending upon the carbon concentration and annealing processes. The $\mathrm{E}_{\mathrm{V}}+0.290$ $\mathrm{eV}$ and $\mathrm{E}_{\mathrm{v}}+0.216 \mathrm{eV}$ traps were only found after annealing samples that came from silicon which had been contaminated with $\mathrm{SiC}$ in its melt. The $\mathrm{E}_{\mathrm{v}}+0.35 \mathrm{eV}$ trap found in the low efficiency wafer samples appears to be a carbon induced trap. This is likely since as shown by FTIR, the substitutional carbon content in both the high and low efficiency materials is high enough for such traps to exist. The only exception is the $E_{v}+0.29 \mathrm{eV}$ peak found on one of the measurements. This peak might be a SiC induced peak but it is not known if this measurement should have shown the $\mathrm{E}_{\mathrm{v}}+0.35 \mathrm{eV}$ peak or why it only appeared once or why it did not show an additional peak for the bulk material not near the $\mathrm{SiC}$ precipitate. For these reasons this measurement is rather suspect and further studies are needed. The high efficiency wafer samples show a trap peak similar to the $\mathrm{E}_{\mathrm{V}}+0.355 \mathrm{eV}$ trap at a lower concentration than in the low efficiency samples. It is not known why there are measurements showing a $E_{\mathrm{V}}+0.3 \mathrm{eV}$ and a $\mathrm{E}_{\mathrm{V}}+0.26 \mathrm{eV}$ trap level but these could be the same trap level with differences in measurement and different sample thermal history. Due to the material growth process, it is possible for different parts of the same wafer to have different thermal histories; this could be of sufficient importance to explain why some high 
efficiency wafer samples show various trap levels while others show only a broad peak, but this is unclear at present.

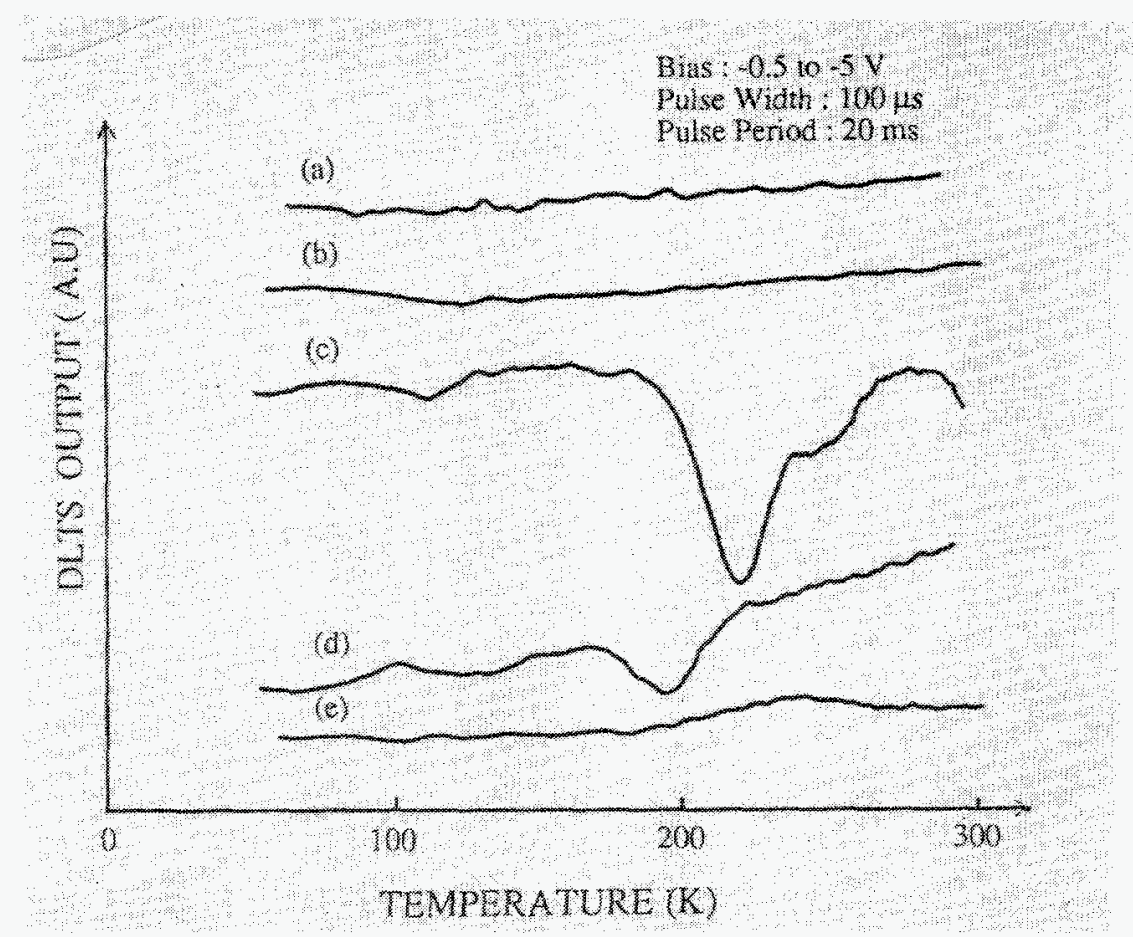

Fig. 5 DLTS output for a, (a) low efficiency cell sample, (b) high efficiency cell sample, (c) low efficiency wafer sample, (d) new high efficiency wafer sample, (e) old high efficiency sample.

Figure 5 shows a typical DLTS measurement for a high efficiency cell sample, low efficiency cell sample, low efficiency wafer sample and two of the high efficiency wafer samples. The low efficiency wafer samples show a larger trap concentration than the high efficiency wafer samples even though the high efficiency material has a higher substitutional carbon content and a direct relation between trap concentration and carbon concentration has been shown for $\mathrm{Cz}$ silicon (10). The higher trap concentration in the low efficiency material makes sense though because the high stress and SiC precipitates present are likely to help in trap formation, especially since carbon induced trap concentrations in $\mathrm{Cz}$ silicon are dependent on whether the carbon contamination came from graphite or $\mathrm{SiC}$ in the original melt (10). Heat treatment, whether by cell formation or annealing, causes any discrete trap levels to disappear and leaves only a broad trap level for both the high and low efficiency materials. Endrös and Krühler did not see such an occurrence in $\mathrm{Cz}$ silicon but in fact saw an increase in trap concentration after an $870^{\circ} \mathrm{C}$ anneal for thirty minutes. Even accounting for the different thermal histories of the cast silicon as compared to $\mathrm{Cz}$ silicon, it 
is obvious that some mechanism present in the cast silicon removes the discrete traps during heat treatment, much like a gettering step. Kimerling (11) has correlated the $E_{V}+0.35 \mathrm{eV}$ trap to a $\mathrm{C}_{\mathrm{S}}-\mathrm{C}_{\mathrm{i}}$ pair which is stable only up to about $400^{\circ} \mathrm{C}$, which could explain the disappearance of the discrete traps in the cast material.

\section{Conclusions}

The high stress in the low efficiency material causes the formation of large SiC precipitates in the material during ingot formation; additionally, higher concentrations of impurities that would otherwise segregate out of the material are trapped. These SiC precipitates are responsible for the nucleation of surrounding defects as well as a local high stress region. Upon cell formation or other heat treatment of the low efficiency material, intrinsic gettering of metal impurities is observed in high stress regions of the material, most notably in the high stress region of $\mathrm{SiC}$ precipitates. Neither $\mathrm{SiC}$ precipitation or gettering is observed in the high efficiency material. DLTS measurements reveal that substitutional carbon induces traps in the cast polysilicon but that any heat treatment will remove these trap levels leaving only a broad, continuous energy trap. The presence of $\mathrm{SiC}$ precipitates in the low efficiency material does not seem to induce any additional traps or have any affect on the material.

\section{References}

1. G. H. Schwuttke, T. F. Ciszek, K. H. Yang, and A. Kran, IBM J. Res. Dev., 22, 335 (1978).

2. J. I. Hanoka, Solar Cells, 1, 123 (1979/80).

3. ASTM Standard F123, 1987 Annual Book of ASTM Standards, Am. Soc. Test. Mat., Philadelphia, 1987.

4. ASTM Standard F121, 1987 Annual Book of ASTM Standards, Am. Soc. Test. Mat., Philadelphia, 1987.

5. J. S. Kang, Doctoral Dissertation, Arizona State University, 1988

6. W.E. Bailey, R.A. Bowling and K.E. Bean, J. Electrochem. Soc., 132, 1721 (1985).

7. H.R. Huff, H.F. Schaake, J.T. Robinson, S.C. Baber and D. Wang, J. Electrochem. Soc., 130, 1551 (1983).

8. R. Falster, J. Electrochem. Soc., 137, 1548, 1990

9. T.Y. Tan, E.E. Gardner and W.K. Tice, Appl. Phys. Lett., 30, 175 (1977).

10. A. Endrös and W. Krühler, J. Appl. Phys., 61, 5051 (1987).

11. L.C. Kimerling, P. Blood and W.M. Gibson, in Radiation Defects in Semiconductors 1978, edited by J.H. Albany, Inst. Phys. Conf. Series 46, 276 (1979). 


\title{
APPENDIX A \\ Preparation of Schottky Diodes on As-Grown EFG Silicon
}

\author{
A1. EBIC Sample Preparation
}

\section{Process Considerations}

Schottky diodes were fabricated on as-grown EFG material doped with $5 \times 10^{15} \mathrm{~cm}^{-3}$ of boron for a resistivity of $2.5 \Omega-\mathrm{cm}$. Specimens were cut from as-grown blanks using a South Bay Technology wire saw. We chose aluminum metallization for the Schottky contact and gold for the backside ohmic contact, mainly as a matter of convenience. Both metals are easily accessible, easy to evaporate and neither require annealing to activate the contact. The critical step in the diode fabrication was cleaning of the silicon surface prior to the Schottky contact evaporation. In our first attempts the silicon was merely cleaned in an $\mathrm{HF}: \mathrm{H}_{2} \mathrm{O}$ or HF:ammonium fluoride solution. Evaporated aluminum metallization produced a low resistivity ohmic rather than Schottky contact. Occasionally the structure would exhibit high resistivity (although no diode characteristic). Obviously a more controlled fabrication process was required. A variety of silicon cleaning processes were tested (see Table A1). The most reliable silicon cleaning process was the RCA clean and we do not recommend any of the others listed due to inconsistency of the diode formation process.

Table A1 Effect of Silicon Clean on Schottky Diode Quality

\begin{tabular}{lll} 
Treatment & Time & Result \\
\hline None & & usually Schottky \\
6:1 40\% & $2 \mathrm{~min}$ & usually ohmic \\
$50: 140 \% \mathrm{NH}_{4} \mathrm{~F}: \mathrm{HF}$ & $3 \mathrm{~min}$ & ohmic \\
$50: 1 \mathrm{H}_{2} \mathrm{O}: \mathrm{HF}$ & $3 \mathrm{~min}$ & ohmic \\
$3: 1 \mathrm{H}_{2} \mathrm{SO}_{4}: \mathrm{H}_{2} \mathrm{O}_{2}$ & $5 \mathrm{~min}$ & usually Schottky \\
RCA Clean & $40 \mathrm{~min}$ & Schottky \\
\hline
\end{tabular}

All ohmic contacts were deposited as two separate side by side contacts. Such contacts allowed measurement of their I-V characteristics without interference by the aluminum Schottky contact to ensure the gold contact ohmic qualities. When deposition of the ohmic contacts became routine, we began using only a single contact to simplify processing. Since an aluminum Schottky contact will be converted to an ohmic contact if annealed, we always applied the aluminum Schottky contact after the gold ohmic contact to avoid any chance of the heat generated during the gold deposition annealing the Schottky contact. 
A standardized fabrication process was developed which although tedious, has consistently produced high quality Schottky diodes. We shall first list the standardized process modules found to give consistently good results then summarize their use by a list of steps to fabricate a diode.

\section{Standard Clean}

The standard cleaning procedure is listed in Table A2. Samples were conveniently clamped in Nalgene ${ }^{\mathrm{TM}}$ polypropylene forceps (catalog \# D2590-1) sold by Baxter Scientific Products. These forceps lock in the clamped position and withstand all the cleaning solutions, securely holding the sample allowing many samples to be tracked throughout batch processing.

\section{Standard Evaporation}

Thermal evaporation was done in a cold trapped Edwards 306A evaporator. The evaporation source was a tungsten basket placed $150 \mathrm{~mm}$ from the sample. All evaporations were done at a vacuum better than $10^{-5}$ torr. Gold ohmic contacts were deposited using $99.95 \%$ pure gold shot evaporated until the glass slide which supported the sample was opaque as viewed with the bright light from the evaporation basket. The double ohmic contacts were produced by laying an 18 gauge wire across the center of the sample to work as a shadow mask. Although it has not been investigated, we feel high purity gold is not required for the ohmic contacts and on one occasion the remnants of a consumed $60 \%$ gold, $40 \%$ palladium sputter target was chopped up and used as source material. Schottky contacts were deposited using reagent grade aluminum granules in a tungsten basket, again we evaporated until the glass support slide had an opaque coating (approximately $30 \mathrm{~s}$ ). Aluminum forms a brittle intermetallic with tungsten and tungsten baskets were found to last for about three evaporations while the tungsten boats last only for one evaporation. This is presumably due to more degrees of flexure allowed in the basket as the heating causes it to expand thus the stress is not concentrated at any one spot. Spring loaded evaporation source holders are available commercially that would probably improve basket life further but their cost cannot justify the savings in baskets for our use. The same evaporator was used for all depositions and was not cleaned between the gold and aluminum evaporation. We found no evidence of any ill effects resulting from cross contamination of metals. The film thickness was never measured due to the difficulty of measuring thin metal films and the lack of a film thickness monitor in the evaporator. Films were deposited within one hour from the time the samples were removed from the RCA clean. Care must be taken to mask the sample edges to prevent coating the edges with metal which will short the front to backside metals. Glass microscope coverslips work well. 
Table A2 Standard Clean Procedure

\begin{tabular}{|c|c|c|c|}
\hline Step & Chemical & Method & Comments \\
\hline 1 & acetone & $\begin{array}{l}2 \mathrm{~min} \text { in ultrasonic, } \\
\text { pyrex beaker }\end{array}$ & $\begin{array}{l}\text { removes wax from saw } \\
\text { operation }\end{array}$ \\
\hline 2 & acetone & $\begin{array}{l}2 \mathrm{~min} \text { in ultrasonic, } \\
\text { pyrex beaker }\end{array}$ & rinse \\
\hline 3 & blow dry with $\mathrm{N}_{2}$ & & \\
\hline 4 & $\begin{array}{l}\text { 3part } \mathrm{H}_{2} \mathrm{SO}_{4}(98 \%) \\
1 \text { part } \mathrm{H}_{2} \mathrm{O}_{2}(30 \%)\end{array}$ & $\begin{array}{l}5 \min @ 100^{\circ} \mathrm{C}, \text { pyrex } \\
\text { beaker }\end{array}$ & $\begin{array}{l}\text { removes any residual organics } \\
\text { not removed in acetone }\end{array}$ \\
\hline 5 & DI water rinse & $\begin{array}{l}2 \text { min in running } \mathrm{DI} \\
\text { water }\end{array}$ & \\
\hline 6 & $\begin{array}{l}\text { 1part HF (49\%) } \\
50 \text { parts DI water }\end{array}$ & $\begin{array}{l}1 \text { min, polypropylene } \\
\text { beaker }\end{array}$ & $\begin{array}{l}\text { removes any residual oxide } \\
\text { from crystal growth }\end{array}$ \\
\hline 7 & DI water rinse & $\begin{array}{l}2 \min \text { in running } \mathrm{DI} \\
\text { water }\end{array}$ & \\
\hline 8 & $\begin{array}{l}\text { RCA clean (part 1) } \\
1 \text { part } \mathrm{NH}_{4} \mathrm{OH}(70 \%) \\
\text { 1part } \mathrm{H}_{2} \mathrm{O}_{2}(30 \%) \\
\text { 5parts DI water }\end{array}$ & $\begin{array}{l}20 \min @ 75^{\circ} \mathrm{C} \text {, pyrex } \\
\text { beaker }\end{array}$ & $\begin{array}{l}\text { the two part RCA clean } \\
\text { removes metallic surface } \\
\text { contaminants and reduces } \\
\text { surface states }\end{array}$ \\
\hline 9 & $\begin{array}{l}\text { RCA clean (part 2) } \\
1 \text { part } \mathrm{HCl}(38 \%) \\
1 \text { part } \mathrm{H}_{2} \mathrm{O}_{2}(30 \%) \\
6 \text { parts DI water }\end{array}$ & $\begin{array}{l}20 \min @ 75^{\circ} \mathrm{C}, \text { pyrex } \\
\text { beaker }\end{array}$ & $\begin{array}{l}\text { by the end of this clean, a } 16 \AA \\
\text { oxide film has grown on the } \\
\text { surface }\end{array}$ \\
\hline 10 & DI water rinse & $\begin{array}{l}2 \min \text { in running } \mathrm{DI} \\
\text { water }\end{array}$ & \\
\hline
\end{tabular}




\section{Standard Patterning of the Schottky Contacts}

In most instances a patterned Schottky contact was required to facilitate correlation of the structure seen using EBIC to that seen with the optical microscope for further sample preparation. Two patterning techniques were used. The shadow mask technique using a thin aluminum sheet with holes drilled through it is the simplest. The mask is simply placed on top of the sample during the Schottky contact deposition. The two disadvantages of this technique are; 1) the dots all look the same making them hard to relocate and 2) each dot is electrically isolated so if a large area is to be screened using EBIC, the sample must continually be removed from the SEM to move the probe to the next dot. Photolithographic techniques overcome these problems. However, fabrication complexity is greatly increased.

\section{Photolithographic Masking}

The basic photolithographic masking sequence requires photoresist application over the metal to be patterned, resist exposure through a suitable mask, development of the resist, etching of the metal and finally, removal of the photoresist. Due to the poor adhesion of gold to silicon the evaporation sequence must be changed. The aluminum Schottky contact must be applied and masked before application of the gold ohmic contact otherwise the gold "lifts-off" the silicon during development of the photoresist. Evaporation of the Schottky contact first did not show any signs of annealing during the subsequent gold contact evaporation as was initially feared.

Due to the relatively low resolution masking requirement and small sample size we made masks using Kodak direct positive film \#5360. This film has a resolution of $320 \mathrm{lines} / \mathrm{mm}$. The masks were supported by a microscope slide and contact printed on the sample as shown in Fig. A1. Mask patterns were drawn using MacDraft software at $10 \mathrm{x}$ the final required size and laser printed. Copying these prints to $35 \mathrm{~mm}$ film at $10 \mathrm{x}$ reduction is convenient.

The film is processed at $20^{\circ} \mathrm{C}$ as listed in Table A3. The various masks used and their application are shown in Fig. A2. Connecting each piece of the mask (ID numbers and diodes) together as one piece of metallization ensures the identification numbers will be visible in EBIC and requires only one probing to see everything on the sample.

The sample was taped to a photoresist spinner chuck, one drop of AZ-1370 positive photoresist was applied and the sample spun for $15 \mathrm{~s}$ at $4800 \mathrm{rpm}$ to produce a $7000 \AA$ thick layer of photoresist. The samples are "soft-baked" at $90^{\circ} \mathrm{C}$ for 30 minutes to remove the solvents. The masks are placed emulsion side in contact with the resist and exposed for 
$16 \mathrm{~s}$ with a Leitz high intensity lamp. Development is accomplished using $0.24 \mathrm{~N}$ (normal) AZ-351 positive resist developer in a tray with gentle agitation for $\approx 3$ minutes. Working with the aluminum Schottky contact is convenient in this case because over developing the photoresist will allow the developer to etch the aluminum in the desired places. Thus, no further metal etch is required after resist develop and the remaining resist can be removed in a two step acetone rinse. The samples are completed by evaporating the gold ohmic contact on the backside.

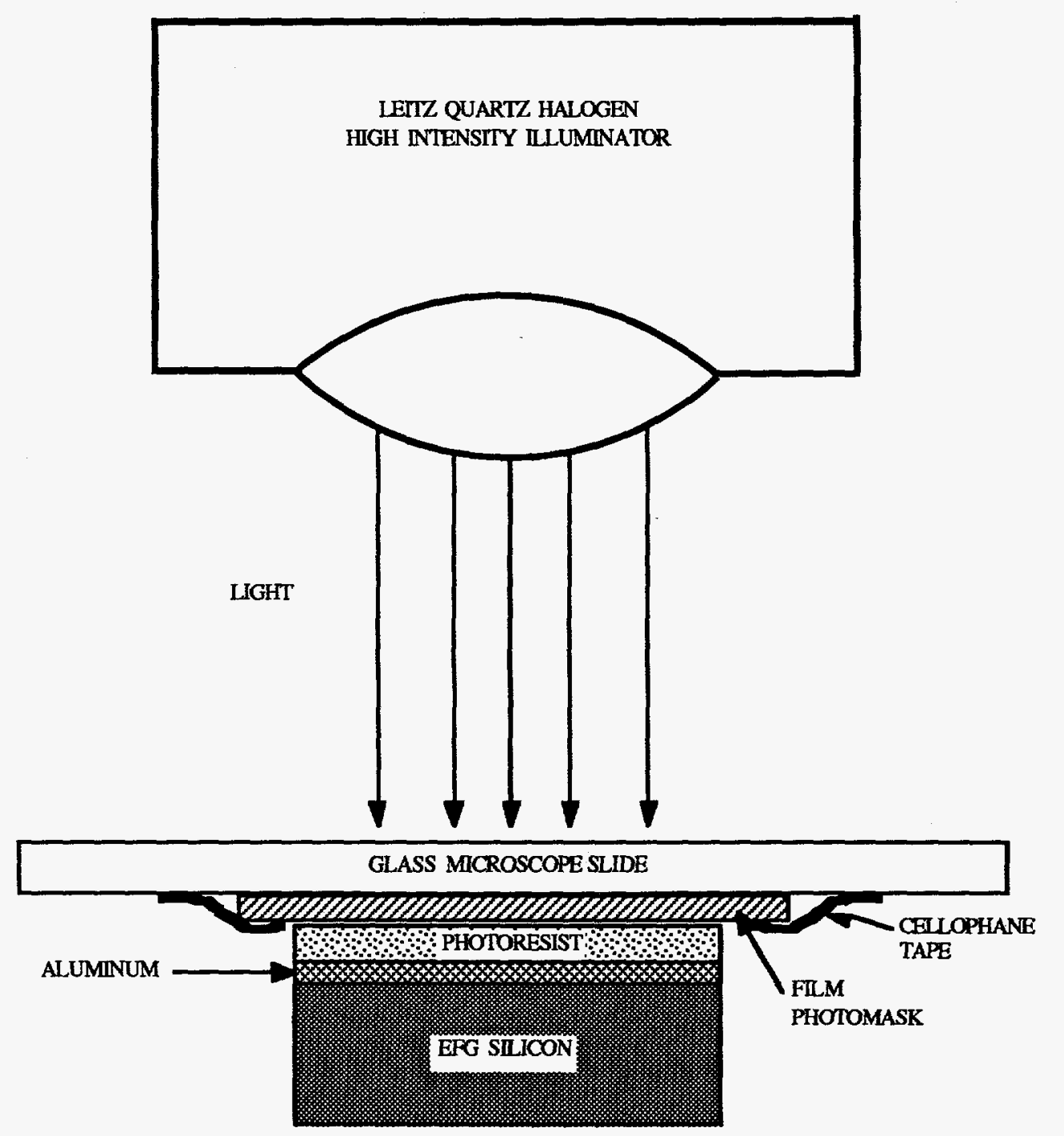

Fig. A1 Schematic of contact printing method for photolithographic patterning of Schottky contacts. 
Table A3 Processing Kodak \#5360 Film

\begin{tabular}{lll} 
Chemical & Time & Comments \\
\hline HRP Developer (Kodak) & $3 \mathrm{~min}$ & Use full strength \\
Water & $2 \mathrm{~min}$ & Rinse in running water \\
Fixer (Kodak) & $5 \mathrm{~min}$ & \\
Water & $20 \mathrm{~min}$ & Rinse in running water \\
Photoflo (Kodak) & dip & To reduce water marks \\
\hline
\end{tabular}
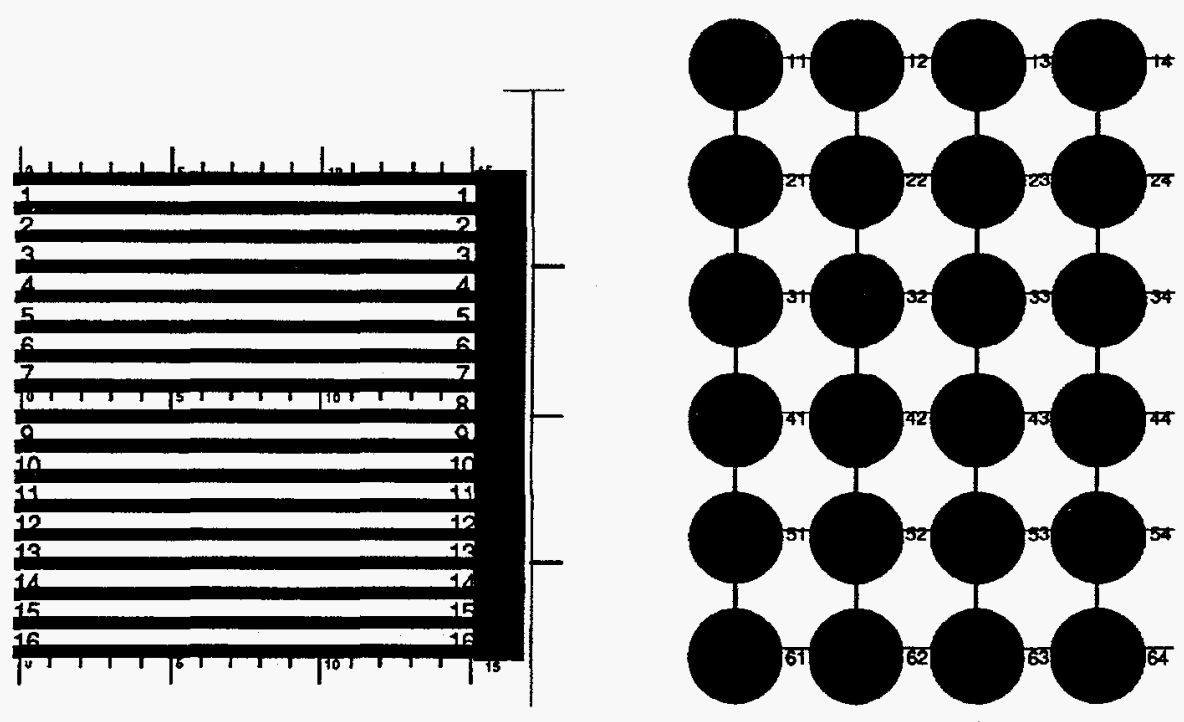

Fig. A2 Masks used to pattern Schottky diodes for EBIC examination. (a) the lines and spaces are approximately $200 \mu \mathrm{m}$ wide and are aligned parallel to the twin boundaries for large area mapping; (b) the disks are $3 \mathrm{~mm}$ in diameter and were used for preparation of TEM samples. 


\section{Fabrication of Schottky Diodes}

In summary, the steps required for diode fabrication are:

1. Cut samples from as-grown blanks using wire saw.

2. Rinse in water to remove grit.

3. Standard clean the as-grown material.

4a. Standard evaporation if using shadow mask.

4b. If using patterned Schottky diodes:

A. Standard aluminum evaporation.

B. Photoresist masking.

C. Standard gold evaporation.

5. Test diode quality:

A. Good: do EBIC

B. Bad: strip in hot phosphoric acid and start at step 3.

\section{A2. Surface Photovoltage Sample Preparation}

Transparent Al Schottky diodes were made on as-grown materials of Cast and EFG polycrystal silicon. The transparency was achieved by using thin $\mathrm{Al}(200 \AA)$. The thin $\mathrm{Al}$ Schottky diodes are easy to make, very stable for long times even after one year, and very reliable in every case. The standard sample preparation sequences are:

SPV sample fabrication steps for as-grown material:

1. Cut samples from as-grown blanks using wire saw.

2. Rinse in water to remove grit.

3. Sample cleaning 3 part $\mathrm{H}_{2} \mathrm{SO}_{4}(98 \%)+1$ part $\mathrm{H}_{2} \mathrm{O}_{2}(30 \%) 10$ min at $150^{\circ} \mathrm{C}$

DI water rinse $10 \mathrm{~min}$. in running DI water 10 part DI water+1 part HF to strip oxide

4. Etch silicon $(10 \mu \mathrm{m}) ; 10$ part $\mathrm{HNO}_{3}+1$ part $\mathrm{HF}$ for $10 \mathrm{~min}$.

5. Al thermal evaporation with a shadow mask: $200 \AA$

6. Au thermal evaporation for ohmic contact: $500 \AA$

For solar cells, the built-in $n^{+} p$ junction in mesa diode was used for both SPV and DLTS measurements. The standard mesa diode fabrication steps are: 
Mesa diode fabrication steps

1. Cut samples from solar cell blanks using wire saw.

2. Rinse with DI water to remove grit.

3. Paint dots of 2-3 mm diameter with black wax on front side and dry for $24 \mathrm{~h}$.

4. Paint black wax on back surface.

5. Etch metal grids; 5 part $\mathrm{HNO}_{3}+1$ part $\mathrm{HF}$ for $20 \mathrm{~min}$.

5. Etch anti-reflection coating; 10 part DI water +1 part $\mathrm{HF}$ for $20 \mathrm{~min}$.

6. Etch silicon; 10 part $\mathrm{HNO}_{3}+1$ part $\mathrm{HF}$ for $4 \mathrm{~min}$.

7. Remove black wax.

TCE in ultrasonic cleaner for $5 \mathrm{~min} .3$ times

Acetone in ultrasonic cleaner for $5 \mathrm{~min} .3$ times

Methanol in ultrasonic cleaner for $5 \mathrm{~min}$.

Rinse in running DI water

\section{A3. DLTS Sample Preparation}

For DLTS measurements of as-grown materials of Cast and EFG silicon, Ti Schottky barrier diodes were used. To improve the contact between the probe and $\mathrm{Ti}, \mathrm{Al}$ was deposited on the Ti film. DLTS measurements were usually done after SPV measurements so that the sample fabrication for DLTS measurement begins with etching the thin Al film. For solar cell, SPV samples were used for DLTS measurement as mentioned before.

DLTS sample fabrication steps:

1. Paint black wax on back surface.

2. Etch thin $\mathrm{Al}$ film; 1 part DI water +5 part $\mathrm{HNO}_{3}$ for $10 \mathrm{~min}$.

3. Remove black wax.

TCE in ultrasonic cleaner for $5 \mathrm{~min} .3$ times

Acetone in ultrasonic cleaner for $5 \mathrm{~min} .3$ times

Methanol in ultrasonic cleaner for $5 \mathrm{~min}$.

Rinse in running DI water

4. Ti thermal evaporation: $800 \AA$

5. Al thermal evaporation: $1500 \AA$ 
Distribution:

Alpha Solarco

Attn: Anco Blazev

6507 South Hardy Drive

Tempe, AZ 85283

Amonix, Inc. (2)

Attn: Sewang Yoon

Vahan Garboushian

3545 West Lomita Boulevard

Unit A

Torrance, CA 90505

Applied Solar Energy Corp. (2)

Attn: Frank Ho

$$
\text { Henry Yoo }
$$

15251 East Don Julian Road

City of Industry, CA 91746

Arizona State University (3)

College of Engineering and

Applied Science

Attn: Robert Hammond

Charles Backus

Dieter Schroder

Tempe, AZ 85287-5806

As troPower

Attn: Allen Barnett

Solar Park

Newark, DE 19716-2000

Bechtel National, Inc.

Attn: Walter J. Stolte

Post office Box 3965

Mail Stop 50/15/D17

San Francisco, CA 94119-3965

Black and Veatch

Attn: Kevin Kerschen

Post Office Box 8405

Kansas City, MO 64114

Boeing Aerospace

Attn: Dr. John W. Yerkes

High Technology Center

Post Office Box 3999, MS 7J-71

Seattle, WA 98124-2499

Mr. Clement Chiang

GE Astrospace, MS NP-2K

100 Nassau Park Boulevard

West Windsor, NJ 08543-800
Crystal Systems

Attn: Fred Schmid

27 Congress Street

Salem, MA 01970

Cummings Engineering

Attn: Richard Cummings

323 Andover Street

Wilmington, MA 01887

ENTECH

Attn: Mark O'Neill

P. O. Box 612246

DFW Airport, TX 75261

EPRI (3)

Attn: Frank Dostalek John Bigger Frank Goodman

P. O. Box 10412

Palo Alto, CA 94303

Georgia Institute of Technology (2)

School of Electrical Engr.

Attn: Professor Ajeet Rohatgi Mr. Gerry Crotty

Atlanta, GA 30331

James Associates

Attn: Larry James

7329 Meadow Court

Boulder, CO 80301

Jet Propulsion Lab (2)

Attn: Russ Sugimura

Ron Ross

4800 Oak Grove Drive

Pasadena, CA 91109

Kopin

Attn: Ron Gale

695 Myles Standish Blvd.

Taunton, MA 02780

Massachusetts Institute of

Technology

Attn: Lione1 C. Kimerling

77 Massachusetts Avenue

Room 13-5094

Cambridge, MA 02139 
Midway Labs

Attn: Paul Collard

2255 East 75 th Street

Chicago, IL 60649

Mobil Solar Energy Corp.

Attn: Juris Kalejs

Four Suburban Park Drive

Billerica, MA 01821

NASA/Lewis Research Center (2)

Attn: Shiela Bailey

Dennis Flood

MS 302-1

21000 Brookpark Road

Cleveland, $\mathrm{OH} \quad 44135$

NREL (5)

Attn: Dick DeBlasio

Laxmi Mrig

Bhushan Sopori

Ted Ciszek

John Benner

1617 Coìe Boulevard

Golden, CO 80401

NREL Library

1617 Cole Boulevard

Golden, CO 80401

Pacific Gas and Electric (4)

Attn: Steve Hester

Joe Iannucci

Howard Wenger

Tammie Candelaria

3400 Crow Canyon Road

San Ramon, CA 94583

Photonic Power Systems, Inc.

Attn: Jan Werthan

550 California Avenue

Palo Alto, CA 94306

Purdue University (2)

Attn: Dick Schwartz

Jeff Gray

School of Electrical Engr.

West Lafayette, IN 47907
Siemens Solar Industries (2)

Attn: Kim Mitchell

Richard R. King

Post Office Box 6032

Camarillo, CA 93011

Solar Engineering Applications

Attn: Neil Kaminar

305 North Mathilda Avenue

Sunnyvale, CA 94086

Solar Kinetics, Inc.

Attn: Shabbar Saifee

P. O. Box 540636

Dallas, TX 75354-0636

Solarex Corporation (2)

Attn: John Wohlgemuth

Mohan Narayanan

630 Solarex Court

Frederick, MD 20701

SPECO

Attn: Walt Hart

Post Office Box 91

Morrison, CO 80465

Spectrolab (2)

Attn: Dmitri Krut James Albeck

12500 Gladstone Avenue

Sylmar, CA 91342

Spire Corporation

Attn: Michael J. Nowlan

Patriots Park

Bedford, MA 01730

Sun Energy Company

Attn: William Todorof

7824 McGroarty Street

Sunland, CA 91040

SunPower Corp.

Attn: Richard Swanson

435 Indio Way

Suite 100

Sunnyvale, CA 94086

SWTDI

Attn: Steven Durand

Box 30001, Dept. 3SOL

Las Cruces, NM 88003-0001 
Texas Instruments

Attn: Jules Levine

Post office Box 655012

Dallas, TX 75265

Texas Southern University

Attn: V. S. Murty, Physics

3100 Cleburne Avenue

Houston, TX 77004

3M Company

Attn: Paul Jaster, 225-2N-06

3M Center

St. Paul, MN 55144

US Department of Energy

Attn: James Ranne1s, CE-131

Forrestal Building

1000 Independence Avenue, SW

Washington, DC 20585

Wattsun

Attn: John Doherty

Post Office Box 751

Albuquerque, NM 87103

University of New South Wales Attn: Dr. Martin Green School of Electrical Engr.

Post Office Box One

Kensington, NSW 2033

AUSTRALIA

Canada Centre for Mineral and

Energy Technology

Attn: Allen Carpenter

2395 Speakman Drive

Mississauga, Ontario L5K 1B3

CANADA

Commission of the European

Communities (2)

Joint Research Centre, ESTI

Attn: H. Ossenbrink

21020 Ispra, VA

ITALY
Fraunhofer Institute for Solar Energie Systeme

Attn: Klaus Heidler

Oltmannsstrasse 22

D-7800 Freiburg

GERMANY

Instituto de Energia Solar

Ciudad Universitaria, $s / n$

Attn: Antonio Luque

ETSI Telecomunicacion (UPM)

28040 Madrid

SPAIN

6200

6202

6213

6213

6213

6213

6213

6213

6213

6213

6218

6218

6219

6219

7141

7151

D. E. Arvizu

G. J. Jones

T. C. Bicke1

P. A. Basore

T. D. Hund

A. B. Maish

J. R. Woodworth

J. M. Gee

D. S. Ruby

W. K. Schubert

D. E. Hasti

P. Valencia, Lib. (5)

M. L. Whipple

D. L. King

Technical Library (5)

7613-2 Document Processing DOE/OSTI (10)

8523-2 Central Tech. Files 